\title{
Bubble Economics: How Big a Shock to China's Real Estate Sector Will Throw the Country into Recession, and Why Does It Matter?
}

Working Paper WP16BM1

\section{Bryane Michael}

University of Oxford

Simon Zhao

University of Hong Kong

\section{May 2016}

The findings and conclusions of this Working Paper reflect the views of the author(s) and have not been subject to a detailed review by the staff of the Lincoln Institute of Land Policy. Contact the Lincoln Institute with questions or requests for permission to reprint this paper.

help@lincolninst.edu

(C) 2016 Lincoln Institute of Land Policy 


\begin{abstract}
How far do China's property prices need to drop in order to send the country into a recession? What does this question tell us about the way Bubble Economies work? In this paper, we develop a theory of Bubble Economics - non-linear and often "systemic" (in the mathematical sense of the word) forces which cause significant misallocations of resources. Our theory draws on the standard elements of most stories of Bubble Economics, looking at the way banking, construction, savings/investment, local government and equities sectors interact. We find that Bubble Economies' GDP growth can depend on property prices changing differently at different times - depending on risks building up in the economy. We argue that a tacit, implicit Bubble Risk Factor might provide a way of understanding a key variable academics and practitioners omit when they try to explain how economies (mis)allocate resources during bubbles. A $15 \%$ $20 \%$ property price drop could cause a recession, if China's economy resembles other large economies having already experienced property-related asset crises. However, a $40 \%$ decline would not be out of the question.
\end{abstract}

Keywords: China recession, bubble economics, DSGE models, fragility, systems of nonlinear differential equations

JEL Codes: D58, N15, L85, G01 


\section{Acknowledgements}

We gratefully acknowledge support from the Lincoln Institute of Land Policy. Naturally, the opinions expressed in this study remain our own — and should not be attributed to funders or institutions to which we affiliate. 


\section{Table of Contents}

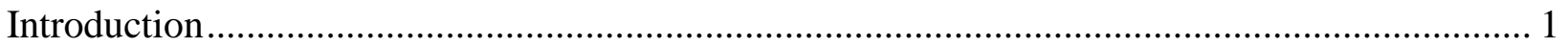

What Can China Learn about the Way Property Price Bubbles Affect GDP Growth?................. 2

Status quo models fail to provide the basis for prediction................................................... 2

The need for a disequilibrium view of China's real estate markets................................... 9

Thinking about structural change in times of crisis ........................................................ 16

What do we know about debt crises and the way property prices contribute to them?.......... 21

A Look at the Five Channels Which Affect China's Bubble Economy .................................... 24

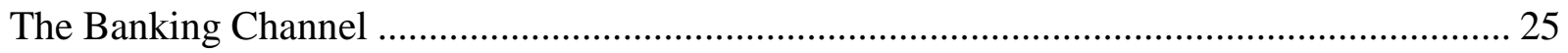

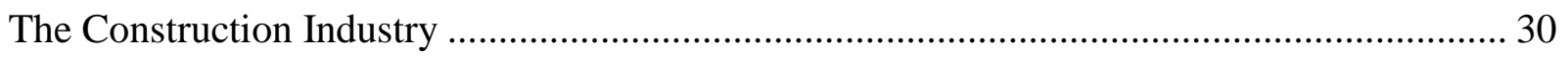

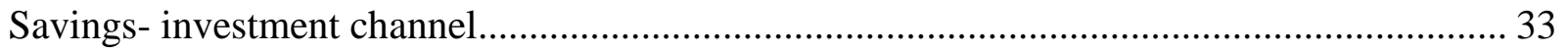

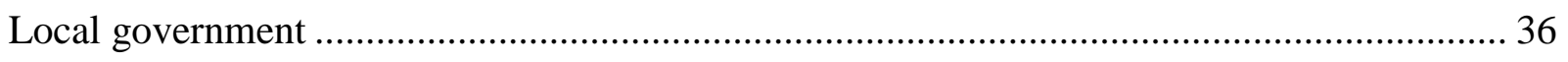

Stock market channel ........................................................................................... 40

A Model of the Bubble Economy with Specific Reference to China ....................................... 43

Previous work on modelling bubbles.............................................................................. 43

The Mathematical and Statistical Problem ................................................................... 43

Looking for a Bubble Risk Factor in Bubble Economies ..................................................... 48

What effect will Bubble Economics play in a possible Chinese recession? .......................... 52

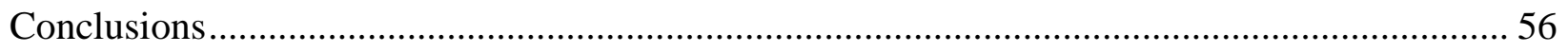

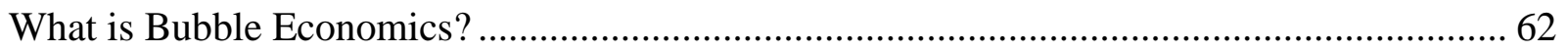

Why have a special concept for Bubble Economies? ...................................................... 62

What led to you think about Bubble Economics?............................................................. 62

Aren't you just assigning what you don't know to a new variable? .................................... 62 


\section{Bubble Economics: How Big a Shock to China's Real Estate Sector Will Throw the Country into Recession, and Why Does It Matter?}

\section{Introduction}

What would happen if China experienced a U.S.-style real estate price/demand collapse similar to the one the U.S. experienced in 2007 and 2008 - or worse? Literally hundreds of analysts have speculated about such a possibility. For example, launched by Jay Bryson's (2014) highly speculative Implications of a House Price Collapse in China - Barron's, Time, and other global news media promptly sounded the alarm. ${ }^{1}$ Reports by academics and advisors at most of the major research universities and international organizations have published some form of analysis looking at whether real estate prices exceed their stable long-run market-clearing equilibrium levels. ${ }^{2}$ The data show China's real estate sector experiencing cycles of boom and bust. Yet, beyond that, economists and other analysts cannot agree whether the current level and growth rates of Chinese real estate prices represents a problem for macroeconomic growth and stability - or not. The legions of scaremongers predicting a real-estate led economic collapse fail to give specifics (about how much prices will fall, how far GDP growth will fall, and so forth).

In this article, we create a stock-flow model of the Chinese economy (drawing on large OECD economies which have undergone a recent property price fall) which tells us something about Bubble Economics. We argue that Bubble Economics differs from classical economics in four structural shifts which an economy experiencing significant property/financial asset price growth can undergo. We show, using a tool from mathematics known as systems of differential/difference equations, how the economies can generate their own instabilities, depending on what is happening in banking, household saving, construction, local government, and equities markets. We discuss the most severe possible price correction and describe the factors which could cause that price change (internal or external shock, clearing out disequilibria in property markets, banking/financial crisis, and sovereign debt crisis). We describe the extent to which a perfect storm causing these events could lead to complete deceleration of China's current 7\% GDP growth rate - leading to a recession. By providing such a benchmark, we hope to provide a "reference point" for our colleagues writing about this topic.

We organize our paper as follows. The first section reviews many of the previous studies about crisis and change in the Chinese economy. These previous studies tend to wrongly predict that a $10 \%$ change in property prices causes a $1 \%$ fall in GDP growth. To accurately gauge the effects of a large property price decline on the Chinese economy, we must look at the experience of other large economies like the U.S., U.K., Japan, and others where their property prices fell. We also look at the case when these property price declines occurred concomitantly with serious crises, such as banking/financial crises and/or sovereign debt crises. These crises make up a large part of the Bubble Economy story - thus we must gauge their effects. The second section looks

\footnotetext{
${ }^{1}$ Almost everyday, a highly credible news organisation publishes an analysis about the bursting of China's property bubble. While we wrote this article, the Economist and several other organisations published their own analysis of the fragility of China's real estate and other markets. Thus, much new material will have probably appeared by the time you read our article.

${ }^{2}$ As we show in this paper, real estate prices naturally affect the supply and demand for real estate. However, these prices also affect demand for bank loans, family savings/investment decisions and government finance decisions. Excessively high real estate prices lead to unsustainable household and government spending patterns. As such, there exists some price level for real estate which helps promote the stability of China's banking and other markets.
} 
at the five sectors driving change in a Bubble Economy. We present data from China and from selected OECD countries as a way to provide the reader with the intuitions behind much of our model-building. We show how these sectors interact - using plain-ish English and simply presented econometrics. The third section reviews the model, showing how we use the mathematics of changes (known as systems of difference/differential equations) to yield insights in China's property markets and GDP growth. We also play with the model to show how structural change occurs in a Bubble Economy. We also show the effect of different shocks. The fourth section goes over the worst case scenario (where sharp property price declines cause a banking and sovereign debt crisis). By showing the parameters under which such an eventuality occurs, we can gauge the credibility of various doomsday naysayers in the media and in other fora. The final conclusion reviews what we have learned about modelling the Bubble Economy.

A few caveats before we begin. First, because of the huge volume of previous studies, we mix and match econometric methods to our needs, describing results in simple English. We base our argument around a stock-flow model, yet we use the resulting intuition in a range of other analyses and critiques of previous studies. We don't want to provide yet another suspicious model of the Chinese property sector. ${ }^{3}$ We also do not provide a Grand Unification Model of the Chinese economy. Second, we purposely omit any discussion of cross-border impacts, monetary policy, exchange rates and so forth. China represents one of the most important traders and investors in the global economy. Yet, to keep our modelling simple, we assume China exists in a vacuum. Third, we use changes in Chinese property prices as the "lever" (or independent variable) in our modelling, despite the fact that housing supply and demand cause these price changes. We talk about (and model) housing price changes directly-and the way they affect Chinese GDP growth - to keep our exposition simple. ${ }^{4}$ Fourth, we do not specify exactly what kind of shock would result in the declines we simulate. Indeed, we do not know where such a shock will come from, as even the global financial crisis failed to set off a domestic property price collapse in China (Kang and Liu 2014). Fifth, we organize our paper differently than you might be used to. We continue to present literature and other studies throughout the paper, comparing and contrasting our results with others'. By organizing our paper in this way, we hope to arbitrate some of the long-standing debates in the field rather than just adding yet another model to the pile.

\section{What Can China Learn about the Way Property Price Bubbles Affect GDP Growth?}

\section{$\underline{\text { Status quo models fail to provide the basis for prediction }}$}

Literally hundreds of analysts have described the reasons for China's upcoming real estate-led economic and financial crisis. ${ }^{5}$ Yet, past performance provides poor grounds for guessing how

\footnotetext{
${ }^{3}$ Slettvag (2015) provides a recent example of a study trying to do what we attempt in this paper. We would not have written this paper if we thought he succeeded.

${ }^{4}$ Rigorously speaking, price changes reflect shifts in real variables - like shadows which allow us to infer the way the markets and the economy changes. We talk about prices like an instrument to be manipulated only as a presentational artifice. By treating the property sector as a black box, we hope to simplify an already complex paper.

${ }^{5}$ In this paper, we will try to talk about the real estate sector as a whole-focusing on both residential and commercial property in all market segments (quality, geographical and so forth). We will often refer to housing, real estate and property markets interchangeably. The availability of data naturally limits the extent of our analysis. Thus, we beg the readers' forgiveness if we treat this highly diverse sector with broad brushstrokes - in order to focus on the bigger picture (a general collapse in property prices). We justify our treatment of "property" prices in this way in the Appendix.
} 
far property prices need to fall in order to send any Bubble Economy's (and specifically China's) GDP into recession. Any simple correlation between property price changes and GDP growth would not yield any sensible results, as China's recent experience only shows the two growth rates moving upward together. Figure 1 shows the relationship between Chinese property price change and GDP growth. In theory, one can just follow the regression line to zero. Yet, it never intersects zero. Thus, the only solution requires a slight decline in property prices of about half a percentage point, and 11 units of another unknown variable! ${ }^{6}$ Figure 2 shows a slightly more nuanced view of the GDP/property price nexus - showing how changes in property prices might correspond to changes in GDP. Even before applying fancy statistical analysis to get rid of the effects of extraneous variables (like money supply, government policy, and so forth) we see that the data reflect the past. If we just draw a line through the data in this figure, at a $10 \%$ drop in property prices, we already observe GDP falling 3\% for every further 1\% drop in property prices. If we fit a non-linear relationship to the data, rapidly falling property prices correspond with rapidly rising GDP, so do rapidly rising property prices. GDP falls only between a $-1 \%$ and $-4 \%$ in property prices. Point 1 and Point 2 on the figure correspond to the same change in GDP, even though property prices are doing radically different things. Such non-linearities conform to our intuitions - that deep underlying structures probably change when we witness a property price drop of significant magnitudes.

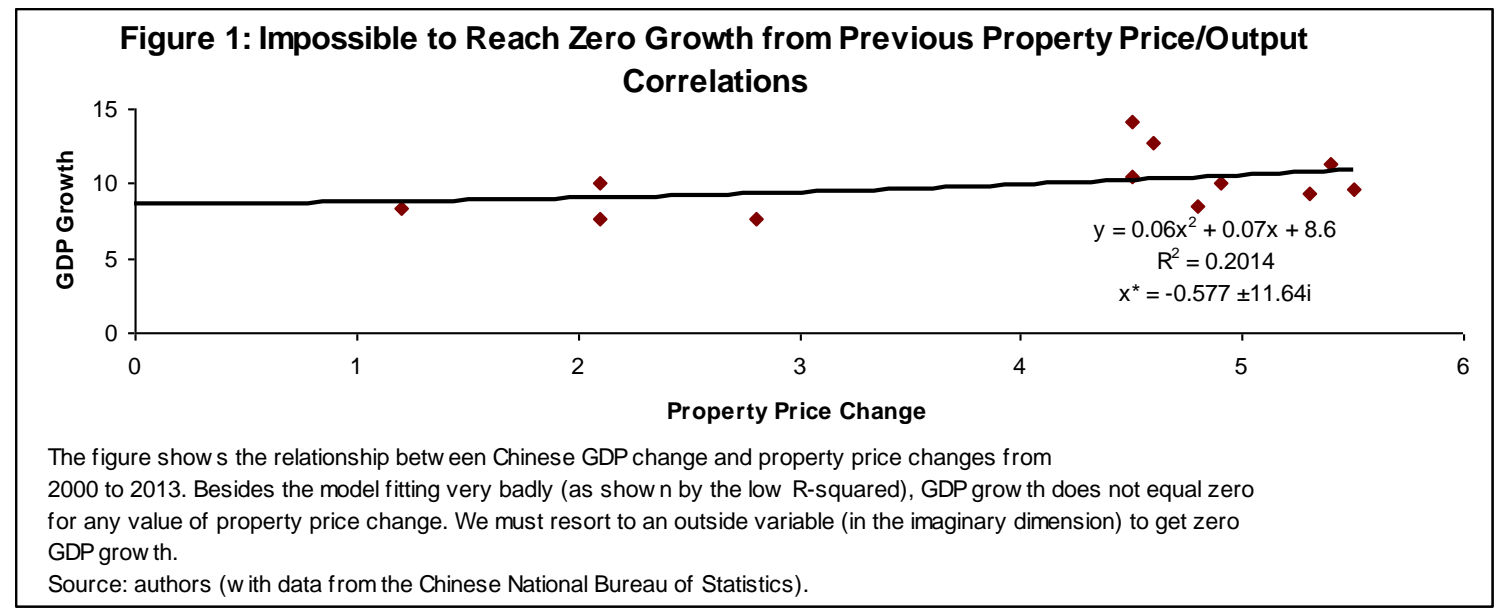

\footnotetext{
${ }^{6}$ In more mathematical language, only solutions involving imaginary numbers exist for the equation we show in the figure (for GDP growth rates equal zero). Such imaginary numbers simply represent adding another dimension (in our case an unknown variable) which solves the equation.
} 


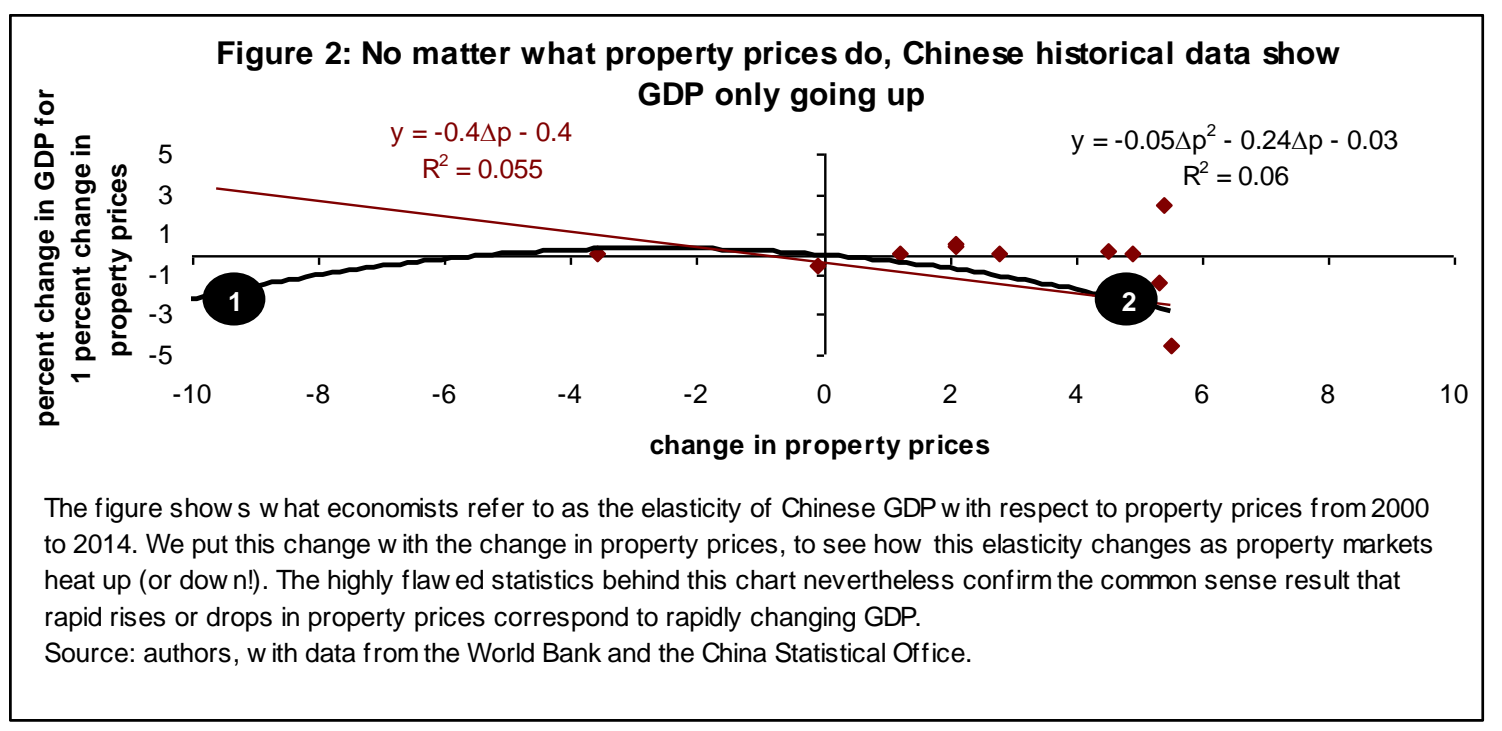

Such a failure to take structure changes into account results in serious errors with all kinds of models of the Chinese economy. Figures 3 shows the expected decrease in GDP as housing prices fall - after taking into account the interaction between GDP, consumer prices, money supply, and housing prices. ${ }^{7}$ Each of these figures looks at a different way of estimating the effects of changing property prices (or the price of borrowing money for property) on GDP. The top panel uses the amount of money as a way of measuring Chinese monetary policy, whereas the bottom panel uses lending interest rates as the measure of changes in China's monetary policy. Using either measure of monetary policy yields roughly the same result. In general, property prices have about a 1-to-10 effect on GDP. Namely, a $10 \%$ fall in property prices leads to about a $1 \%$ decrease in GDP levels in the short-term (1-2 quarters). Reflecting the selfcorrecting nature of a "normal" economy, GDP levels end up rising around 15 months after the crisis, until finally settling at their pre-shock levels. Assuming the Chinese economy operates the same way as before a huge shock, an $80 \%$ reduction in real estate prices would been needed to throw China into recession. ${ }^{8}$ Yet, we know that the Chinese economy wouldn't operate as before - our models cannot take the structural changes of a Bubble Economy into account.

\footnotetext{
${ }^{7}$ The study shown in Figure 3 focuses mostly on monetary policy-estimating the effect of housing price changes on GDP as one in a series of variables. Other authors like Ma (2010) have reached similar estimates of the effect of housing price changes on GDP of around 0.1 and provide strong evidence that past price changes drive future price changes.

${ }^{8}$ If recession is defined as a decrease in GDP for at least 2 consecutive quarters, and if we assume that China's GDP will grow by $7.7 \%$, then the relationship in Figure 2 shows that we need a decrease in real estate prices of $80 \%$ to decrease GDP by $8 \%$ basically erasing the growth driven by other parts of the economy. The figure also shows that decline continues for about 3.5 quarters - which also exceeds the definition of recession lasting 2 quarters.
} 


\section{Figures 3: Real Estate Prices Would Need to Halve In Order to Knock GDP Growth Into Negative Territory}
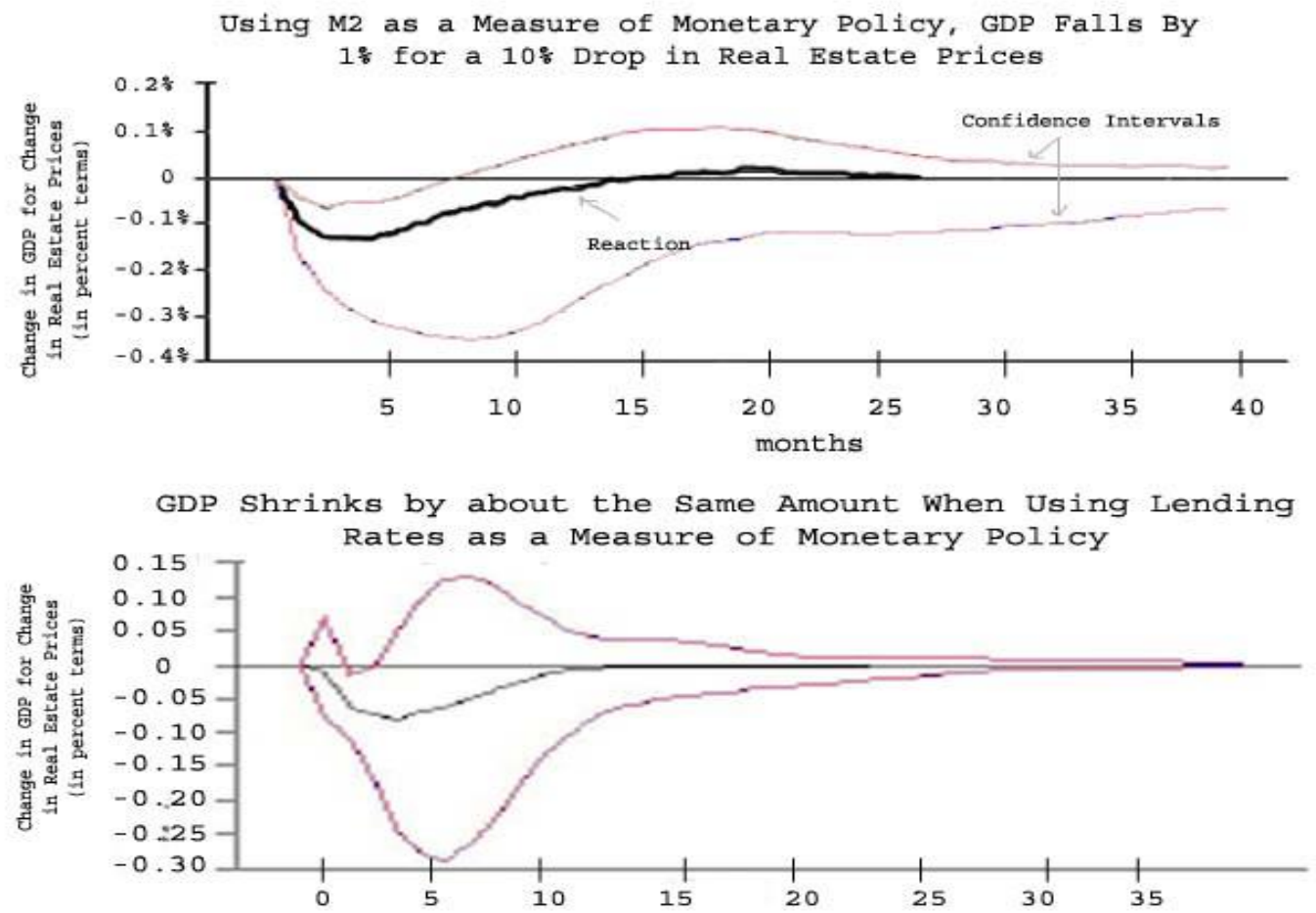

The figure shows the effect on Chinese GDP of a property price fall using vector auto regression (VAR) methods. The solid black line shows the estimated response (per month) for a $1 \%$ change in property prices. The red lines show confidence intervals. The main effect appears in about $3-4$ months (with downside predictions placing the maximum effect at about 8-9 months). We flipped the original source graph along the $x$-axis in order to show a decrease in property prices.

Source: Tan and Chen (2013).

Part of the problem lies in the way past decisions to make and buy real estate and property reflect on today's decisions. Authors like Nie and Cao (2014) show that real estate comprises roughly $20 \%$ of China's GDP - and probably directly contributes about $2 \%$ to China's GDP growth. ${ }^{9}$ Yet, housing and other types of real estate investment drive GDP growth in other ways. Figure 4 shows the linkages between housing and non-housing investment in China in the early part of the post-2000 period. As shown, a $1 \%$ increase in housing investment drives about $0.14 \%$ increase in GDP, confirming previous studies. A $1 \%$ bump-up in housing investment yesterday also drives a $1.5 \%$ increase in housing investment today. These data show that property prices influence investment decisions and consumption decisions - which drive GDP growth. Again, like with the previous studies-yesterday's investment and output levels best explain the future... until they don't! ${ }^{10}$

\footnotetext{
${ }^{9}$ The authors' estimate refers to the "authors' calculations" of "real estate investment" without further information on the techniques they used or the exact definition of such investment. Even taking the authors at their word, such a measurement would exclude expensed (rather than capital deductible) spending/production on the existing stock of properties and other economically productive activity. As we describe in Figure 4, real estate investment drags along other investment and consumption which counts toward GDP.

${ }^{10}$ In other words, like most time series data, lagged variables often provide better predictors than other independent variables. As we describe in our own modelling, the rate of change of housing (real estate) depends on the level of such a stock. Mathematically inclined readers will recognise this as a differential equation.
} 
Figure 4: GDP Depends on Housing Investment and a Bunch of Unknown Factors

\begin{tabular}{|c|c|c|c|}
\hline $\begin{array}{l}\text { Dependent variables -.-> } \\
\rfloor_{\text {Independent variables }}\end{array}$ & GDP today & $\begin{array}{l}\text { Housing } \\
\text { Investment } \\
\text { today }\end{array}$ & $\begin{array}{l}\text { Non-housing } \\
\text { Investment }\end{array}$ \\
\hline Noise & 0.13 & 0.84 & 1.2 \\
\hline GDP yesterday & 0.38 & -2.0 & -0.21 \\
\hline Housing investment yesterday & 0.14 & 1.5 & \\
\hline Non-housing investment yesterday & 0.1 & & 0.9 \\
\hline Equal to zero? & 4.1 & 1.6 & 0.02 \\
\hline
\end{tabular}

Cells marked in black are statistically significant at the 5\% level.

Source: Liu et al. (2002).

The method used to model Chinese GDP growth clearly impacts how we guess the effect of property price changes. Another approach looks at the way property price changes might affect the major expenditure categories of GDP growth. Figure 5 shows how a change in Chinese property prices has traditionally filtered through to changes in various types of national expenditure. Property prices have unsurprisingly had the biggest impact on investment - with a $1 \%$ change in property prices correlating with a $0.4 \%$ change in investment. In line with our description of the effect on households and local governments, property price changes also encourage consumption and government spending. A sudden decline in property prices by $10 \%$ would thus lead to a total change in expenditure of around 7\% (if the effects shown in Figure 5 work together). ${ }^{11}$ This study highlights three problems with current methods to model China as a Bubble Economy. First, such an estimate varies wildly from the previous one by one order of magnitude! As such, we cannot rely on these classes of models to provide consistent results. Second, these models cannot show the combined effect on GDP. We have no idea what happens when consumption and investment shocks operate together. Third, we do not know what happens when large, rather than small, changes occur in property prices. Figure 5 shows marginal (or small) effects. We cannot simply add up these small effects to get a large effect.

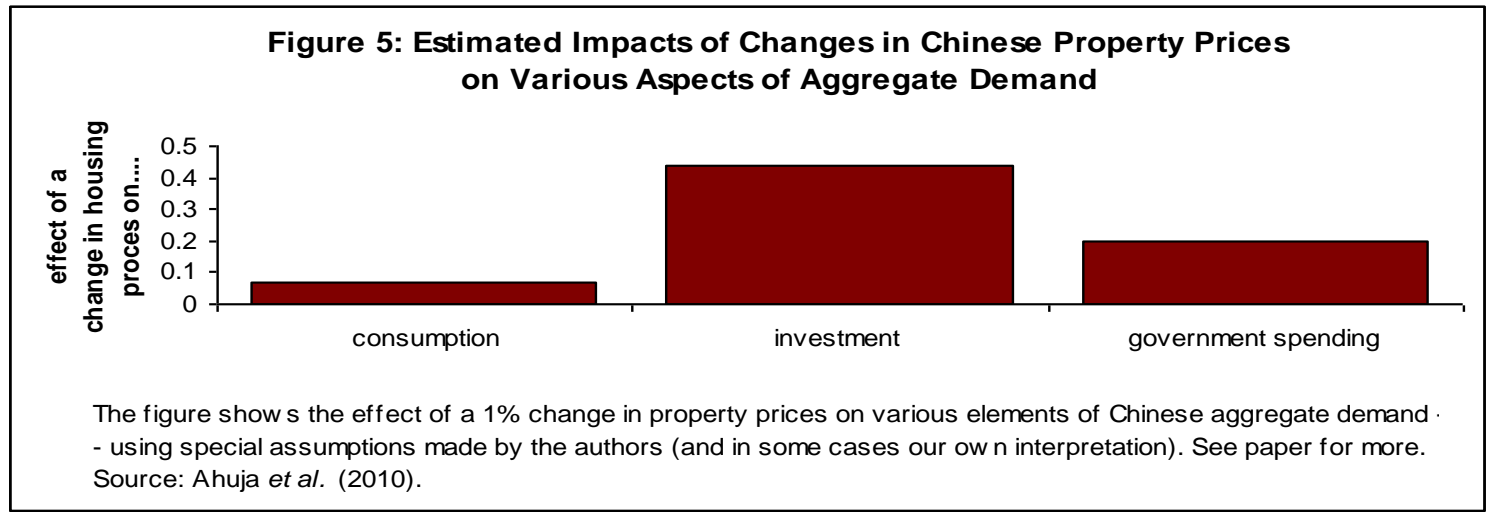

\footnotetext{
${ }^{11}$ The exact effect of a change on total expenditure depends on the interaction between consumption, investment and government spending. In theory, the authors' results take into account changes in the other variables. However, in practice, we would want to see a study of these interactions before telling something more definitive.
} 
Could the "feedback" between changes of GDP growth and real estate prices - through other variables like the money supply or consumer prices - distort or amplify the way property price markets impact GDP $?^{12}$ Figure 6 shows the contribution of various macroeconomic factors to housing price instability in China. At first glance, changes in GDP seem to explain changes in Chinese property prices better than any other variable. While the money supply also explains these movements, other factors like food price inflation and real sector policies have far less explanatory power. Seemingly, these results support more rigorous studies like Chen and Zhu (2008), who show bidirectional Granger causality between housing investment (and thus presumably housing prices) and changes in GDP growth. ${ }^{13}$ Ostensibly, changes in GDP affect housing/property prices.

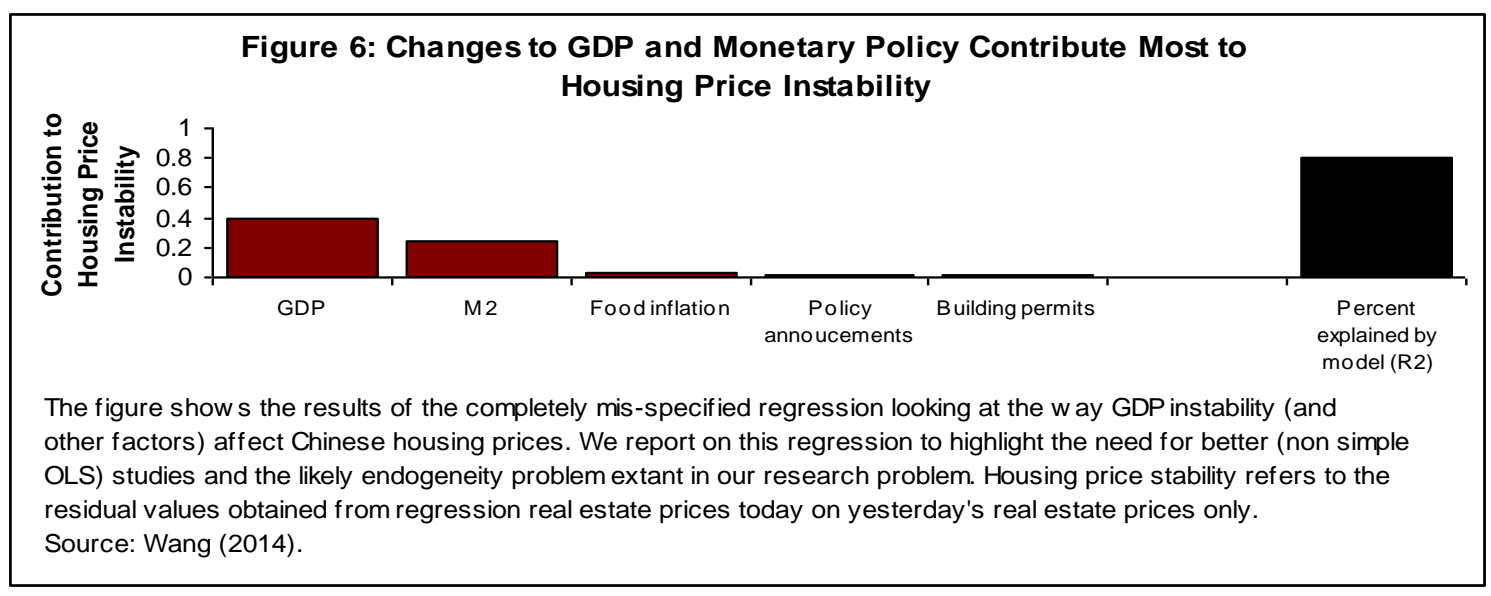

Yet, first impressions lie, and GDP probably has little role to play in property price changes... even during non-bubble times. Figure 7 shows the factors contributing to property price changes over time in China. In recent years, housing preferences, excess savings, and productivity gains explain rising property prices. Changes in aggregate production/expenditure just don't seem to drive property prices. Figure 8 tackles the problem from a different angle. Let's suppose that the Chinese government instituted an "affording housing" policy (which generated sudden large demand for housing). Such a sudden expansion of GDP in the areas specifically focused on housing should lead to price changes. Yet, the simulation and regression analysis shows that prices actually fall by a very, very small amount. A shock in government investment in housing causes a -.0001 change in housing prices. If such effects even exist, they are too small to seriously worry about. Models like Sinclair and Sun (2014) produce similarly tiny effects. Changes in Chinese GDP do not cause changes in property prices.

\footnotetext{
${ }^{12}$ In economic terms, we want to know whether an economically significant endogenous relationship exists between property price growth and GDP growth. In a macroeconomy, everything affects everything else. Yet, by focusing on large effects, we can keep from getting lost in details and complexity.

${ }^{13}$ Granger causality refers to a statistical technique in which (very roughly translated into English) the analyst sees whether today's changes in property prices explain the previous quarter's or year's changes in GDP better than the converse (today's changes in GDP explains yesterday's changes in property prices better).
} 


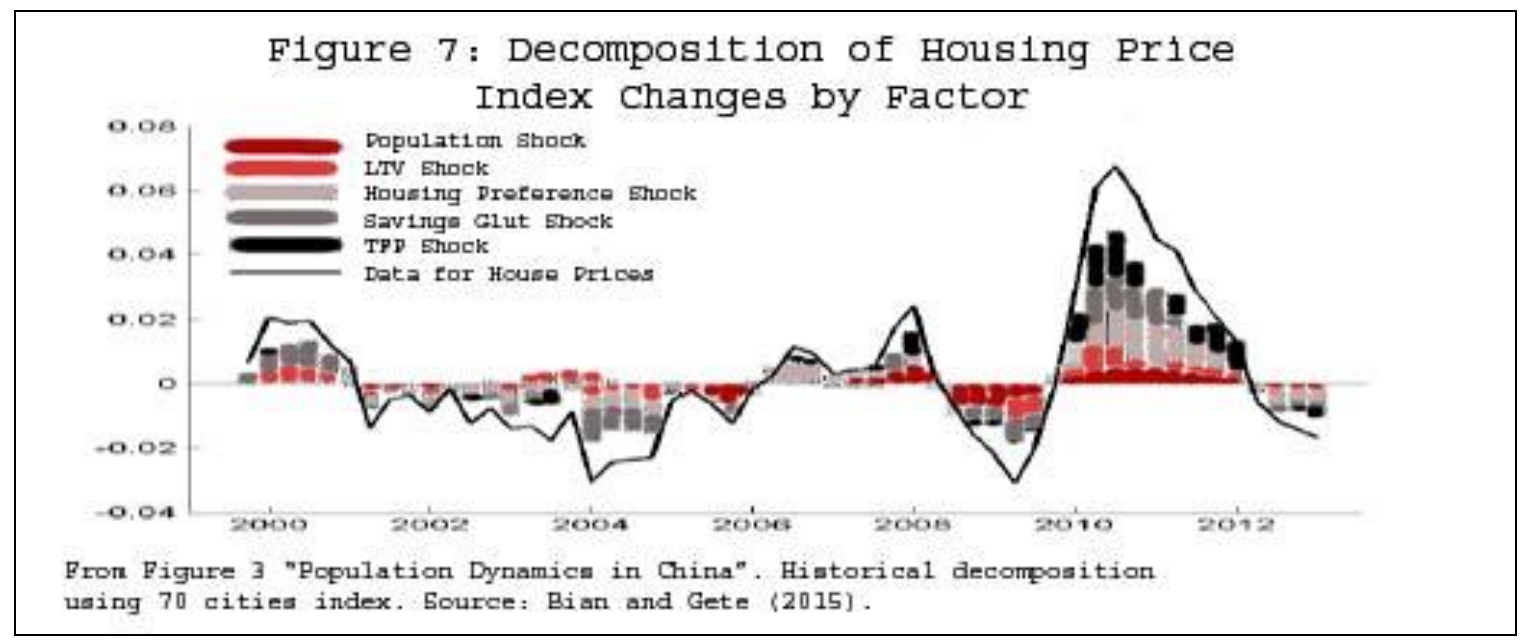

\begin{tabular}{|c|c|c|c|}
\hline \multicolumn{4}{|c|}{$\begin{array}{l}\text { Figure 8: Another Model Produces Microscopic } \\
\text { Shocks of "Affording Housing" Shock } \\
\text { (effect at peak) }\end{array}$} \\
\hline Variable & extent of effect & Variable & extent of effect \\
\hline Consumption & -0.00013 & Output consumption & 0.0008 \\
\hline Output housing & 0.07 & Housing prices & -0.0015 \\
\hline Labour housing & 0.005 & Labour consumption & 0.0012 \\
\hline inflation & 0.000075 & Total investment & 0.00045 \\
\hline \multicolumn{4}{|c|}{$\begin{array}{l}\text { The figure shows the response of each variable shown to an "affording housing" policy shock. The } \\
\text { shock considers the effect of big bang Chinese government investment in housing. We show the level at } \\
\text { the height of its effect (using between 3-6 periods). See source for definition of the shock, the model } \\
\text { and other particulars. } \\
\text { Source: Zhou and Jariyapan (2013) at Figure 1. }\end{array}$} \\
\hline
\end{tabular}

As if to belabor the point, changes in GDP do not seem to directly impact property (real estate) price change. Figure 9 shows the probability of a property bubble (from a range of countries). If China follows these other countries, price changes affect the real economy far more than the real economy affects property price changes. As shown, the endogeneity problem seems at first glance minor. Thus, property price changes reflect excessive momentum in pricing, suggesting that serious misalignment can occur. More fundamental to our paper, the failure of the literature to draw conclusions about even basic questions - like whether an endogenous relationship exists between property price changes and GDP changes - highlights the need for our study. ${ }^{14}$ Yet, to the extent we can draw conclusions; we know that something other than the underlying fundamentals reflected in GDP drive property prices in China and elsewhere!

\footnotetext{
${ }^{14}$ The patchy quality of the statistical analysis conducted in many of these studies represents a far worse problem than the lack of models themselves. Many Chinese authors - having access to statistical software — performed time series analyses on a number of variables and reported on all the statistics the software provided. We thus try to report their findings when applicable, often corroborating or interpreting their studies with our own analysis of data similar to those these authors used. Unfortunately, because of the Chinese distain for criticism/critique, these studies go unchallenged and represent a serious danger to our project/profession!
} 


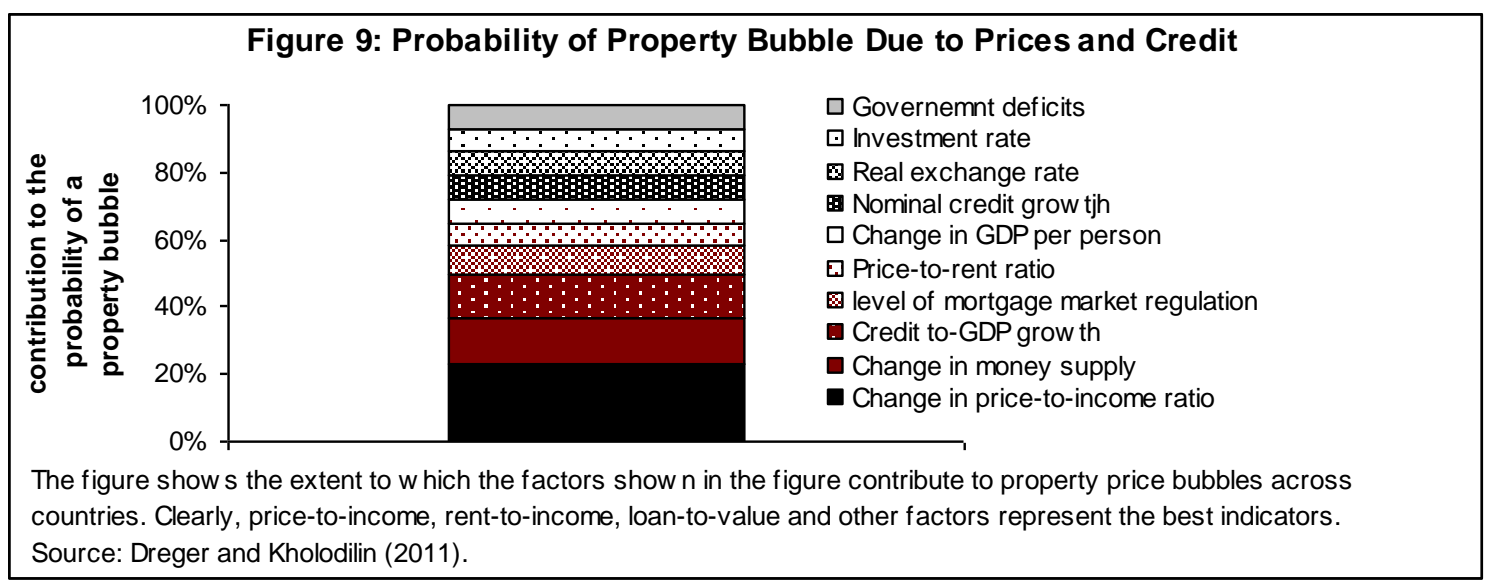

$\underline{\text { The need for a disequilibrium view of China's real estate markets }}$

The lack of property prices' response to economic fundamentals points to potential distortions in property markets which keep prices out-of-equilibrium. Figure 10 shows the standard economic analysis of property markets. The existence of high real estate prices, significant over-supply (particularly in China's supposed ghost cities) and significantly high demand reflects artificially high prices for reasons which we will not discuss at length in this paper. ${ }^{15}$ The resulting disequilibrium though concerns us greatly. As illustrated in the figure by the "short-side rule," a gap appears between a low quantity of property demanded at high prices, very high demand at lower prices, and high levels of supply based on artificially high prices. The bursting of the putative property price bubble will incentivize Chinese authorities to remove the distortions keeping prices about equilibrium. The removal of the part of the figure we have labelled as "disequilibrium" will result in ironically more actual property coming onto the market at lower prices. Thus, we need to know how high these prices are in order to estimate the effect on GDP growth rates. The figure also refers to price points below equilibrium which result from the general crisis. We know from other countries' experiences that the entire property model changes (at least in the medium-run). Thus, we cannot even use existing supply and demand curves to talk about the way property price changes affect GDP. Thus, to model the Bubble Economy, we need to know how removing the existing disequilibrium will affect prices and lastly how the ensuing crisis will affect prices and GDP.

\footnotetext{
15 Even the Australian documentary Living in a Bubble highlights the reasons for artificially high prices (reflecting high savingsfuelled demand, low interest rates, and local government development policies). Our paper's goal consists of modelling these effects without dwelling on their particularities in the Chinese context. See Shepard (2015) for more.
} 


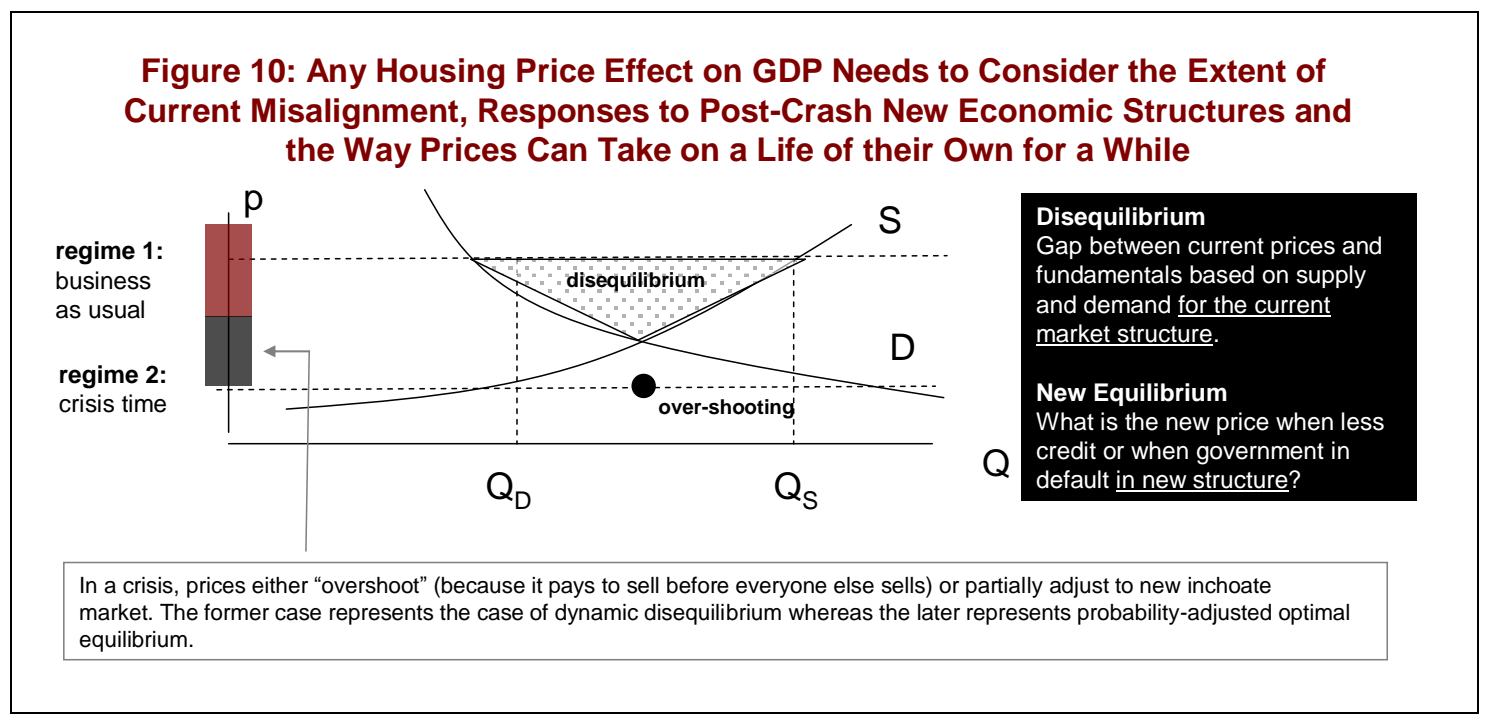

Of course, existing studies do not agree about whether Chinese property prices exceed their equilibrium values. ${ }^{16}$ Yet, most studies suggest that Chinese property prices have remained above their equilibrium values for many types of real estate, at least as of the time of this writing. ${ }^{17}$ Figure 11 shows the results of many of the key studies, which either look at the extent to which property prices exhibit temporal serial correlation or the extent to which variables grow over time with other variables like the availability of bank credit. ${ }^{18}$ The current literature suffers from three flaws which seriously jeopardizes its ability to predict China's (and other Bubble Economies') next crisis. First, while the theoretical literature models property prices 'taking on a life of their own," empirical work fails to use these insights to determine how far property price misalignment could go. ${ }^{19}$ Many of these studies establish both unit roots and co-integration in the data. ${ }^{20}$ Yet, they do not actually use the parameter estimates to predict (and test their predictions) what will happen to Chinese GDP and property prices. Second, these studies fail to establish the conditions for market clearing in the real estate sector and use that yardstick as a measure for price disequilibria. Most studies attribute changes in property prices to changes in variables like credit, under the assumption that these changes reflect changes in demand (or supply if credit goes to construction companies). The observation of large amounts of unused real estate, high prices, and attendant regulations like the Hukou system obviously imply some degree of disequilibrium. ${ }^{21}$ For studies that do find disequilibria pricing, they fail to provide testable

\footnotetext{
${ }^{16}$ We say "of course" as economic studies rarely agree-reflecting differences in methods, interpretations and datasets.

${ }^{17}$ We are writing this brief at a time of rapid change in Chinese property prices, making any statements about disequilibrium possibly irrelevant by the time you read this paper.

${ }^{18}$ In other words, these authors use either time series analysis or vector autoregression (and in some cases error correction models).

19 "Taking on a life of their own" means that property-related physical and financial asset buyers and sellers may engage in herding (buying and selling based on the actions of other traders) instead of focusing on the intrinsic value of the asset(s) as determined by discounted cash flows, supply and demand.

${ }^{20}$ In plain English, "unit roots" refer to a statistical value which shows the tendency of yesterday's prices (or other economic variables) to completely and totally determine today's prices. "Cointegration" refers to a relationship in data which grows or shrinks over time.
} 
explanations which result in predictions about when disequilibria grow or change. These studies use past property prices to predict disequilibria in current prices. Yet, they do not use past or current disequilibria (and the misallocation of resources) to explain future (predicted) disequilibrium pricing. Distorted markets create distorted price-based incentives. Third, these studies cannot explain sudden momentum in property prices or the way output might respond to property prices. Property prices can change sharply and suddenly. None of these models explain the spurts or times of sudden intense activity.

\section{Figure 11: Previous Studies about Chinese Real Estate Prices}

\begin{tabular}{|c|c|c|}
\hline Author(s) & Results & Bubble? \\
\hline Xu (2014) & $\begin{array}{l}\text { Focus: Looks at whether real estate bubble has formed } \\
\text { Findings: Finds that property prices take on a life of their own. Economic } \\
\text { fundamentals do not explain property prices. } \\
\text { Implication for our study: We should look for divergence from equilibrium } \\
\text { and the effect of that divergence. May also signal downward inertia in case } \\
\text { prices change. }\end{array}$ & Yes \\
\hline Ma (2010) & $\begin{array}{l}\text { Focus: Do bubbles affect China's housing market } \\
\text { Findings: The author erroneously claims that housing prices depend on their } \\
\text { previous values - so they "bubble" } \\
\text { Implications: none - the study has been done and interpreted incorrectly }\end{array}$ & Yes \\
\hline $\begin{array}{l}\text { Huang et } \\
\text { al (2015) }\end{array}$ & $\begin{array}{l}\text { Focus: Looks at effect of credit expansion and local amenities on housing prices } \\
\text { Findings: Availability of credit drives up house prices and develops markets for } \\
\text { amenities. } \\
\text { Implications for our study: Any crisis response to stimulate the economy } \\
\text { could make housing bubble worse and its eventual correction worse. }\end{array}$ & Yes \\
\hline $\begin{array}{l}\text { Ahuja et } \\
\text { al. (2010) }\end{array}$ & $\begin{array}{l}\text { Focus: } \\
\text { Findings: Housing prices are NOT over-valued, except in big cities, selected } \\
\text { markets and in luxury segment. } \\
\text { Implications for our study: }\end{array}$ & Yes \\
\hline $\begin{array}{l}\text { Bian and } \\
\text { Gete } \\
(2015)\end{array}$ & $\begin{array}{l}\text { Focus: Look at the extent to which fundamental factors drive housing prices } \\
\text { Findings: property prices rise due to fundamental factors like population rising, } \\
\text { easier credit, more demand for housing, higher savings rates, and or most } \\
\text { importantly a change in productivity (technical progress). } \\
\text { Implications: a shock to another part of the economy likely to drive both } \\
\text { property markets and GDP. Causality runs from these outside variables to both } \\
\text { property prices and GDP. }\end{array}$ & No \\
\hline
\end{tabular}

\footnotetext{
${ }^{21}$ Indeed, no reasonable economist would ever claim markets always operate in equilibrium. Accepting some disequilibrium and then trying to assign parts of that disequilibrium to various factors like fast credit expansion serves as a more credible method of analysing Chinese property markets than just wishing these disequlibria away. Hukou refers to the permits Chinese citizens need to live in a particular city.
} 


\begin{tabular}{|c|c|c|}
\hline Author(s) & Results & Bubble? \\
\hline $\begin{array}{l}\text { Fang et al. } \\
(2015)\end{array}$ & $\begin{array}{l}\text { Focus: Looks at the comparability of returns in housing to other types of } \\
\text { financial products. } \\
\text { Findings: Housing prices inertial and purchasing by lower income-to-rent ratio } \\
\text { clients worrying } \\
\text { Implications for our study: Financial crisis - like in the U.S. - will likely start } \\
\text { among lower income strata of customers and spread out from there. }\end{array}$ & No \\
\hline $\begin{array}{l}\text { Ren et al. } \\
(2011)\end{array}$ & $\begin{array}{l}\text { Focus: Looks at streaks of housing price increases to decide if "rational } \\
\text { expectations bubbles" form over time. } \\
\text { Findings: No streaks of price rises provide encouragement for gambling } \\
\text { investors. Thus, no bubbles appear to have formed. Housing is an investment } \\
\text { good which doesn't depend on the local economy. } \\
\text { Implications for our study: Changes in housing prices should have very } \\
\text { limited impacts on the real economy. Even very large collapse in property } \\
\text { markets should not lead to recession. }\end{array}$ & No \\
\hline Lan (2014) & $\begin{array}{l}\text { Focus: Looks at whether monetary policy and other factors influence property } \\
\text { prices } \\
\text { Findings: No evidence of price bubbles (as other factors besides property } \\
\text { price's own momentum drive prices). } \\
\text { Implications for study: }\end{array}$ & No \\
\hline $\begin{array}{l}\text { Deng et al. } \\
(2012)\end{array}$ & $\begin{array}{l}\text { Focus: Looks at whether land prices drive real estate price changes } \\
\text { Findings: Land prices and other factors drive property prices. Because prices } \\
\text { exhibit "mean reversion" no bubble or long-term disequilibrium likely exists. } \\
\text { Implications for study: }\end{array}$ & No \\
\hline
\end{tabular}

The figure summarizes many of the studies reviewed for our paper. We do not critique the quality of the econometric analysis done (as many authors have simply reported the output from econometric software of time series data on the Chinese property market and macroeconomy.

Let's illustrate the problem with this literature by looking at the extent to autocorrelation (memory) in property prices. Figure 12 illustrates the memory in Chinese property prices and the effect such memory would have in the case of a large shock. The upper part of the figure shows that property prices in any year reflect prices from the previous year. In contrast, momentum (or the difference between this year's price change and last year's price change) has no memory. Momentum spikes hard in some years (like in 2011) and remains quiet in other years (like 2007). Some event embodied in this momentum statistic (like government policy or even sunspots) could "naturally" knock property price growth rates well into negative territory. ${ }^{22}$ As shown in the bottom part of the figure, when prices suddenly move (thanks to their momentum), they may stay negative for a long time. As shown by these simulations, Chinese prices - if they operated under the rules that currently drive them-would stay negative in most scenarios and for many years. Current models fail to build-in such jumpiness into Chinese prices (and model the way output reacts during the jumpy periods).

\footnotetext{
22 "Sunspots" refer to rational and normal large changes in prices which other economists have observed for no underlying economic reason. Some event (like a solar flair) causes actors to react in the same way for irrational reasons. Yet, these sunspots have very real economic effects. We rely on these sunspots in our modelling later in the paper when talking about a very large price change, explicitly to abstract away from the reasons that prices might change.
} 
Figure 12: Even Property Growth Rates in China Seem to Have a Memory (with Disruptions)...
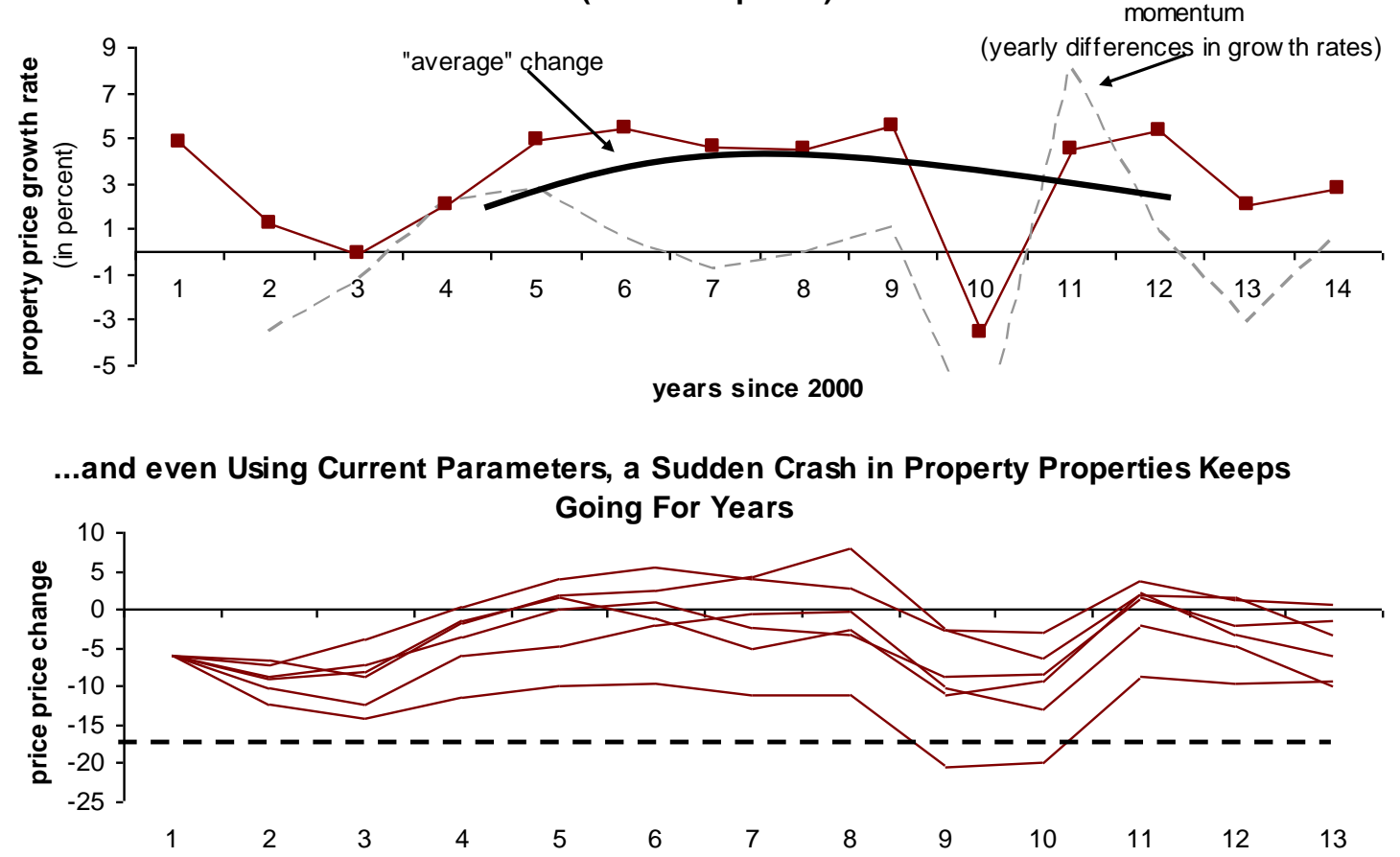

The figure on the top show s the way that Chinese property prices moved over time (and the "stationary" difference in those grow th rates). We show the extent to autocorrelation as as traciing out the one-year lag term on the autoregressive (AR1) process. The bottom part show s the simulated time-series structure of China's property price data (basically the second difference of the data which has no memory and a moving average component of 0.76 ). We kept the moving average, adjusting by the standard deviation of the price data from 2000 to 2014 and basically integrated up to arrive at the price change simulations you see. Source: authors, using data from the Chinese Statistics Office.

Even if we do model such jumpiness at the sector level, failing to look at the economy as a whole can lead to serious problems. Existing models tracing through the impacts of property price disequilibria on output highlight the differences between a sector-based rather than whole-of-theeconomy based view. ${ }^{23}$ Indeed, we know that wringing disequilibria out of Chinese property markets can actually increase GDP growth - by removing existing distortions. Figure 13 shows the estimated effect of removing the output wedges caused by excessively high property prices. While property price bubbles have resulted in shortages in property markets themselves (in partial equilibrium), they have led to out-of-equilibrium output growth rates (in general equilibrium) ${ }^{24}$ High property prices affected employment and the use of capital, and even encouraged higher total factor productivity until around 2009. The net gain in GDP growth from hyper-growth versus the loss from resource misallocation has come to about $2 \%$. These results

\footnotetext{
${ }^{23}$ Economists refer to this as taking partial equilibrium, rather than a general equilibrium, perspective. Economists are famous for showing counter-intuitive results when looking at the economy as a whole.

${ }^{24}$ Numerous studies show how rapidly rising property prices can create real estate shortages, yet generate temporarily higher incomes for investors and builders who create bustling economic activity around empty neighbourhoods and business centres.
} 
suggest that any property price correction of around 10\%-20\% would likely knock off $2 \%$ of "bad" GDP growth, thus raising welfare. More generally, any analysis of China's (or any Bubble Economy's) changing property prices must look at the whole economy.

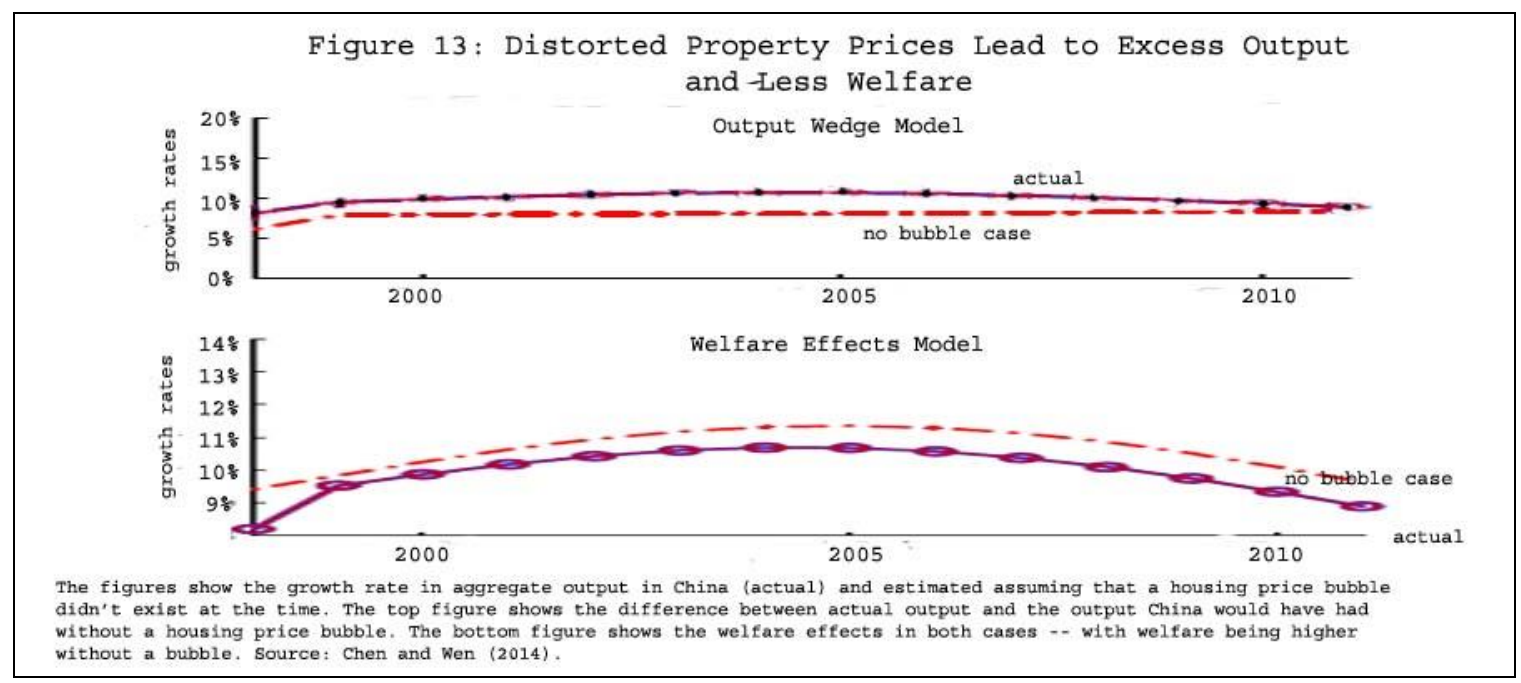

We know that GDP growth rates react very differently to changes in property prices during and after a banking, financial and/or sovereign debt crisis than before. China probably has yet to experience its cycle of debt-price increases-bubble. Figure 14 shows for several large OECD economies which we compare with China throughout this paper the correlation in property prices before and after crisis. For the U.K. and Canada, property price correlation increases in volatility after a period of property price contraction (such that the following year's prices tend to go in the opposite direction more strongly). For countries like the U.S. and Germany, periods of negative property price growth seem to dampen prices. After China's brief property price decline in 2009, property prices seem to have shorter-worse memories. Again, to belabor the point, Figure 15 shows, after removing the noise, the cycles present in property prices in China and the U.S. ${ }^{25}$ Because the U.S. has already had its regime shifting structural change after its Great Recession in 2008-9, we observe a longer 14 year cycle in the data while we do not observe in the Chinese price data. We need better tools to detect the aspects of the Bubble Economy which we already observe in the U.S. data, but we can only hope to predict in the Chinese property price data.

\footnotetext{
${ }^{25}$ No credible economist since the 1940 s would argue that period cycles exist in these types of data. However, the idea of cycles remains entrenched in the popular psyche. So we use these data to illustrate poignantly our point about "structure change" in a way a non- $\mathrm{PhD}$ would understand.
} 


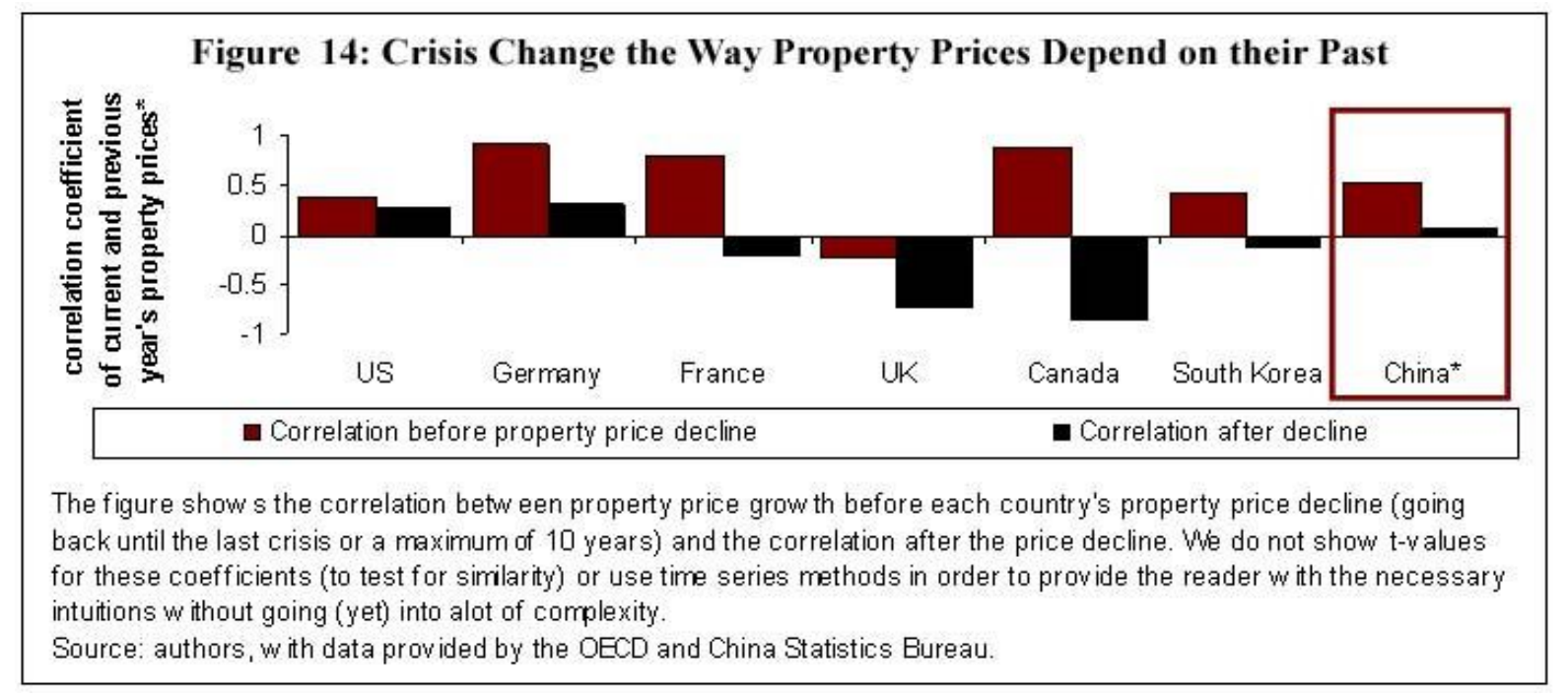

\section{Figure 15: Different "Cycles" Suggest that Forces Have Played Out in the U.S. that Have Yet to Play Out in China}

China USA

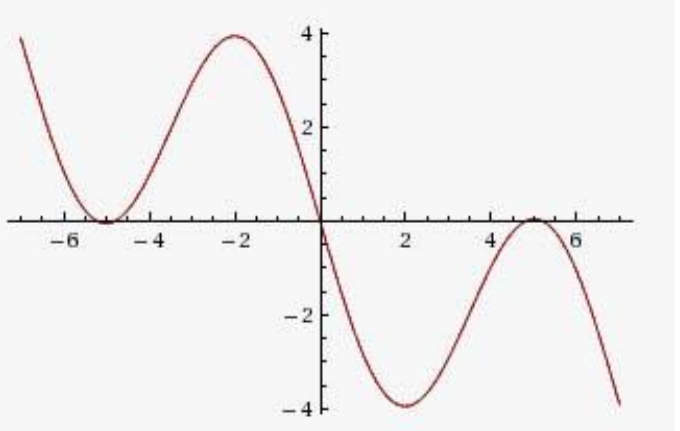

$\mathrm{p}_{\mathrm{t}}=2.5 \cos (2 \pi / 3.5) \mathrm{p}_{\mathrm{t}-1}-2.9 \sin \left(2 \pi / 7 \mathrm{p}_{\mathrm{t}-1}\right)$

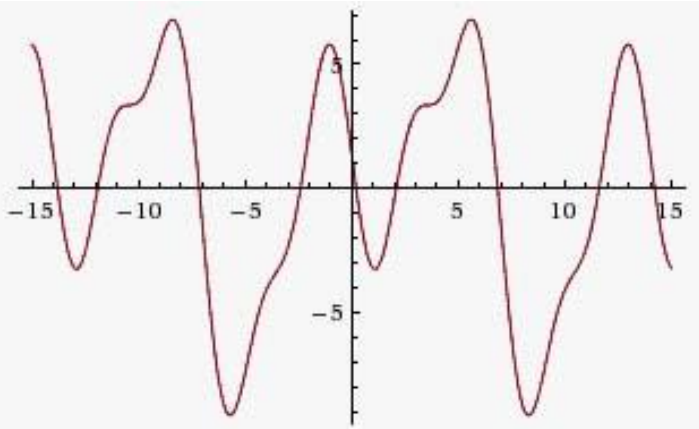

$\mathrm{p}_{\mathrm{t}}=1.43 \cos \left(\pi / 7 \mathrm{p}_{\mathrm{t}-1}\right)+3.35 \sin \left(\pi / 7 \mathrm{p}_{\mathrm{t}-1}\right)-5 \sin \left(2 \pi / 7 \mathrm{p}_{\mathrm{t}-1}\right)-2.1 \sin (2 \pi / 3.5$ $\left.\mathrm{p}_{\mathrm{t}-1}\right)-1.66 \cos \left(2 \pi / 2.8 \mathrm{p}_{\mathrm{t}-1}\right)-1.33 \cos \left(2 \pi / 2.3 \mathrm{p}_{\mathrm{t}-1}\right)$

The figure shows a Fourier (spectral) analysis. Such analysis fits sin and cosine curves to data to try and detect underlying cyclical nature in data. We allude to periodicity only to highlight the argument that a deeper cycle has probably already played out in the U.S., U.K. and other economies with more experience with property-based lending.

Source: authors, based on data from the China Statistical Bureau and the OECD.

Even if herding occurs, we need a way of understanding the ways that structural changes affect such herding. Figure 16 shows a rather pedestrian - and probably wrong-model of herding among Chinese property buyers. While the methodology may confound, the results accidently tell us something about the way crises and other "structural breaks" affect disequilibria property pricing. In theory, everyone should pay what property is worth, sending its rates of return to the market level (even after accounting for differences in the types, quality, and other attributes of such property). Yet, we see these differences magnify in certain types of markets. In times of rising prices, we observe "herding" (or at least increased differences in pricing) much more than 
in down markets. After a significant fall in prices, we observe less variation. A type of shock absorber seems to dampen downward price movements - either meaning that prices adjust much less to negative events, or will really slide during those rare large crises.

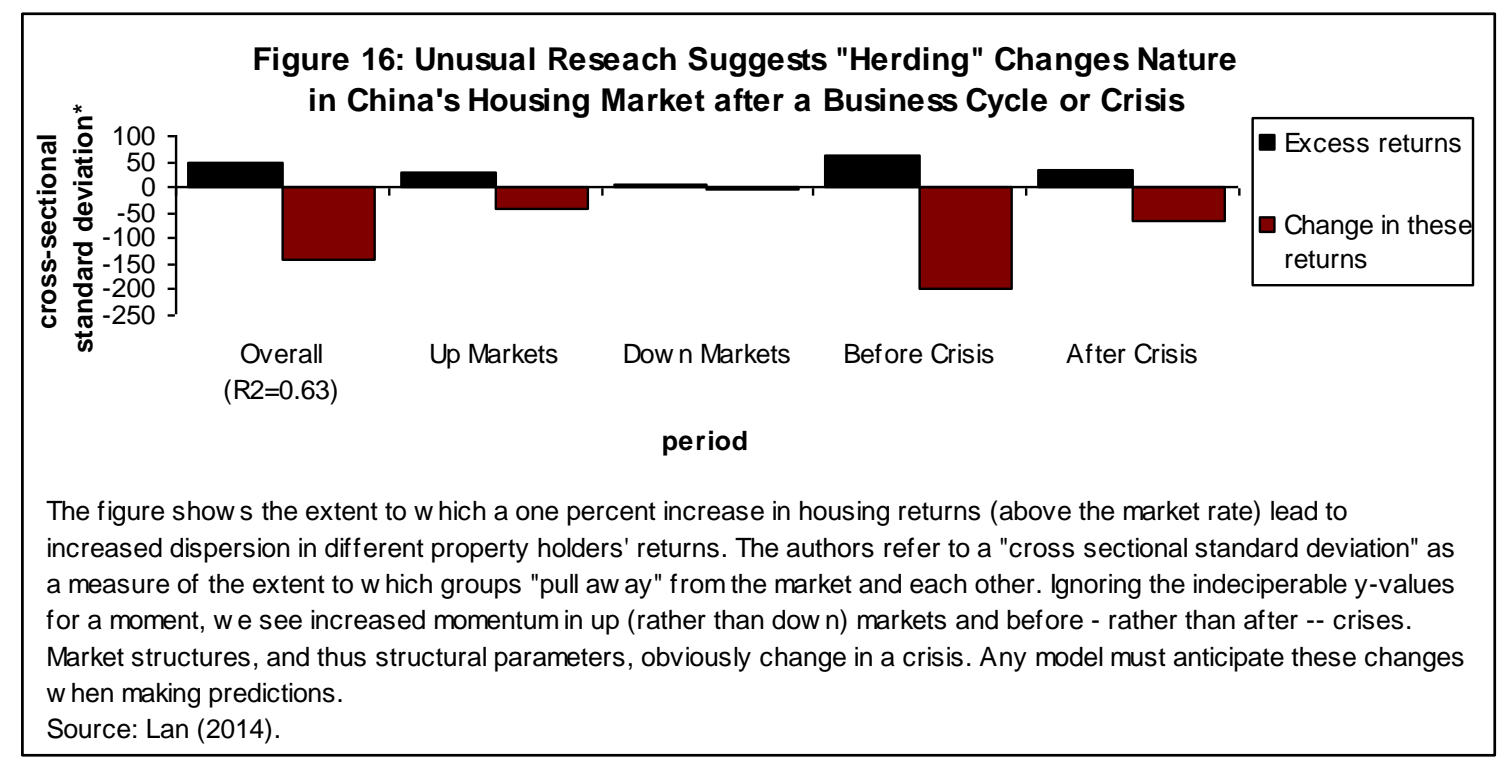

\section{Thinking about structural change in times of crisis}

What effect would a very large crisis have on Chinese GDP growth and property prices? We know we cannot use historical data to estimate these effects, as China has not witnessed a serious recession since 1973. What do large economies' own experiences with Bubble Economics teach us about the way their structures changed and adapted to rapid property price declines? How might their GDP contractions parallel China's future? Figure 17 shows the way that GDP growth rates have varied across time before rapid property price decline. In theory, even if China's experience follows other countries', China could experience a recession. We have labelled as "high point" the GDP growth rate exhibited by upper quartile countries in the IMF's study, and "low point" as the sharpest decline in its lower quartile countries. If China exhibits the best and worst growth shown by other countries, the difference could come to around $7 \%$. However, arguing by analogy takes us only so far. We must understand the specifics of the Chinese economy in order to assess the likelihood of such an event. 


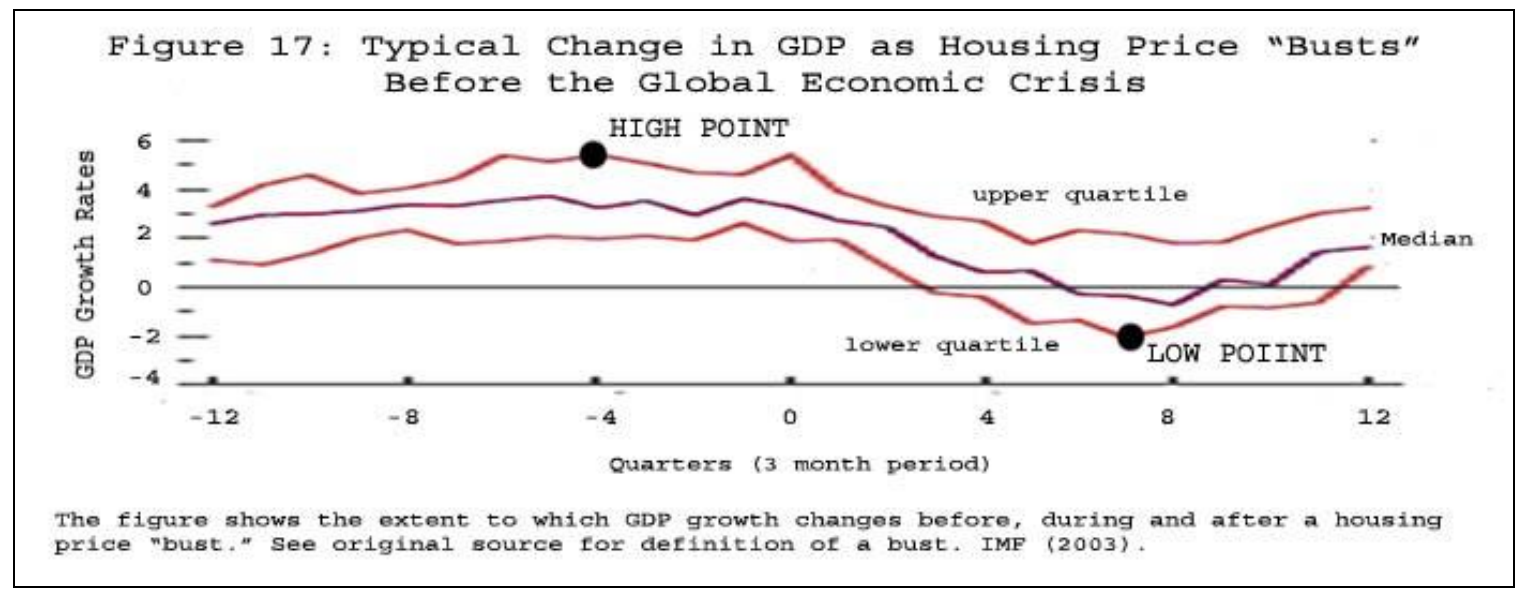

These other countries did not have the GDP growth rates that China has. As such, we cannot directly use these growth rates (even at their apogee) to figure out how far property prices must fall. Instead, we need a way of guessing how far property prices would have collapsed if OECD countries had growth rates similar to China's. Figure 18 tries to show the intuition behind this calculation. Once growth rates in real estate decelerate to about $5 \%$, we notice a significantly different relationship between property prices and GDP. Such a non-linearity almost represents a type of structural break - whereby GDP growth acts differently than it did before. $^{26}$ These data suggest that if the U.K. had China's growth rates, a $30 \%$ or more drop in real estate prices would have to occur before any significant GDP growth impact. We also show the relation between housing prices and the next year's GDP growth (on the assumption that maybe property price impacts need time before they affect the real economy). Even simple analysis suggests that the economy feels property price changes very quickly.

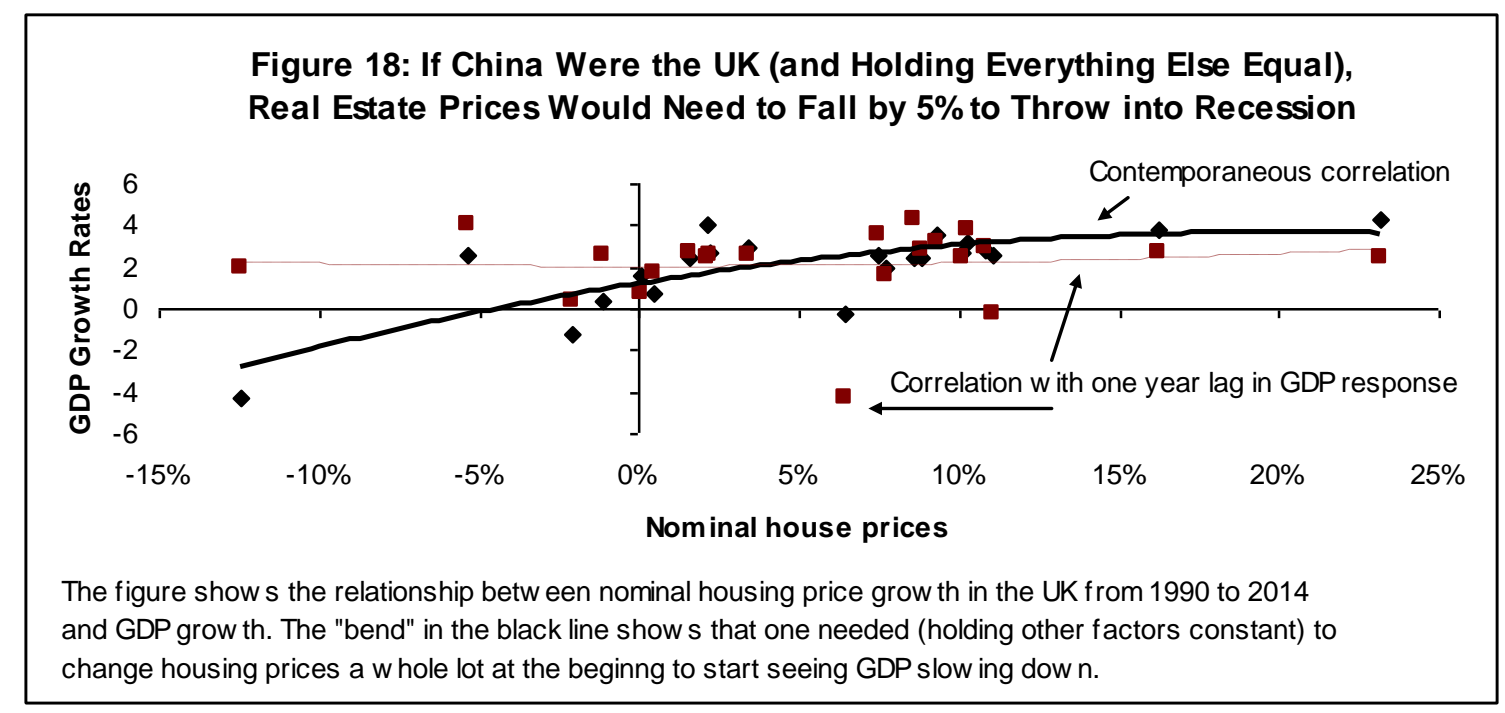

\footnotetext{
${ }^{26}$ The economists in the audience will disapprove strongly of this statement. Technically a "structural break" refers to any discontinuity - and the non-linear line of best fit in the figure clearly shows a continuous function. We wanted to give the nontechnical reader an intuition for the way that the relationship between two variables can shift quite suddenly, misusing language that has become itself misused in popular discourse.
} 
How do price changes affect GDP growth during the pre-crisis and post-crisis period? Figure 19 shows the percent change in GDP growth for changes in property prices. Numbers greater than one mean property price changes more (proportionally) than property prices. Numbers between zero and one mean GDP responds less than property prices. Negative numbers mean decreases in property prices actual lead to more GDP growth (or vice-versa). As shown, each country's economy has its own way of responding. The German economy grew more than proportionately with rapidly falling property prices, and then shrank rapidly four years later. The U.S. and Japan experienced a period of recovering GDP relative to property prices three and four years after the Global Financial Crisis. China's reaction to a property price slide will depend on whether it is a U.S.-Japan style country or other-style country. Figure 20 (basically an easier to read form of the previous figure) shows the average way that GDP growth responded to property price change before and after their property crises. Even for average changes of 0.50 , such elasticities imply that a $30 \%$ property price change would reflect a $15 \%$ GDP change. Yet, the U.S. and Japanese data also suggest that a large recovery in property prices (after a crisis) translate in a very limited way to GDP recovery.
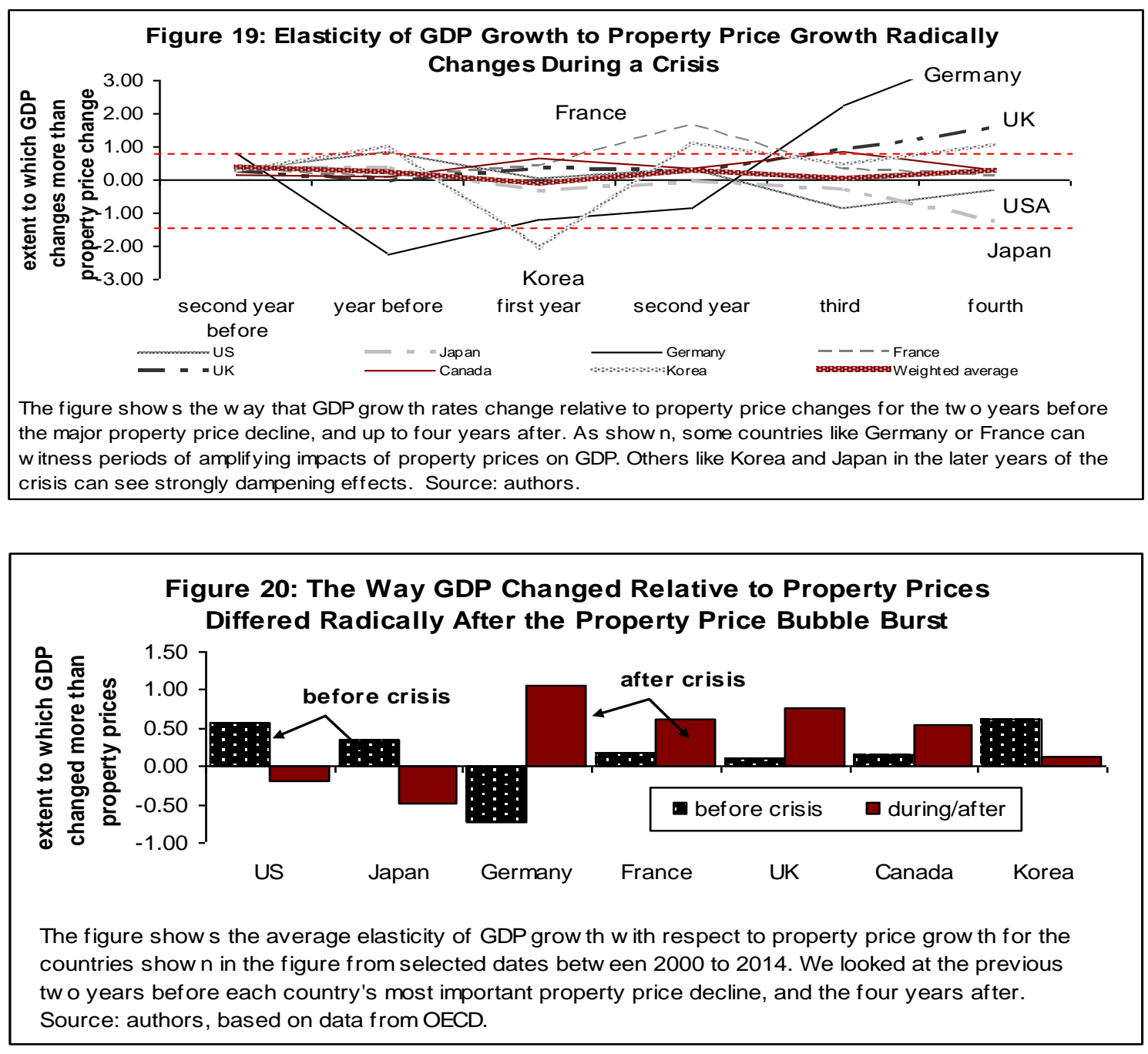
How does GDP respond to property price movements, when we control for other extraneous factors? We know that the availability of credit, profits coming from the stock market, and other factors affect GDP. They also affect property prices, which in turn affect GDP. Figure 21 shows the way that property prices correlate with GDP growth after controlling for some of the most important factors driving GDP. As shown, even after removing the effects of several macroeconomic variables, a $1 \%$ increase in property prices correlates with a $\$ 52$ billion bump in GDP. Once we "cook" the effects of the crisis into our "pure" property price variable, we see any effect of the crisis in our main regression disappear. ${ }^{27}$

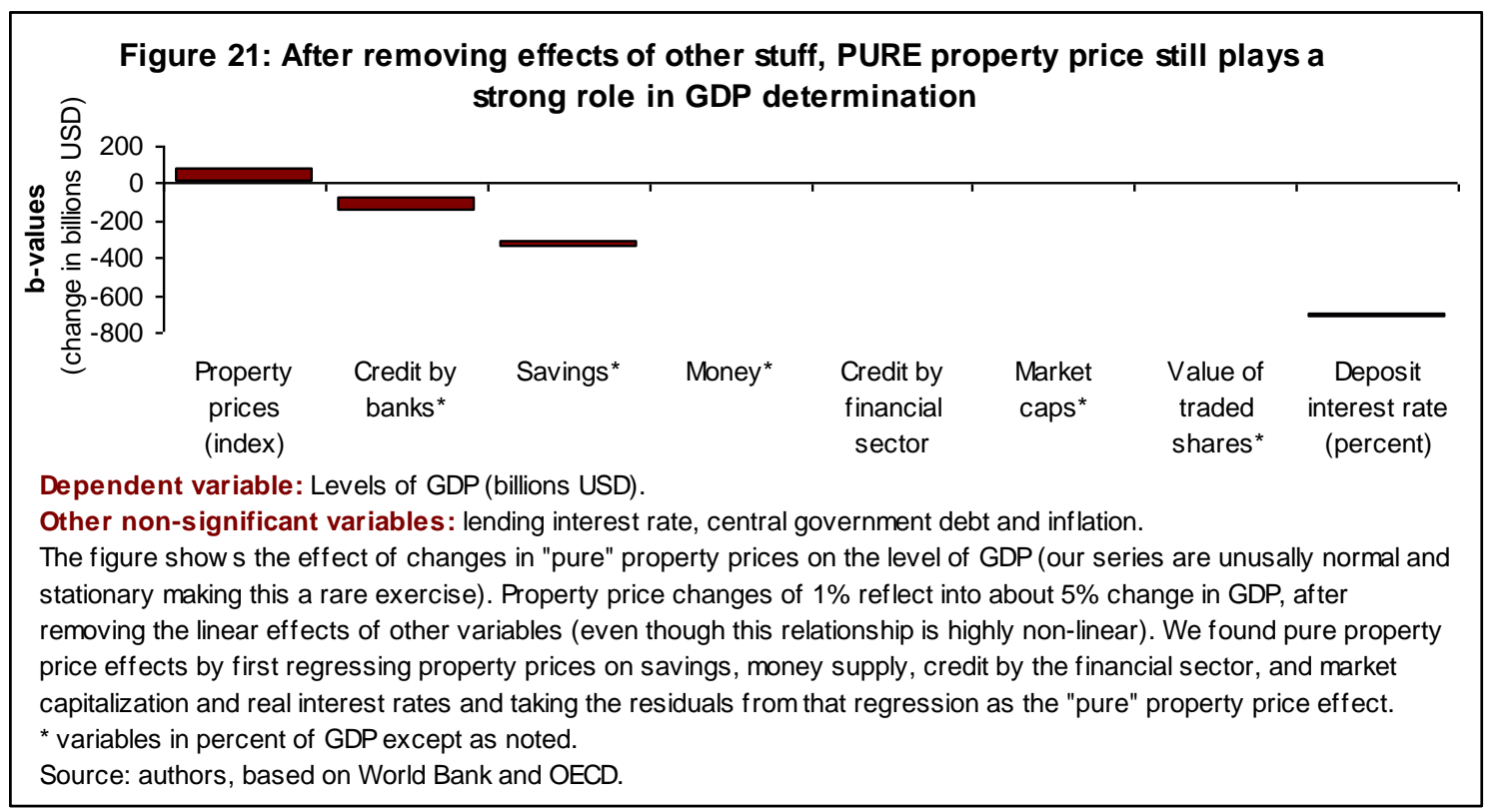

When we look at the data using more conventional methods, we see that "true" property prices remain a key factor in explaining GDP change. ${ }^{28}$ Figure 22 shows the relationships we described previously - the extent to which GDP growth in our OECD comparator countries changes as property prices change - while controlling for other factors. We see that GDP grows (or falls) roughly $40 \%$ as much as each percent change in property prices after controlling for the feedback of other variables (including GDP) into property price change. Household savings represent the only other significant variable coming out of this analysis once we take into account the differing

\footnotetext{
27 "Cooking" means to include a dummy variable in the first regression whose residuals we used to obtain an estimate of the part of property price movements not related to credit, interest rates, money supply, savings, and stock market capitalization. These residuals account for the different means in property prices in the pre-crisis as opposed to post-crisis period. Thus, we would not expect the crisis variable to again show a statistically significant relationship in the main (and highly mis-specified) regression on levels of GDP. We discuss in the Appendix why we should use this regression for illustrative purposes only (namely the regression fails to include a lag, making this a difference equation).

28 "True" property prices refer to estimated property prices from a procedure known as instrumental variables estimation. We differentiate "true" from "pure" property prices (which use two stages least squares estimation) in order to highlight the different technique used and explain it in a way the average reader can understand. As we describe in the Appendix, both the estimation method (using levels of GDP for example) we use and the statistical procedures we use (instrumental variables for example) do not matter much — as we use math to manipulate the expressions we obtain to triangle believable relationships in the data.
} 
way these variables behave during a crisis. ${ }^{29}$ The relationship in the way money, credit, central government debt, and other factors do not remain consistent over time leads to a loss of explanatory power in these variables as a determinant of changes in GDP.

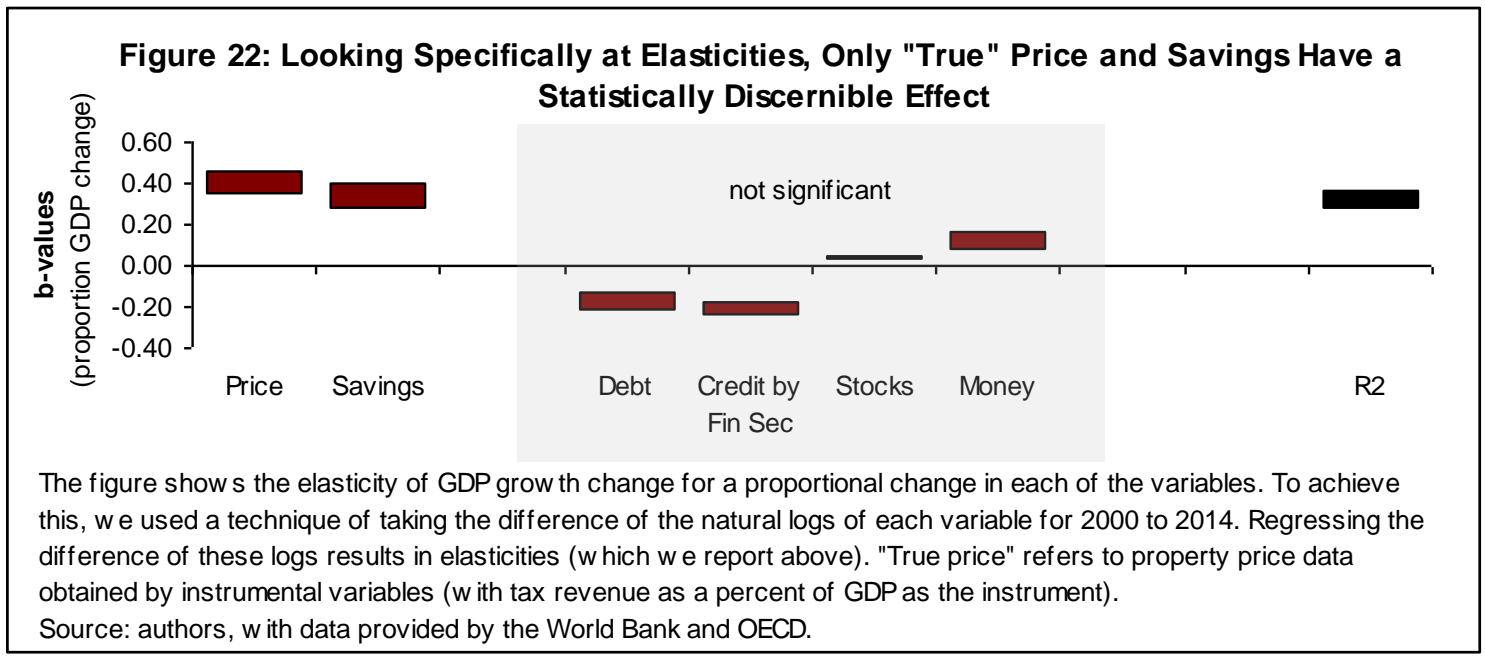

One obvious structural change which could occur consists of a banking/financial crisis for very sharp declines in property prices. Obviously, the way GDP reacts to the money supply, government debt, property prices, and other factors changes in times of crisis (and probably thereafter). How likely are the structure changes concomitant with rapidly rising property prices? Figure 23 shows the extent to which countries experiencing a real estate boom (and credit boom or both) experienced a sharp decline in GDP as the result of a crisis or "poor performance" (a less dramatic decline in GDP growth). As shown, for real estate booms alone, over $80 \%$ of countries experiencing such a real estate boom subsequently experienced either poor performance or a financial crisis - with the GDP-related problems attendant with such crises. If other countries' experience serves as a guide, China has a high probability of experiencing structural changes attendant with a financial (or other) crisis.

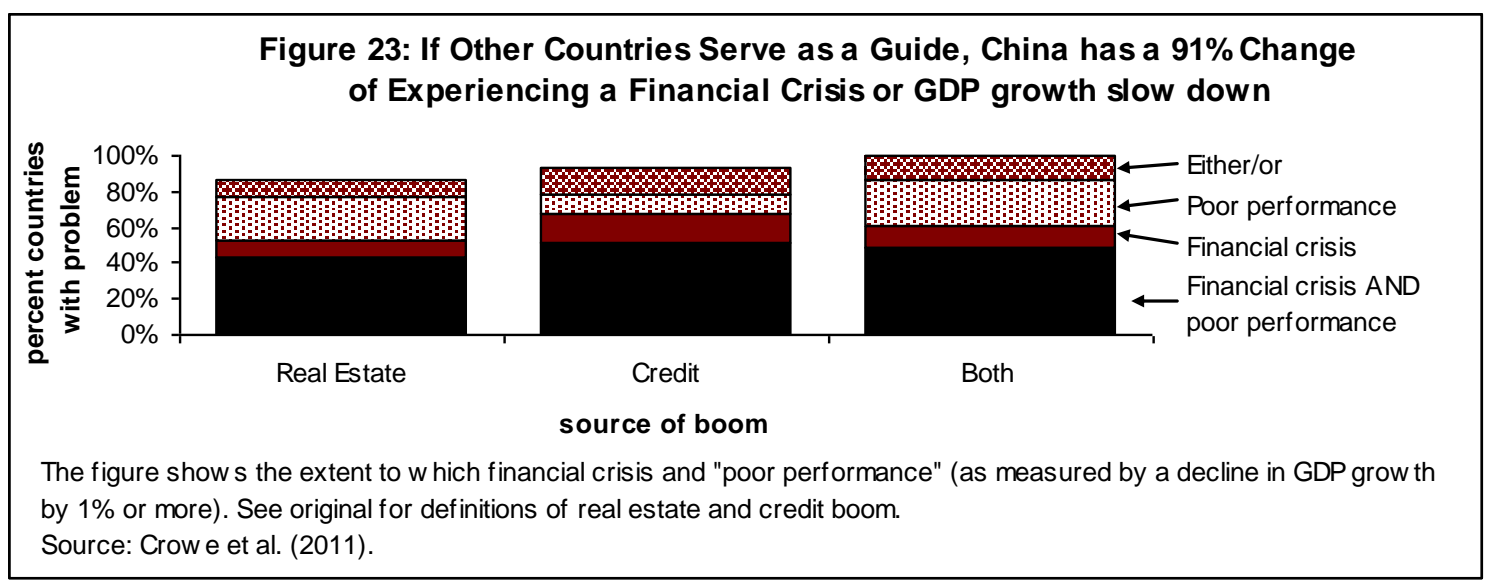

\footnotetext{
${ }^{29}$ The analysis shown in the figure includes a dummy variable for the year in which each country's property prices declined. Thus, the figure shows the way that these variables relate to each other in a crisis.
} 
If other countries' experience serves as a guide, China can expect to lose up to 1\%-2\% of GDP per year in case of a banking crisis. Dell'Ariccia et al. (2008) found that a banking crisis, and the sudden cut off from finance, causes higher value adding industries to forego investment of roughly $-5 \%$ of growth of value added. ${ }^{30}$ While output shocks can range up to $30 \%$ of GDP, most economies similar in size and scale to China's (like OECD economies) exhibit GDP declines of only around 3\%-5\% at the most in recent years. Studies like Berkman et al. (2009) show that leverage and credit growth speeds help explain the extent to which a financial crisis affects GDP. As such, even an extreme events analysis - using past data as a guide - suggest that a severe banking crisis caused by freezing up real estate markets would shave at most 5\% off of Chinese GDP growth. ${ }^{31}$

What do we know about debt crises and the way property prices contribute to them?

If the Chinese government(s) and households deplete their resources (including possibility of borrowing) as property prices fall, how would this affect Chinese GDP growth? We know that the most severe crises occur when governments (including local government) no longer have the ability to engage in expansionary fiscal and/or monetary policy. Figure 24 shows the estimated fall in GDP during crises in various countries. Outside of the Great Depression, Finland and several countries in Eastern Europe and the Former Soviet Union experienced GDP contraction of $10 \%$ - certainly enough to throw China into recession. Looking specifically at crises resulting from sovereign defaults, GDP shrank by about 3\%. However, as shown in Figure 25, the mean conceals far more than it reveals. At the extreme, using other countries as an example, GDP could easily fall by $40 \%$ or more if China represented the fastest grower before-crisis and the worst grower after-crisis. With total government debt (edging toward 300\% of GDP) as one of the highest historically known world-wide, China inches ever-closer toward potential sovereign crisis.

\footnotetext{
${ }^{30}$ This includes the effect of the crisis of -2.74 on sectors more heavily reliant on external finance and another -2.44 for more important sectors (as reported in Table 1). As a cross-check, a simple skim of Table 7's "Cost of Crisis from Bank Lending Channel" shows that these declines do not defy common sense. Also, simply adding the difference in annual growth rates between crisis and non-crisis years across time (as shown in Table A3) gives roughly the same result. With the exception of the US's 1980 crisis, few of the countries reported have the same economic scale as China.

${ }^{31}$ As an aside, the 2013 Financial Stability Report also places the maximum decline in GDP from the most extreme banking crisis at around a 4\%-5\% reduction in GDP (page 162). Le et al.'s (2013) place the effect at closer to 9\% because of an expected tightening of monetary policy by the People's Bank of China., which we do not assume (p. 18).
} 


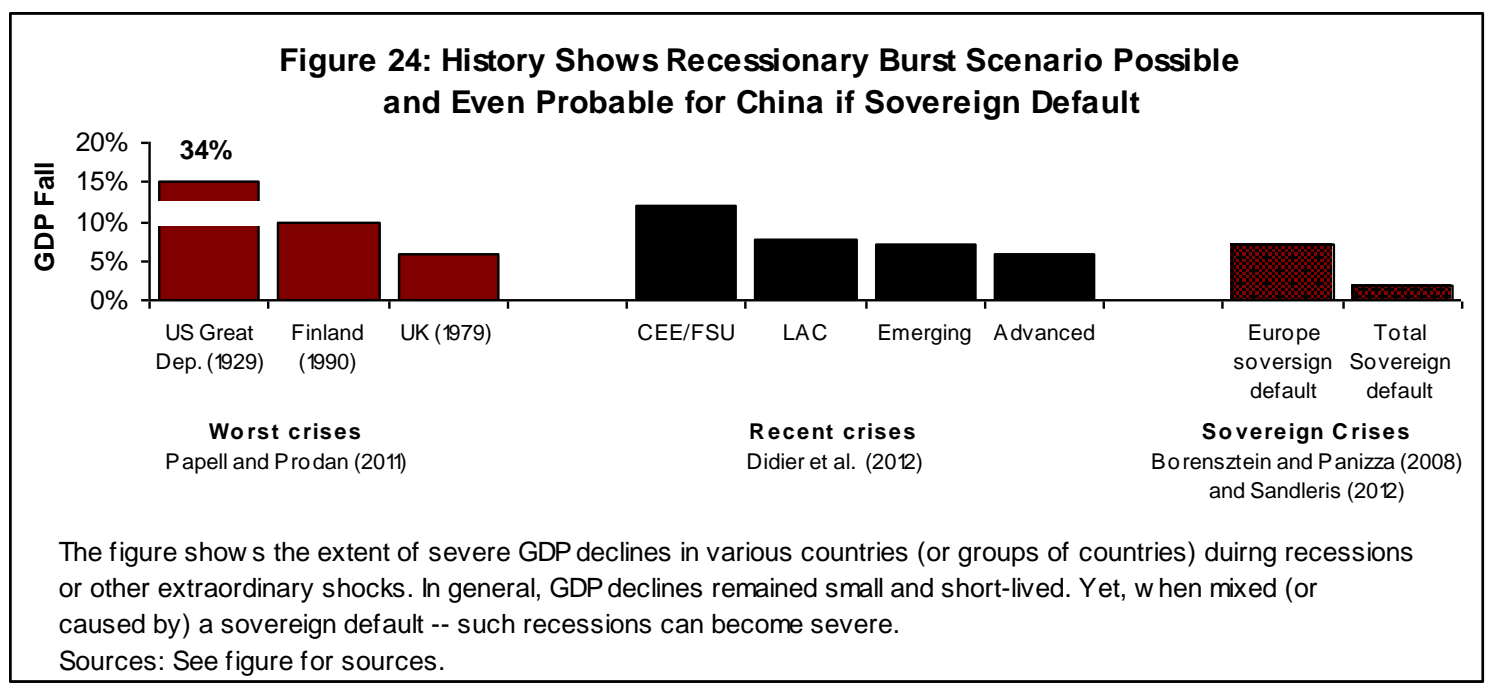

\section{Figure 25: GDP Shrinks By About 5\% -- But Can Shrink Up} to $20 \%$ or More After Sovereign Default

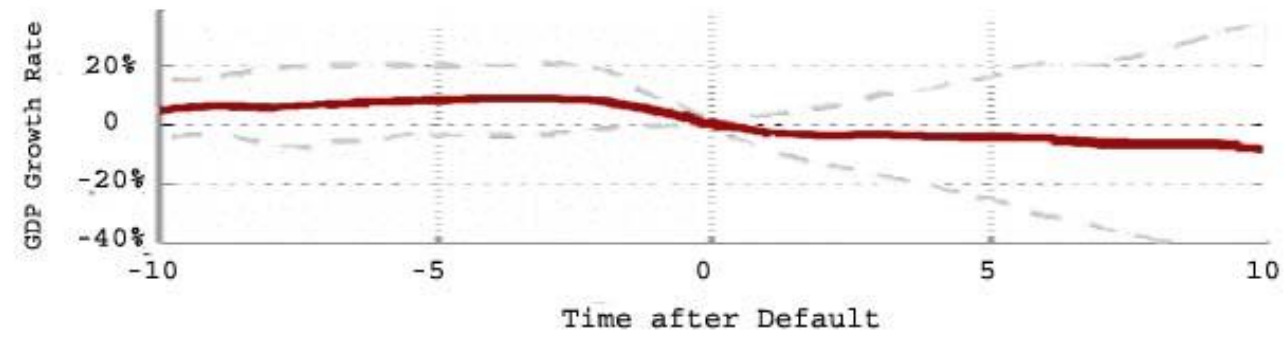

The figure shows the extent of GDP growth rate changes after various financial crises. We have relabelled the $\mathrm{y}$-axis (which originally represented the difference in log values of GDP). Source: Gornemann (2014) at Figure 10.

How likely is such sovereign default in China specifically? China has very different political and economic structures to the emerging markets we have previously discussed. Thus, we cannot use historical data. Nevertheless, Figure 26 shows the results of econometric modelling looking at that question for China. According to the results of Le and et al. (2013), a recessionary crisis has a $2.9 \%$ probability of occurring every year! They show that for a range of plausible model parameterizations, GDP falls abruptly. The longer the time period, the higher the risk of sudden GDP collapse. Even without changing the structural parameters of their model (as we argue should be done) and without simulating the effects of extreme events and shocks (as we also argue), their model generates rather large GDP drops. Such modelling reflects the non-linear dynamics most closely related to our own work-showing how Bubble Economics has the roots in intrinsic instability which must enter our macro models! 
Figure 26: Economic Crisis Comes to China Infrequently -- Yet Inevitably Even with Previous Structural Variables
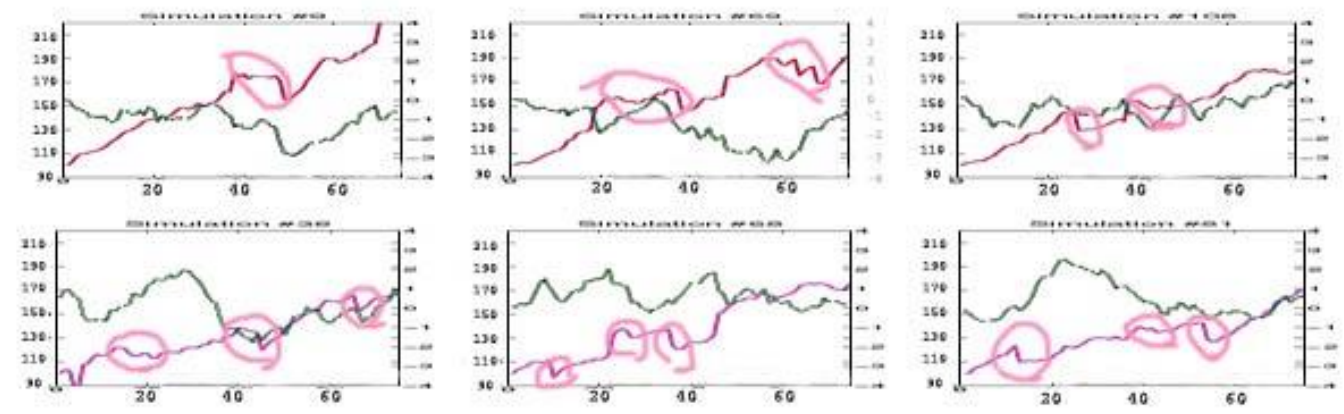

- Riak Dreniunt - Output response orisis periods

The figure shows six demonstrative simulations of the evolution of GDP and risk premia from the authors' model of the Chinese economy, using past data to calibrate the model.

Source: Le et al. (2013)

What about household savings? The story goes that households will dis-save before a crisis and/or a crisis will impact such savings - exacerbating the crisis. Wang and Wen (2012) for example show that Chinese households do not save for housing. They find that rising housing prices can generate an additional aggregate saving rate of at most $4.3 \%$. As such, under extreme assumptions in their model, a $10 \%$ sudden fall in housing prices would lead to a $43 \%$ fall in savings rates. Yet, in line with our previous discussion, changes in "structural variables" (in this case a change in down payments from $50 \%$ to $40 \%$ of loan value) reduces these saving rates, with savings falling to $16 \%$ in case of a sudden $10 \%$ fall in housing prices. We know, given the key role that disposable income rather than life-cycle planning plays in Chinese savings, that sudden declines in disposable income would impact heavily on housing savings as one of the Twin Buffers (Mees and Ahmed 2012).

\section{Figure 27: The US and UK Experience Suggest China Could Experience} $10 \%$ More Insolvencies When Indebtedness Doubles
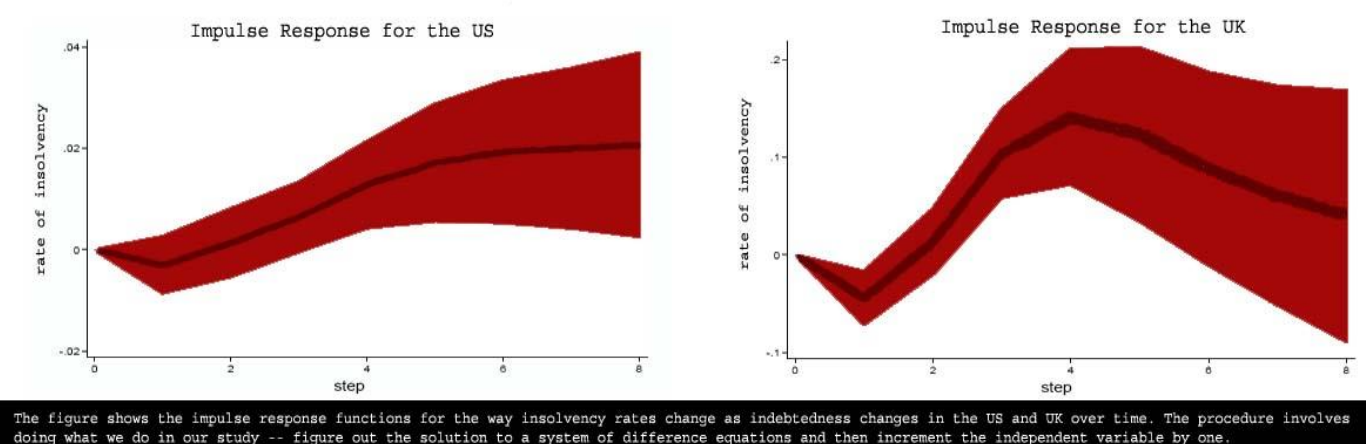


\section{A Look at the Five Channels Which Affect China's Bubble Economy}

How would a significant property price decline (of more than 10\%) actually translate in GDP reductions? In the previous section, we described the reasons why property prices might fall suddenly - to remove disequilibria, as the result of structural change, and in response to a debt crisis. Figure 27 shows the way that most commentators in popular media argue that a shock to China's housing/property markets might translate into broader economic crisis and consequent reductions in Chinese GDP (Gaulard 2013). Analysts of all stripes bring up five facts about the Chinese economy in particular to support the argument that a severe real estate-led financial crisis looks likely. ${ }^{32}$ First, a shock to Chinese real estate markets will disrupt vast amounts of local government debt, which they took on to build and buy real estate (Sanderson and Forsythe 2013). Falling real estate prices make debt repayment more difficult_putting local governments (and their spending) at risk. Second, lower real estate prices will result in falling equities prices by reducing listed construction companies' profits and the profits of the listed banks that lend to them and residential borrowers (Huang 2011; Huang and Ge 2012). Third, construction companies and other companies dependent on a booming real estate market will contract, leading to wider impacts on demand (Chivakul and Lam 2015). Fourth, banks' mortgage and other securities backed by real estate lose value and/or fail to make expected payments-leading to the declining capitalization and profits, which lead to an eventual financial crisis (Huang et al. 2015). Fifth, households use real estate as a form of savings (in the presence of poorly functioning alternatives) and a real estate shock would lower household wealth and thus reign in consumption and other production investment (Jin 2011; Bian and Gete 2015).

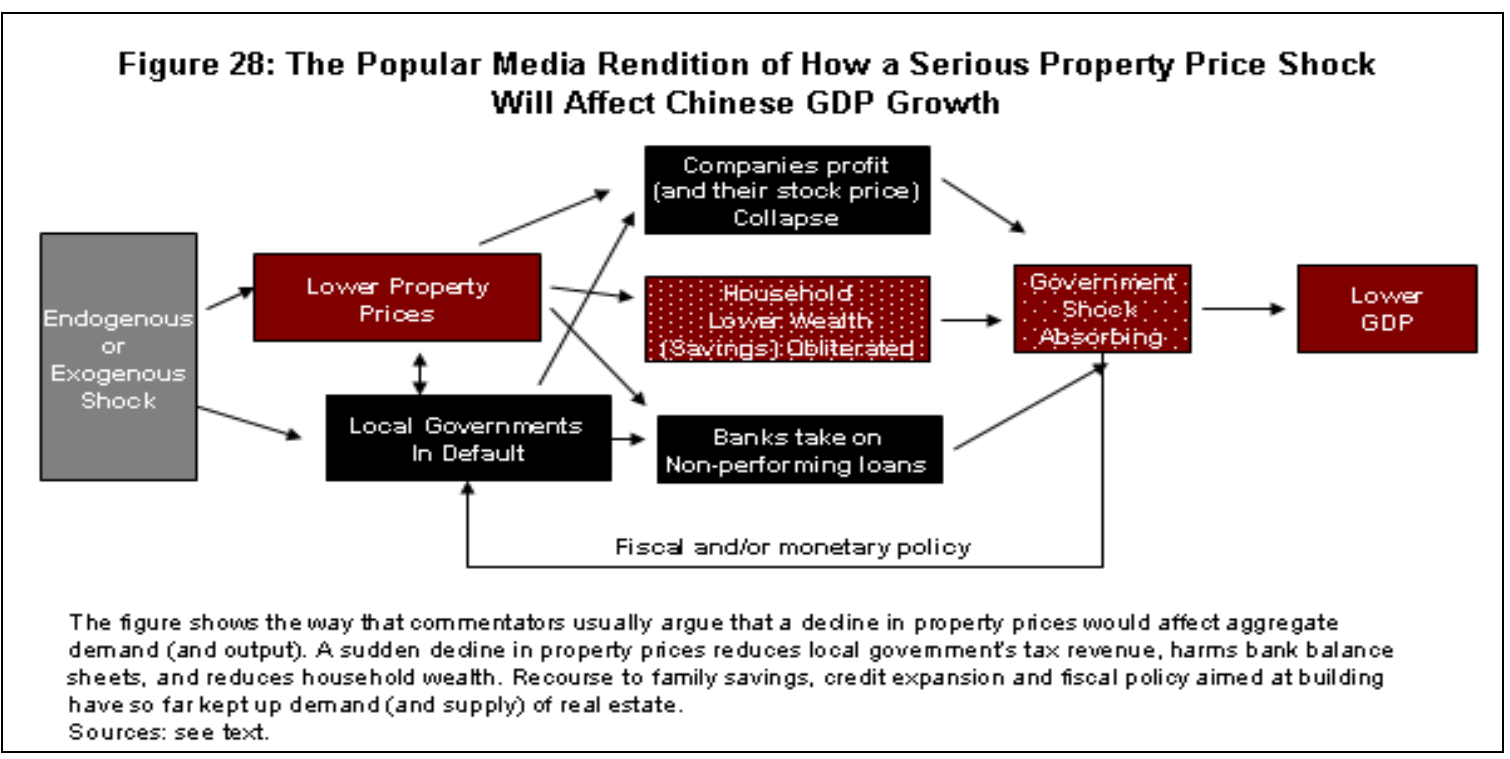

${ }^{32}$ Of course, not all analysts see the possibility of a crisis. Seki (2012) for example sees such a remote possibility. 


\section{The Banking Channel}

Bank lending (and subsequent buying of securities based on real estate lending) represents a key part of the Bubble Economy story. In China, previous studies confirm the commonsensical notion that commercial and residential lending forms an important bridge between property price change and changes in GDP. The supply of funds helps determine the change in Chinese property prices and extent of broader economic change/growth. Figure 29 shows the extent to which various real estate-related variables affect the macroeconomy (and vice-versa). The figure shows the probability that each variable shown in the figure does NOT "Granger cause" the other variable. ${ }^{33}$ Bank lending for real estate clearly represents a key determinant of property price change. Yet, these data suggest that lending and ultimately output changes come from changing interest rates - not property price changes. ${ }^{34}$ If these authors' analysis is accurate, loans expand by 2.2 units as housing prices rise and decrease by about 1.4 units as output rises. We see the problematic (and probably incorrect) relation in this study, in that changing output causes changes in housing prices, rather than the other way around and with the wrong sign $!^{35}$ While these relationships might explain the past, they clearly cannot help us understand the future.

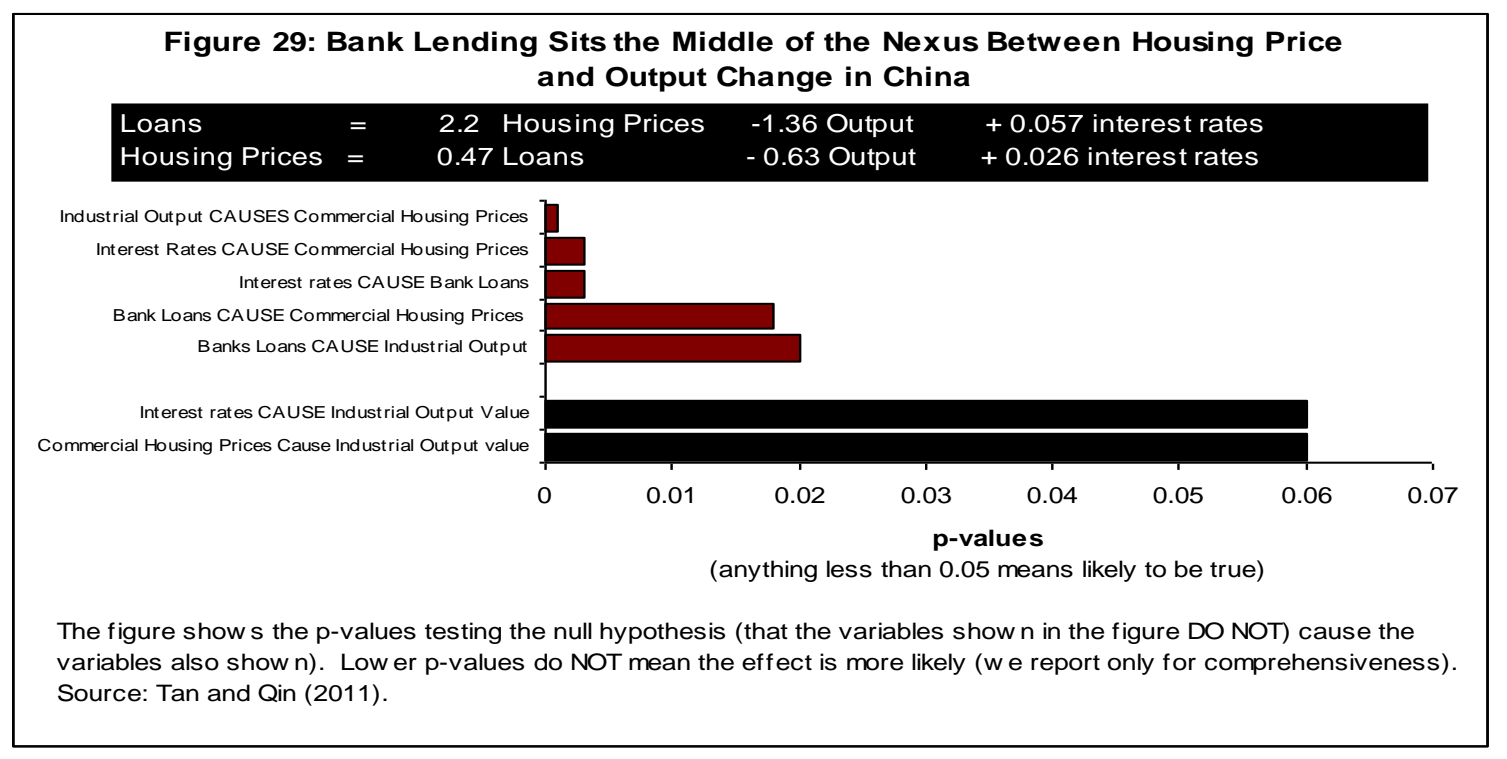

\footnotetext{
${ }^{33}$ Granger causality refers to an econometric method whereby the econometrician can show that one variable affects another variable by showing that a lagged variable statistically significantly correlates with another variable. For example, changes in the amount of bank lending in the Chinese economic "Granger causes" changes in GDP if changes in the previous year's bank lending statistically significantly correlate with changes in the current year's GDP. Thus, low p-values mean that we reject the null hypothesis that changes in one variable do NOT "cause" the changes in the other variable.

${ }^{34}$ As we will describe in the next section we do not model the effects of interest rates directly. Our focus centres on characterizing the Bubble Economy and describing macroeconomic change at a time when interest rates would likely hover around zero. Because - following recent experience — we assume that interests cannot represent an important policy tool, we avoid an in-depth analysis of this very important variable. Of course, we acknowledge the historical role they played in building up crises pressures in the first place.

${ }^{35}$ Part of our study aims to critique previous studies. Clearly, when differing studies cannot even agree on the sign (much less the magnitude) of an effect, further work is needed.
} 
Bank credit clearly affects housing prices, even if money supply and the stock market do not (so much). Figure 30 shows the results from two more studies looking at the determinants of Chinese housing prices. As shown, bank credit represents the most important factor (outside of interest rates, which we do not discuss in this paper). Bank credit, and credit of all kinds, tended to stoke demand for real estate (and thus prices) by about $10 \%$ for every $1 \%$ change in real interest rates. Money supply increases tended to have the slightest impact in all studies - with high-range estimates placing changes in housing prices at about $0.5 \%$. Changes in the stock market also have miniscule effects on housing prices, suggesting that the stock market liquidity seems an unlikely vector of transmission for property price effects. Yet, because these studies do not include feedbacks or the building up of risks over time in the banking and property sectors, we cannot use these relationships to guess the Chinese property market's future.

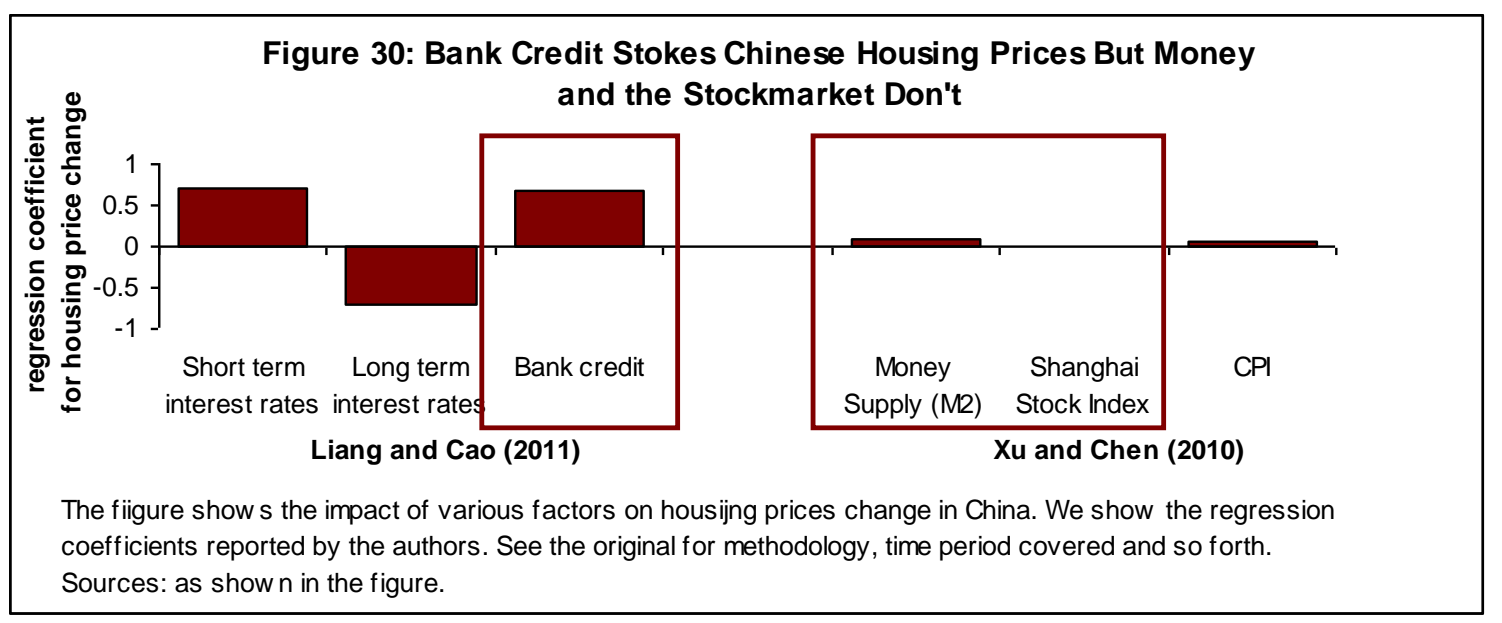

How do we know that the past doesn't represent the future? Banks' balance sheets tell us. Any slowdown or sudden stop in real estate borrowing/lending would cripple financial institutions' balance sheets - posing the risk of a banking crisis and attendant economic effects. Yet, we have no way of knowing exactly when such risks translate into lost Chinese GDP. Figure 31 shows the percent of debt-at-risk of non repayment in case of a severe real estate crisis. Roughly $25 \%$ of all non-financial corporations run the risk of non-repayment in case of a real estate crisis. Figure 32 shows the estimated effects — even taking the implausibly low non-performing loan rates reported by banks - of three kinds of shocks. For the average bank, the proportion of nonperforming loans rises by only about $1 \%-2 \%$. Yet, for the bottom $10 \%$ of banks (banks with the most value-at-risk), these shocks would have significant effects on their balance sheets. Negative property price shocks have the least impact (albeit almost tripling the 2011 level of nonperforming loans). Interest rate shocks quadruple this level of non-performing loans to around $2 \%$. GDP shocks have the largest effect, quintupling the proportion of bad loans. At odds with these studies, we know that price, rather than interest rates, will probably represent the most important variable of interest in the future. Yet, we have no way to know just how much debt needs to be at risk before a crisis occurs. 

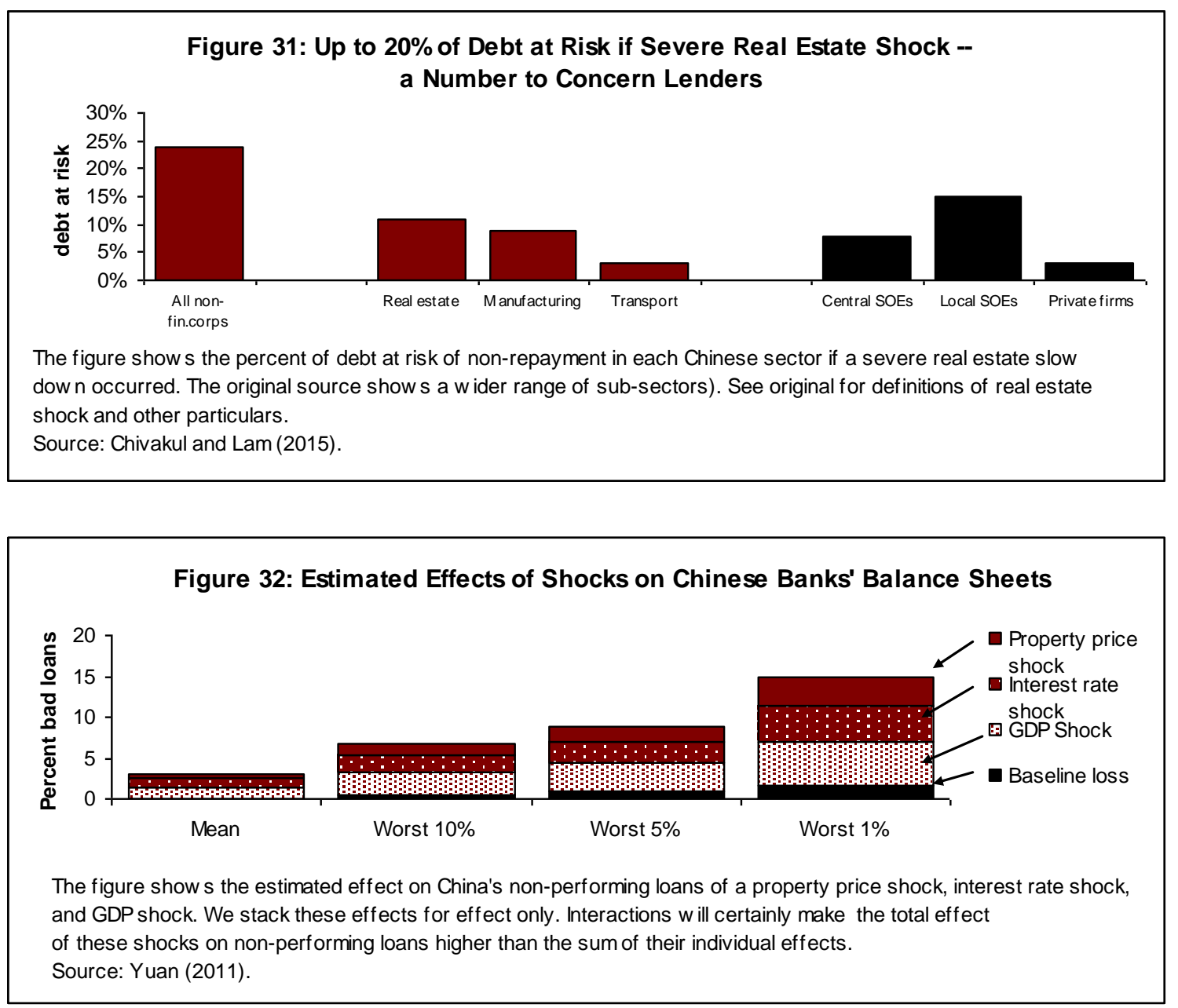

These studies show we need a model of the Bubble Economy for two reasons. First, we know that bad loans, shaky GDP and falling property prices feed into each other. Worse still, we know that interest rates probably won't arbitrate in the contest between property supply and demand when a crisis comes. These previous studies fail to anticipate the changes in the Chinese economy that these historical trends have wrought. Second, these models do not predict what will happen when these bad loans exceed a certain value. Takahashi (2015) for example argues that banks already hold roughly $20 \%$ of the value of their loans as bad loans. He argues that the relabeling of short-term lending to long-term lending has simply hidden the non-performing loan problem. ${ }^{36}$ Yet, even without such misclassification, any serious shock to China's economy will result in significant increases in bad loans. When Chinese banks can no longer lend money, the old relationships between property prices, lending, and GDP growth will break down.

Indeed, a cursory look at the data clearly shows why we cannot use previous data to forecast the future. Figure 25 shows increases in Chinese property prices have historically coincided with lower mortgage lending volumes (expressed as a percent of GDP). The false impression from

\footnotetext{
${ }^{36}$ Not to pick on Takahashi, but this paper reflects the patchy quality of research about China's real estate price bubble. Much of the argumentation relies on anecdotal evidence and one or two data series presented to weave a particular argument.
} 
history suggests that a sudden drop in property prices would correlate with largely expanded mortgage lending. Even more confusingly, after controlling for other financial variables (but before correcting for endogeneity), the negative relation only gets stronger. ${ }^{37}$

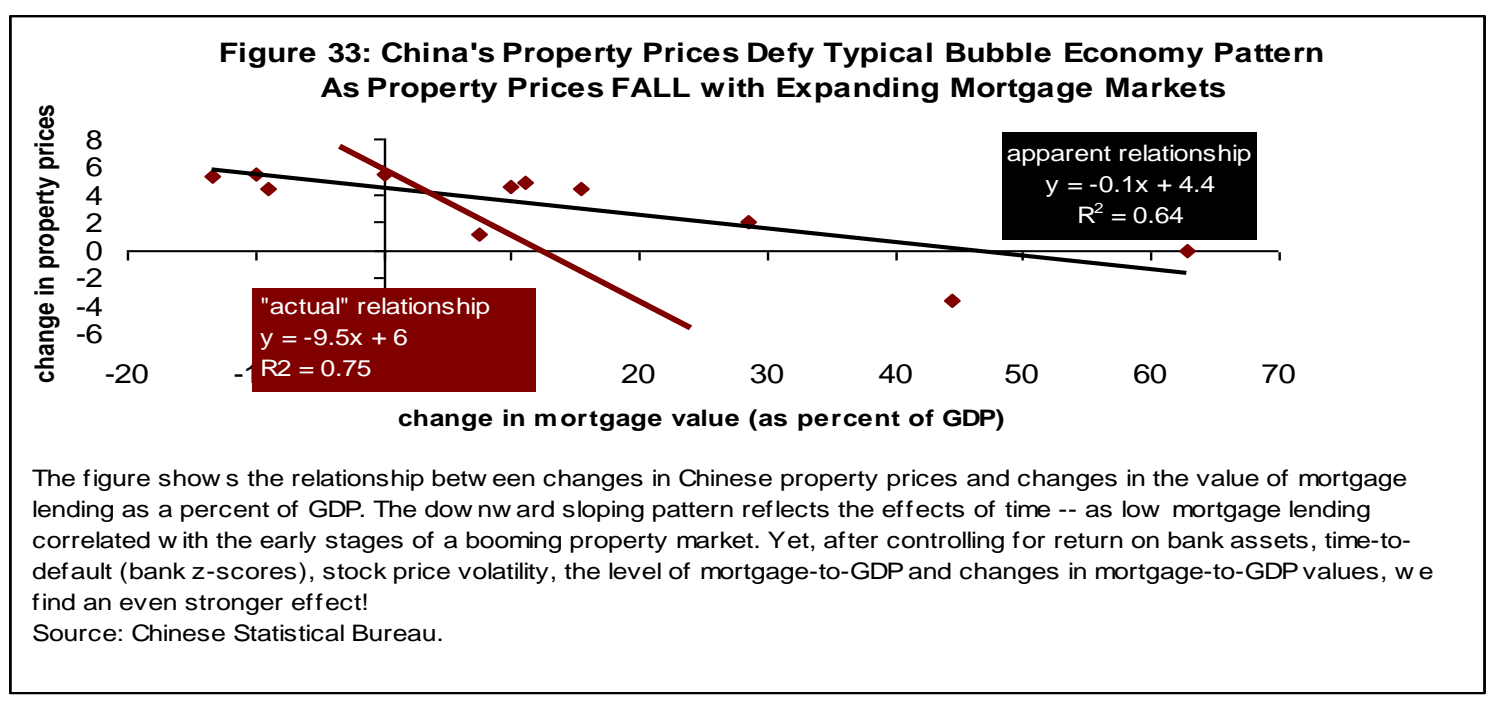

Judging by our comparators' experience, China's banking system would undergo large-scale change. Figure 34 shows the way our OECD comparators' banking sectors changed in their postproperty-price-decline period. As shown, returns on assets, time to bankruptcy (z-scores), and return on equity went down - while stock price volatility rose and residential mortgages-to-GDP saw no statistically significant change (though saw a possible decrease). Figure 35 shows how the relationship between property prices and mortgage markets would change if a crisis affects China's banks in the same way they affected the OECD comparators' banking sectors. Average property prices would fall and the relationship between prices and mortgage volumes would gain elasticity.

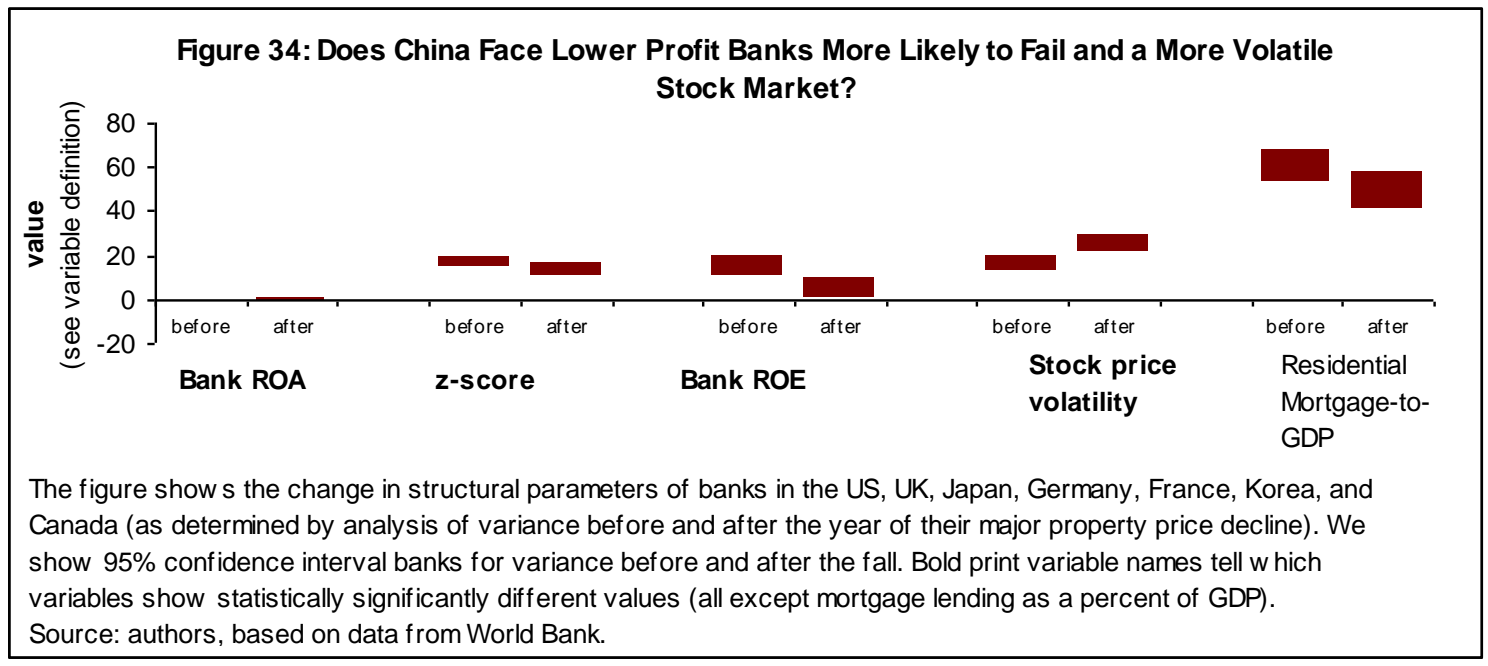

\footnotetext{
${ }^{37}$ The "actual" line we show controls for return on bank assets, time-to-default (bank z-scores), stock price volatility, the level of mortgage-to-GDP and changes in mortgage-to-GDP values.
} 


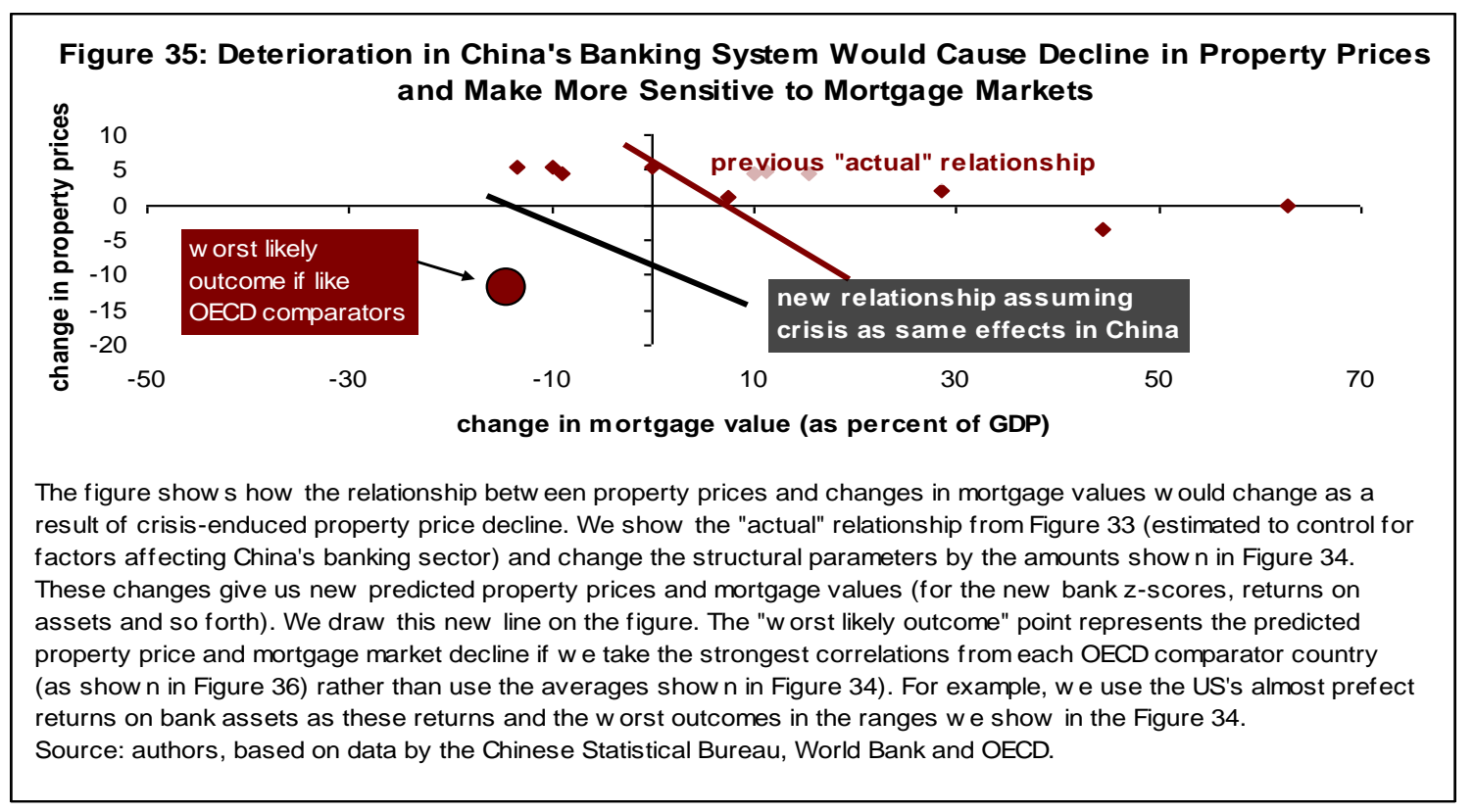

Yet, even that hypothetical relationship conceals other likely plausible outcomes for changes in property prices and mortgage values during a sharp property price decline like the one experienced by our OECD comparator countries. In Figure 35 above, we have labelled a "worst likely outcome point." To derive that point, we use the strongest, rather than average, correlations between property prices, mortgage volumes/values, and the banking variables we described previously. Figure 36 shows the range of these correlations, illustrating as well how China's financial system might change during a crisis. In the first view, existing similarities in the way financial indicators correlate with property price changes suggest that China more closely resembles Japan or Germany than the other comparators. In the figure, we see this by the "pattern" of dots. Gross portfolio debt liabilities respond the most to changes in property prices (having the largest positive correlation coefficients). Bank non-performing loans shrink the fastest (having the largest negative correlation with property prices). ${ }^{38}$ In this view, China's response to declining property prices would represent - at the appropriate order of magnitude - a response similar to Germany's or Japan's. In the second view, the larger property price fall would lead to structural change, putting China's financial sector response closer to that of the U.K. or the U.S. In this view, returns on bank's assets fall precipitously (following the U.S. and U.K. example) rather than moderately (following the Nihon and Tutonic examples).

\footnotetext{
${ }^{38}$ In other words, rising property prices result in fewer non-performing loans and vice-versa (a reassuring result).
} 


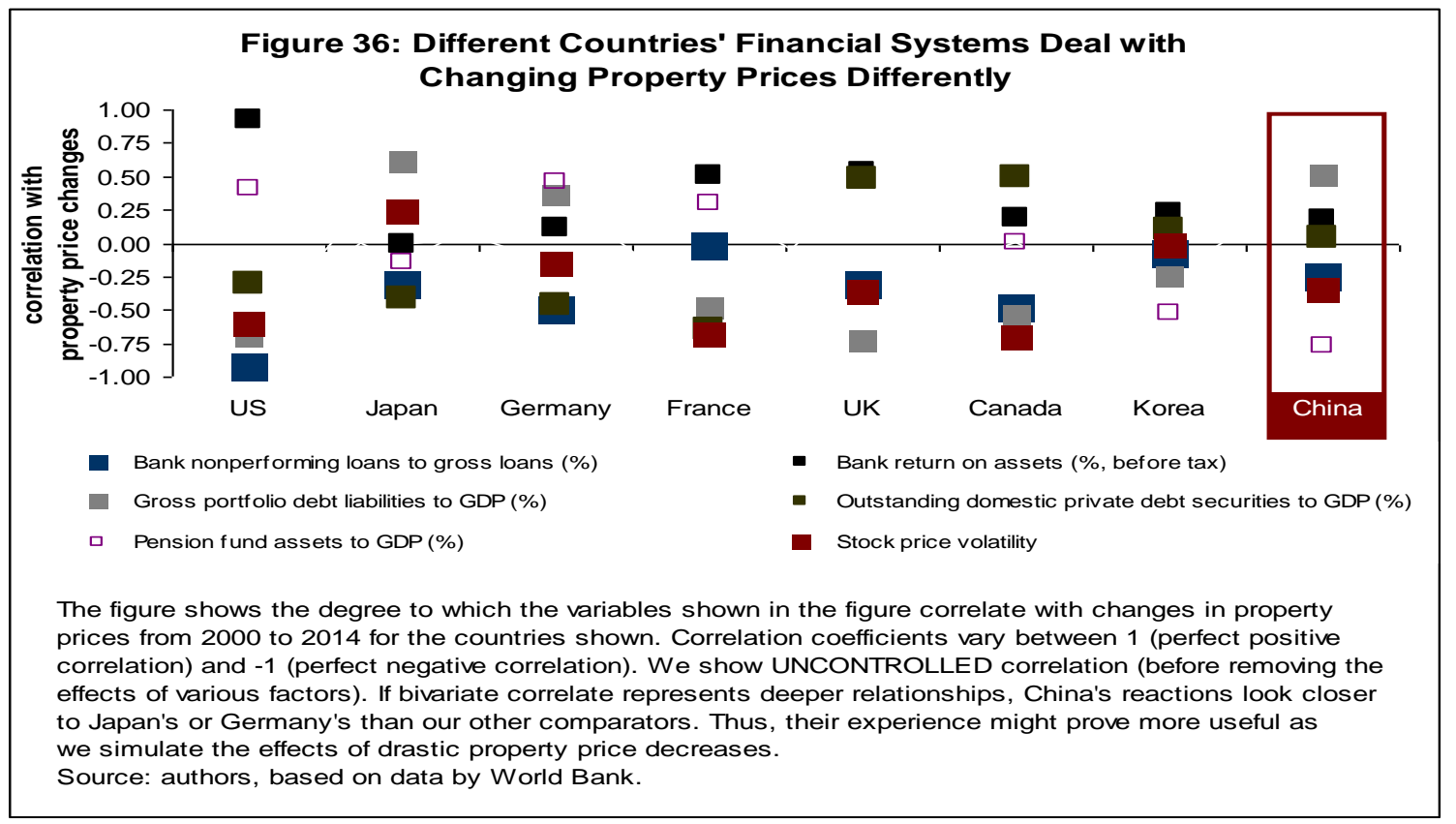

Any model of the Bubble Economy needs to describe how China moves from the "actual" relationship shown in Figure 35 to the worst point. We know from other countries' experiences that this move can happen suddenly as structural parameters change. We illustrated several of these parameters from OECD member countries, and showed how they changed during their own crises. Such a model would likely be non-linear, as passing some threshold value of loans-at-risk (for example) would likely set off the changes we described.

\section{The Construction Industry}

What effect would a massive and sudden drop in demand for real estate have on China's construction sector, and thus eventually on GDP? ${ }^{39}$ Figures 37 and 38 show the effect on construction companies in cases of a real estate shock. As shown in Figure 37, in homebuilding and appliances, roughly $60 \%$ of firms would lose money and roughly $30 \%$ of construction companies would lose money. Part of these losses would result from higher interest rates concomitant with higher risk premia on loans and possibly higher bank rates due to the need to keep money in the banks. Figure 38 shows interest payments as a percent of profits. As interest rates rise, they would eat into over half of local state-owned enterprises' profits. Even for private firms, roughly $40 \%$ of their profits would dissipate into interest payments. Leverage among private real estate and construction companies reached over $200 \%$ in 2013 and over $250 \%$ for state owned enterprises (IMF 2014). The share of these companies with leverage ratios over $400 \%$ rose to over $40 \%$ in 2013.

\footnotetext{
${ }^{39}$ The most likely vector for an over-night drop in real estate prices would come from demand rather than supply-a banking crisis which chokes off funding, a financial crash which makes buyers nervous, a scandal at a major property intermediary and so forth. We keep this section relatively brief to focus on the more interesting local government and banking sections.
} 

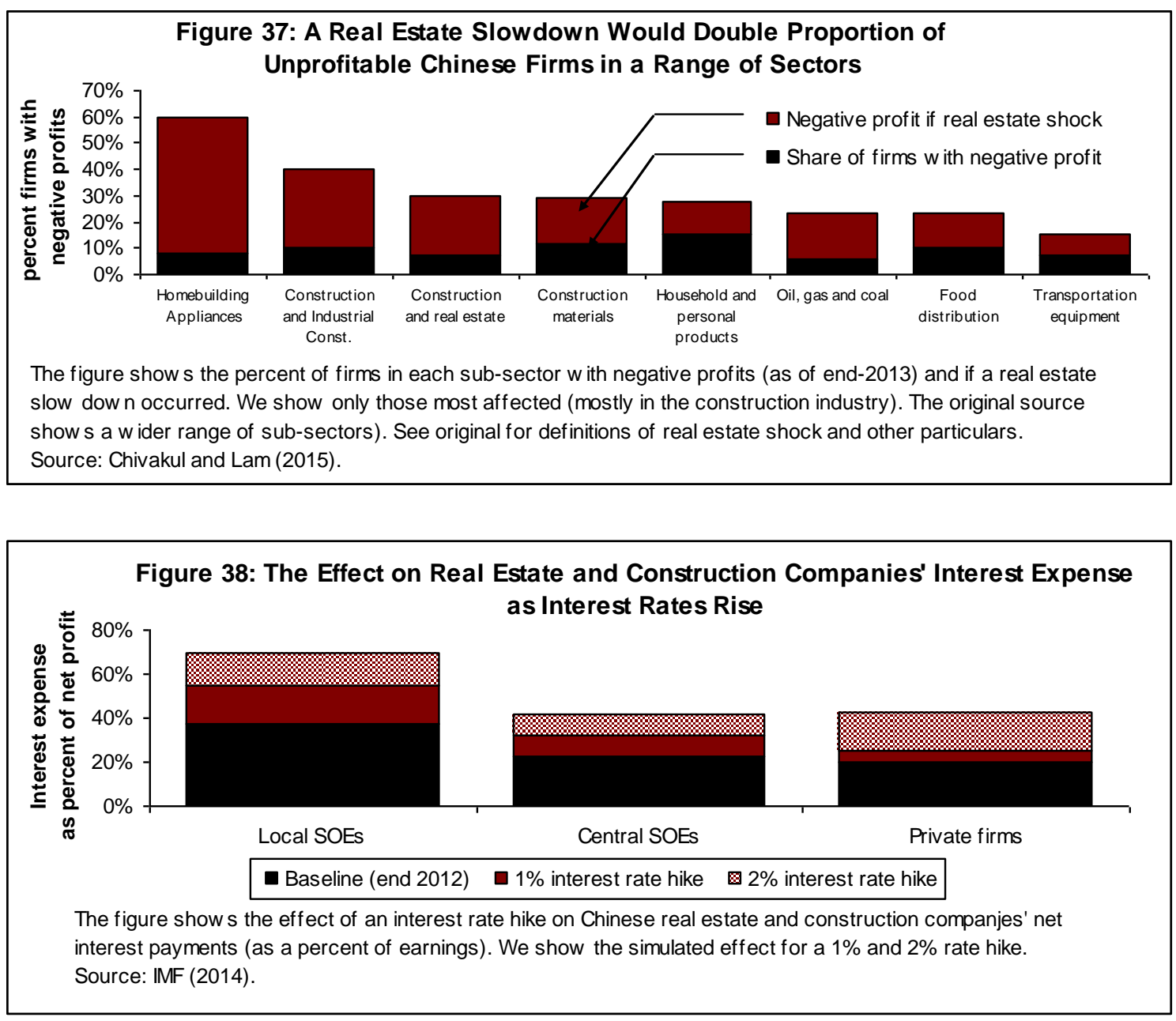

Figure 39 shows the historical relationship between changes in Chinese property prices and various construction-related indicators. The data predict that a deceleration of construction related investment corresponds to a $4 \%$ drop in property prices (or vice-versa). ${ }^{40}$ Yet, as with the banking sector, these data tell us nothing about the way economic structures could change in case of a crisis. Figure 40 shows the way that GDP growth becomes more sensitive to changes in the construction sector. In the post-crisis period, changes in prices yielded far greater changes in both construction values and changes in GDP - suggesting that responses to prices change structurally during a crisis. Moreover, econometric analysis shows that only the interaction between property price changes, construction value changes, and a dummy variable representing the year of the crisis statistically significantly explains changes in GDP growth. ${ }^{41}$

\footnotetext{
${ }^{40}$ We do not know causality from this graph. Also notice that investment does not need to decline in order to witness negative property price growth — only decelerate past a certain point.

${ }^{41}$ We show the exact regression results in the Appendix. However, we considered individually and all the possible combinations (interactions) between changes in equity prices, changes in construction production, changes in property prices, and the dummy variable representing the year of the crisis (leading to 16 possibilities).
} 

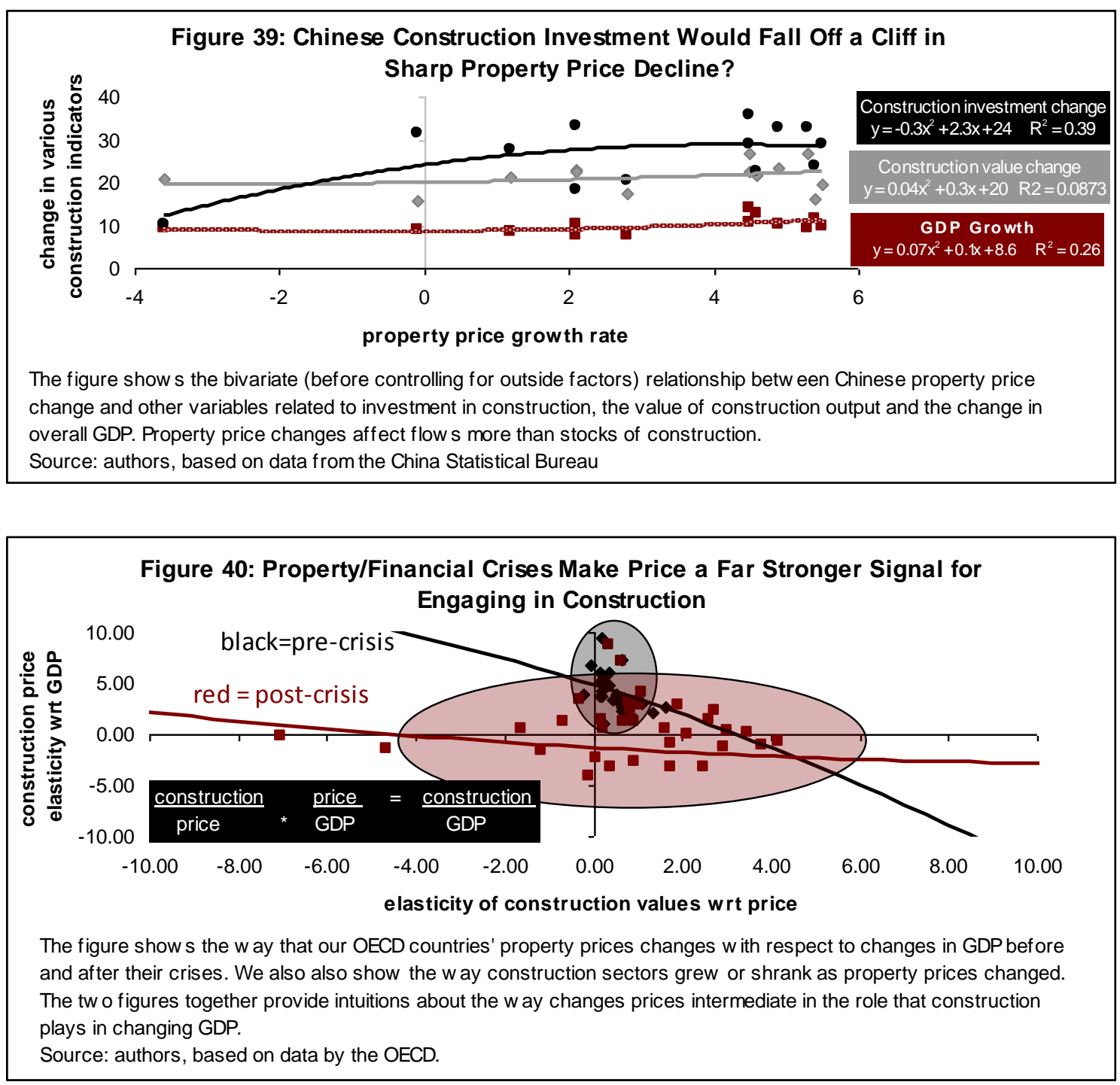

Construction sector activity obviously declines during a crisis, yet little about China's construction sector indicates that we need to worry seriously about the construction industry as a source or aggravating cause of crisis. Figure 41 shows the relationship between Chinese construction company profitability and property prices. After controlling for a range of factors, such profitability goes to zero only for a 5\% decrease in property prices. A $10 \%$ decline would result in roughly $15 \%$ decline in construction company profits. Yet, as we showed above, many of these companies would simply scale back rather than fall into bankruptcy. The price elasticity of housing supply hovers at around 1.28, assuming previous studies can be trusted. Thus, a downturn in price would lead to a sustained drop in supply, hardly a crisis-causing event. We can assume that any changes in the construction sector would not dramatically affect our modelexcept to the extent that lending to construction companies goes bad. Thus, we can model problems in this sector as part of the banking sector. 


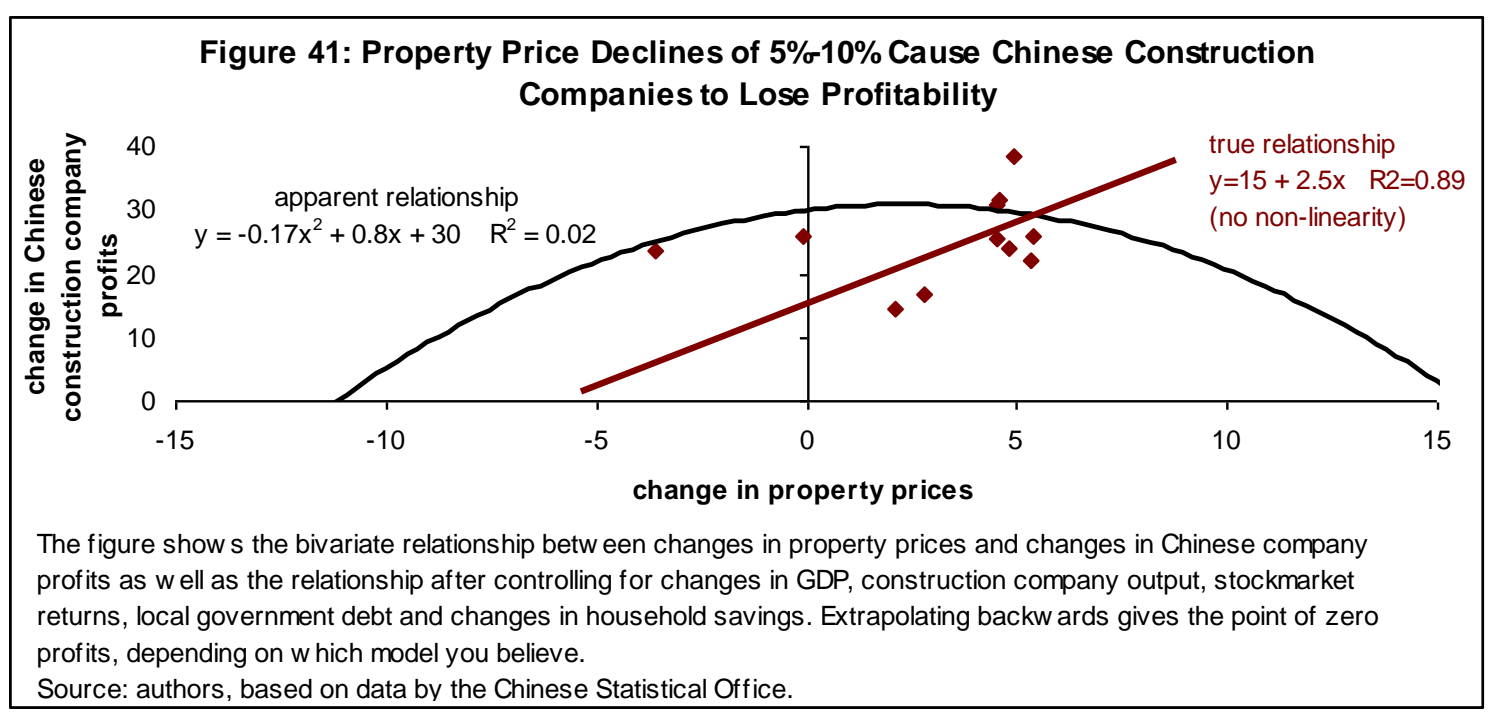

\section{Savings- investment channel}

We have very little idea what role savings play in Chinese housing markets. Despite numerous studies conducted on the subject, none paint a convincing story about how household savings translate into GDP and property price changes. ${ }^{42}$ Figure 42 shows the parameter estimates for real income and age, as well as the variance explained by each model (as reported by R-squared statistics). Like most of the studies in this ilk, estimates of the factors affecting Chinese savings change very significantly, depending on the model. Even in a general equilibrium framework, the scholars cannot agree on the likely magnitude of a shock to savings from property price changes. Figure 43 and Figure 44 show the estimated response of household savings to these shocks. In one case, the savings change by 0.2 and in the other by 2 . The profile of these changes also reflects the researchers' own models rather than any likely effect on savings. Property investment represents a major method of pecuniary savings for Chinese households. Yet, despite the many studies previously done, we simply don't know how their savings react to changing property prices.

\footnotetext{
${ }^{42}$ Zhi (2011) also looks cursorily at the relationship between savings and property prices. In her regression, the parameter was not statistically significant.
} 


\section{Figure 42: Previous Studies of Savings Behaviour and Property Prices Produce Parameter Estimates All Over the Map}

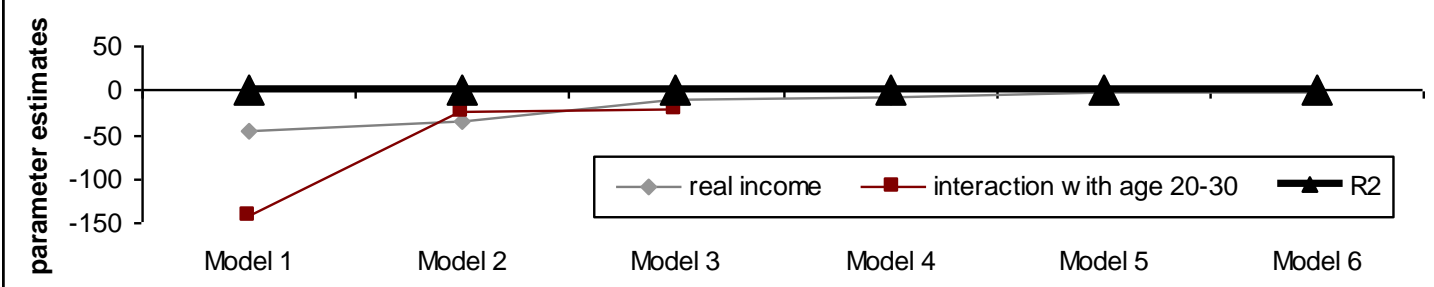

The figure show s the range of parameter estimates for the parameters show $\mathrm{n}$ in the figure over the range of models used by the authors. Despite confident claims about the robustness of their findings, none of the variance explained rose about 0.10 .

Source: Bussiere et al. (2013).

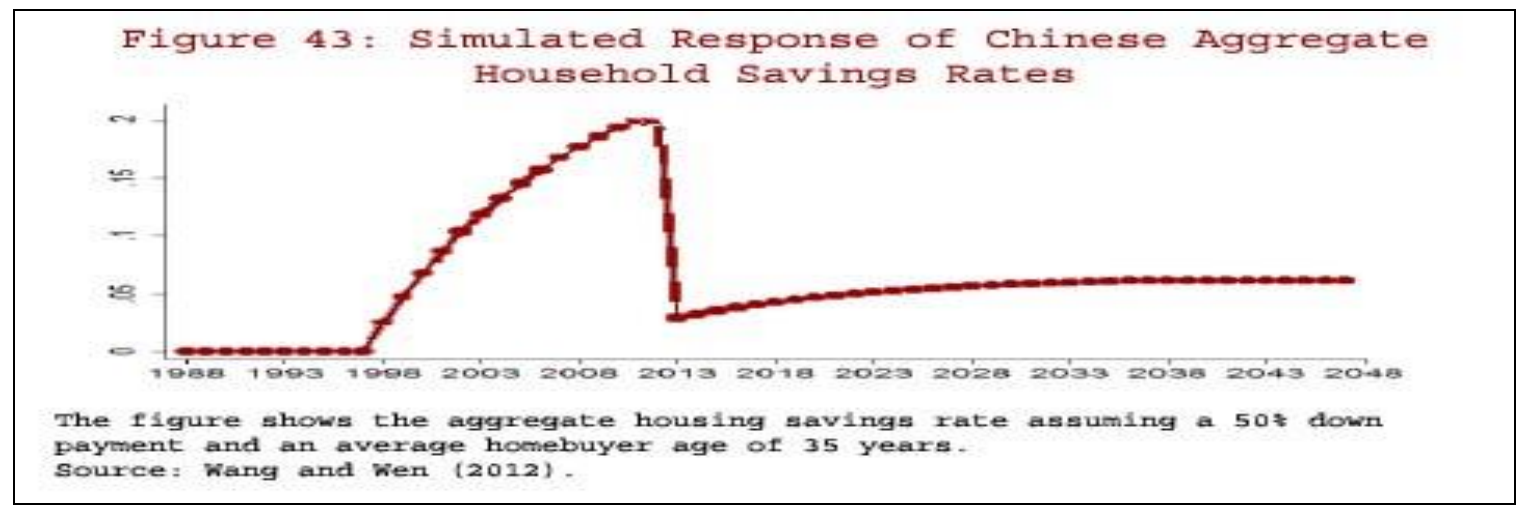

Figure 44: Effect of a Savings Shock on Chinese GDP Growth Rates

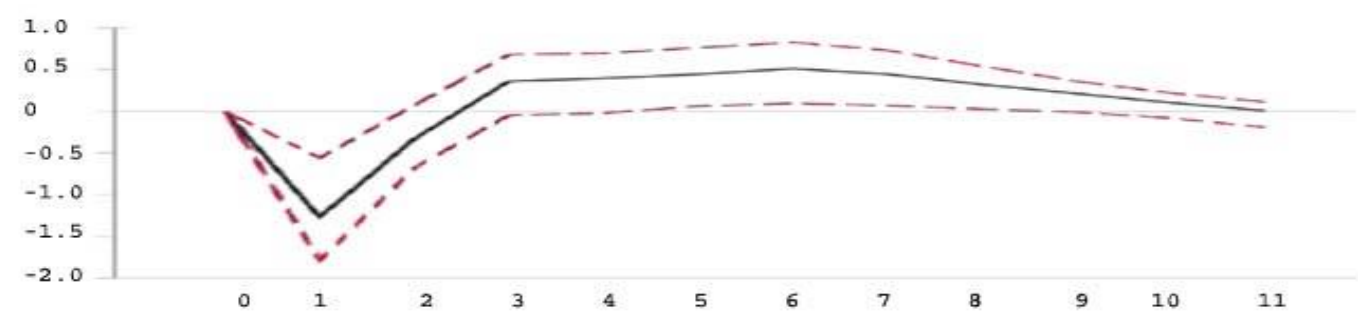

The figure shows the effect of a savings shock to GDP after taking a range of other factors into account. See original for more on the methodology and factors controlled for.

Source: Bonham and wiemer (2012)

As the prospects of crisis in China loom, how might savings react to a sudden property price collapse? Figure 45 highlights two important trends to consider when thinking about China's Bubble Economics. First, savings generally increase in the post-crisis period-if the OECD comparators serve as any point of comparison. Thus, we know that structures around saving, investment, and thus consumption, change. ${ }^{43}$ Second, Chinese savings already acts "strangely"

${ }^{43}$ Savings represents the part of households' income left over after consuming goods and services. Thus (and under many
conditions when we ignore debt), any reference to savings automatically implies a converse statement about consumption. 
compared with the OECD. We observe savings having decreased as property prices rose. Thus, any consideration of structural change must consider whether the slope of the line shown in the figure simply changes (like the OECD lines) or whether savings patterns will look more like those in the OECD comparator countries in a post-crisis era.

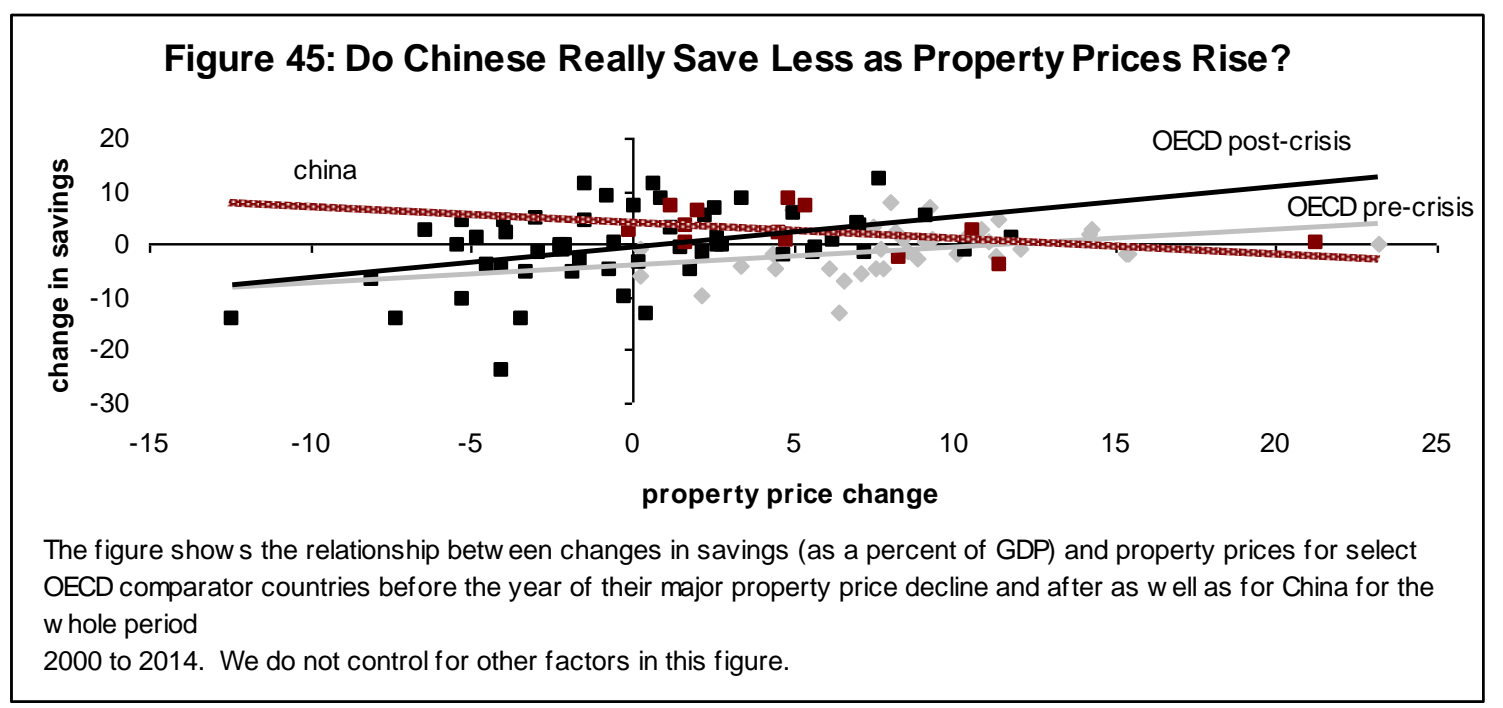

Maybe property prices move more because of the debt households take on to buy real estate, rather than because of their savings? If Chinese households use "social financing" (or money provided by a range of sources besides simple financial institutions) to buy real estate, looking at household savings tells us little about savings. ${ }^{44}$ Yet, none of the evidence suggests that we need to take household debt levels into consideration when thinking through the ways China's Bubble Economics will affect our model. ${ }^{45}$

\footnotetext{
${ }^{44}$ Chamon and Prasad (2007) find almost 10 years ago that Chinese households used only about 5\%-10\% of their income on housing (loan repayments, maintenance, etc.) and any money taken from savings represented only a tiny fraction of their income anyway. We do not dig very deeply into this issue as our objective consists of modelling a Bubble Economy (and not guessing exactly how much debt-to-savings contributes to a bubble and the subsequent crisis).

${ }^{45}$ Of the more than $200 \%$ of debt-to-GDP, household debt forms less than $10 \%$ of that amount. Nevertheless, many households lend in China's shadow banking markets, making any debt crisis likely to affect households on the lender rather than borrower side.
} 


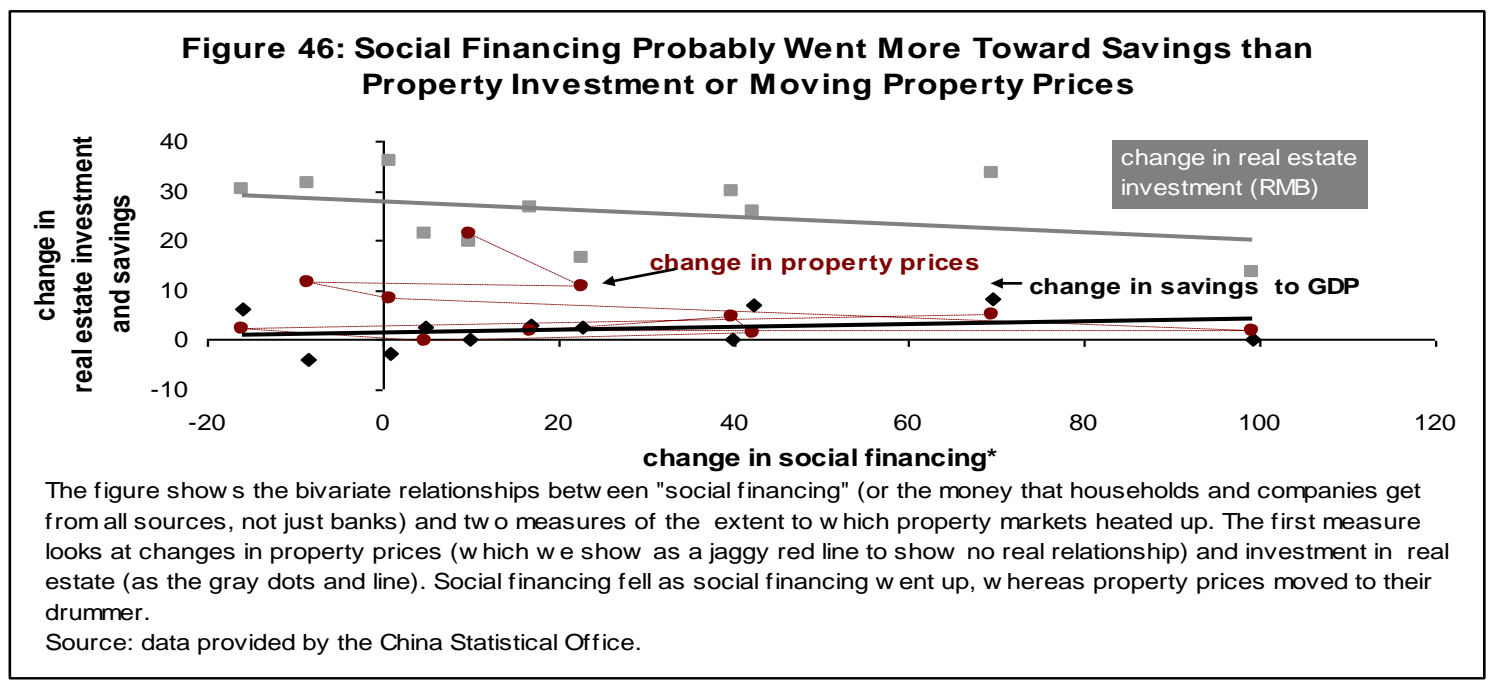

The best way to model the effect savings have on China's particular bubble economy consists of looking at householders as lenders and focusing on risks to the banking sector. Estimates have put the effect of a financial crisis on reduced savings at around 1\%-2\% of GDP - through losses in shadow banking products which households cannot recoup, household debt which households cannot repay, and so forth (Valckx et al. 2014; Leigh 2012). Even more worrying, we do not know how savings "buffers" might stock out due to debt or wealth effects. ${ }^{46}$

\section{$\underline{\text { Local government }}$}

Chinese local governments have increased their debt exposure, and remain partially beholden to property markets. As shown in Figure 47, Chinese provincial governments depend on revenue from land sales as "non-tax revenue" and from property taxes. In some areas (like Tibet), local governments run large budget deficits - meaning that a large property price decline could reduce their ability to pay back loans. As the central government's and various local governments' indebtedness increases, the prospects of a sovereign debt crisis increases.

\footnotetext{
${ }^{46}$ Most of the data in this area involves chasing rumours. Wang (2011) for example provides estimates of household wealth difficult to reconcile with data from other sources. See
} 


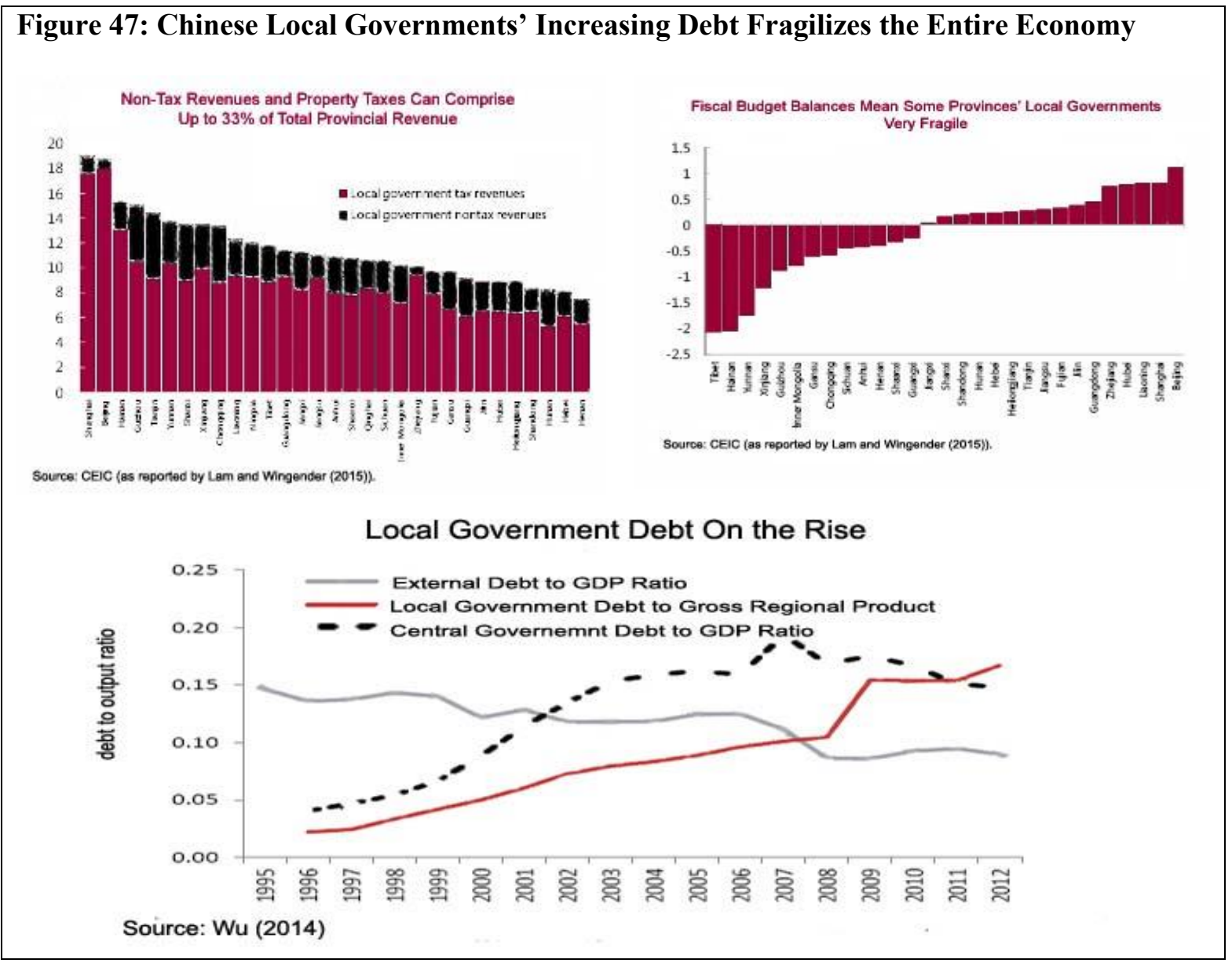

What do we know about the way the accumulation of local government impacts the probability of a sovereign default? Government indebtedness represents one of the key variables in explaining the onset of sovereign debt crisis, with debt of over 50\% of GDP a warning indicator (Manasse and Roubini 2005). ${ }^{47}$ We also know that banking crises generally leads to a sovereign crisis in roughly $30 \%$ of the cases (Genniaioli et al. 2014). If China has a property price-fuelled banking crisis - and given that China's debt-to-GDP ratios enter the danger zone (at roughly $250 \%$ of GDP) — a sovereign crisis appears more and more likely. And markets have started pricing in this risk. Figure 48 shows the probability of sovereign default, as proxied by yields on credit default swaps. ${ }^{48}$ Markets deem China's default risk roughly three times that of other very large economies like the U.S. and U.K. Figure 49 shows the costs of these defaults. If China follows the average, non-performing loans would increase from around $1 \%$ to almost $30 \%$-a positively disastrous outcome for a banking sector the size of China's. The number of banks declines around $20 \%$ in the three years following the outset of the crisis, and the government

\footnotetext{
${ }^{47}$ In fact we don't know exactly when sovereign debt leads to crisis. General studies of large economies like Cecchetti (2011) find that overall debt levels of around 85\% debt-to-GDP comprise growth — while Pescatori et al. (2014) fail to find such an effect.

${ }^{48}$ Credit default swaps basically represent a form of insurance against bankruptcy-related default. As the probability of a default increases, the cost of insurance rises. In theory, their yield tells us about the probability of default of the entity insured by these swaps.
} 
must spend large amounts of national output recapitalizing the banks and getting demand running again.

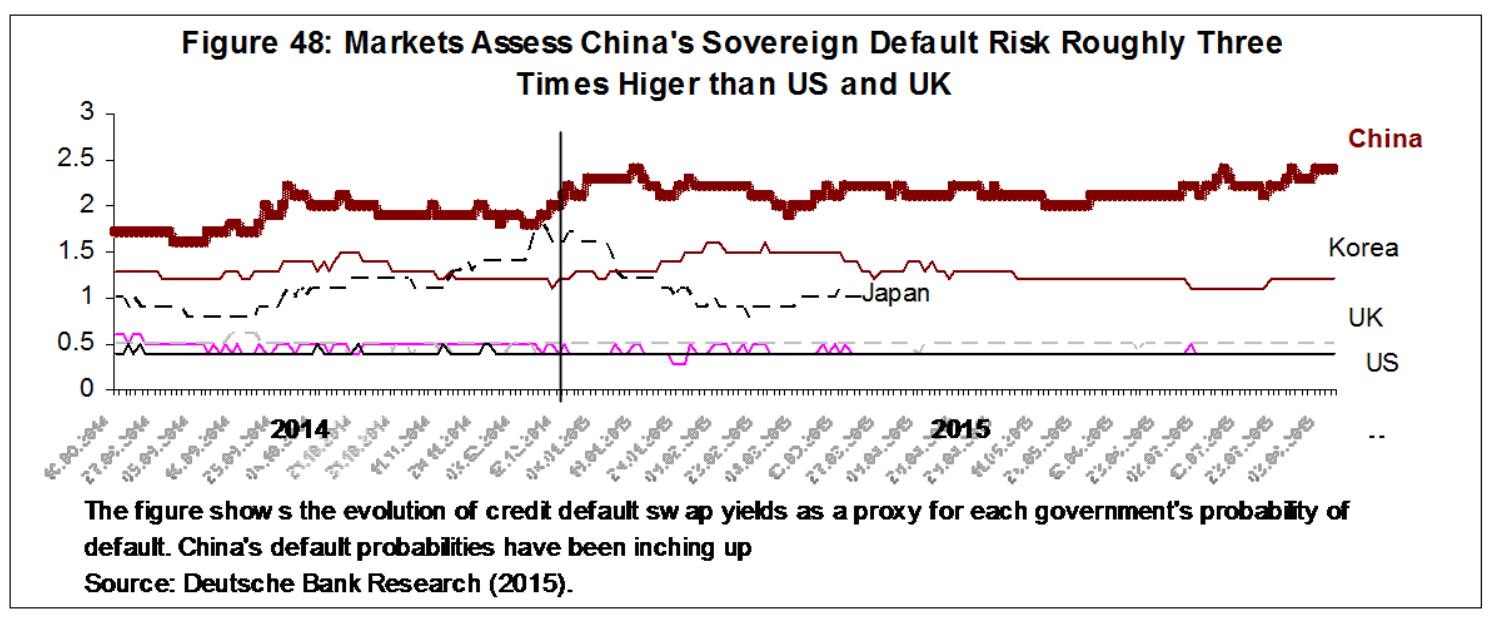

Figure 49: The Costs of Sovereign Debt Crises

\begin{tabular}{|lrlrl|}
\hline Crisis type & $\begin{array}{l}\text { NPL at peak } \\
\text { (percent bank } \\
\text { loans) }\end{array}$ & $\begin{array}{l}\text { Change in number of } \\
\text { banks (three years } \\
\text { later) }\end{array}$ & $\begin{array}{l}\text { Fiscal costs } \\
\text { (percent GDP) }\end{array}$ & $\begin{array}{l}\text { Net } \\
\text { Recapitalisation } \\
\text { costs } \\
\text { (percent GDP) }\end{array}$ \\
\hline $\begin{array}{l}\text { Banking crisis only } \\
\begin{array}{l}\text { Banking crisis leading } \\
\text { to debt crisis }\end{array}\end{array}$ & $28 \%$ & $-19 \%$ & $13 \%$ & $5 \%$ \\
\hline
\end{tabular}

Source: Laeven and Valencia (2008)

Despite hundreds of dire descriptions of the ghastly impacts of high Chinese local government debt levels, few studies have actually attempted to model what might happen if a default occurs. Wu (2014) estimates that local government growth starts slowing when local government debt reaches about $35 \%$ of gross provincial product and reaches zero when $72 \%$. ${ }^{49}$ So far, only Guizhou has reached the slowdown level, with Yunnan, Beijing and Hainan approaching this limit. Yet, with debt levels continuing to climb — such debt adds to the fragility of economic growth. A banking crisis, rapid property price falls, or a stock market crisis could increase the probability of local government default (and/or raise their need to accumulate debt more quickly). Figure 50 and Figure 51 support the conclusion that local government involvement/participation in real estate investment increases macroeconomic fragility. Figure 51 shows the way that local government bond yields shrink as governments and companies sink more money into a province's real estate sector. Shrinking yields mean more money goes into government debt - driving down the "excess yields" which are supposed to compensate investors for taking on risky debt. Figure 51 shows the extent to which local government-financed real

\footnotetext{
${ }^{49} \mathrm{We}$ describe their results as gross provincial product rather than the commonly used gross regional product (GRP) to make clear that the regions in question refer to Chinese provinces. We confirmed this finding by taking the derivative of his regression equation.
} 
estate suffers from higher default rates than other ventures. When local governments engage in funding real estate activity (or building via state owned enterprises), default risks go up. Implicit guarantees of these investments make these investments more risky — as once funding to support these companies runs out, we would expect to see a huge wave of defaults rather than just a trickle.
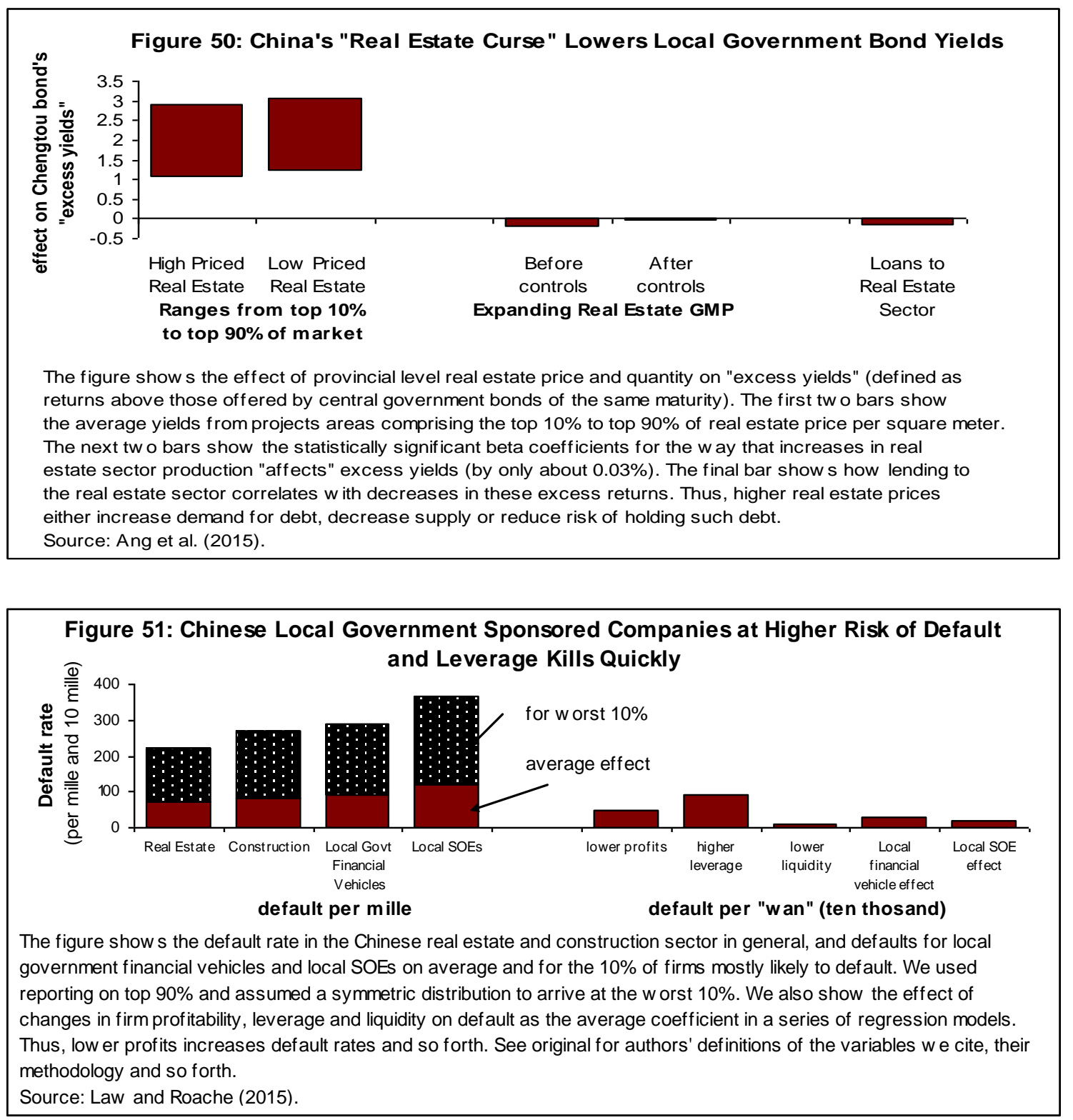

How can we model the way that local government debt contributes to Bubble Economics? From a modelling perspective, as local government debt approaches $35 \%$ of gross metropolitan product, we can assume that further increases knock-off GDP growth points linearly/continuously until growth stops at around 72\% of GDP. We can also assume that GDP instability increases, as shown in our OECD comparator countries. After that point, nothing in 
China's recent history or the experience of our OECD comparator countries provides any basis for prediction. However, as shown in Figure 52, in the period before any potential sovereign debt crisis, government spending will likely increase GDP growth volatility by up to $1 \%$. The figure shows the effect of Chinese government spending in the post-Asian Financial Crisis period. Clearly, government spending became the major contribution to GDP growth variability in that period. As such, our own model should reflect this experience in any government response to crisis.

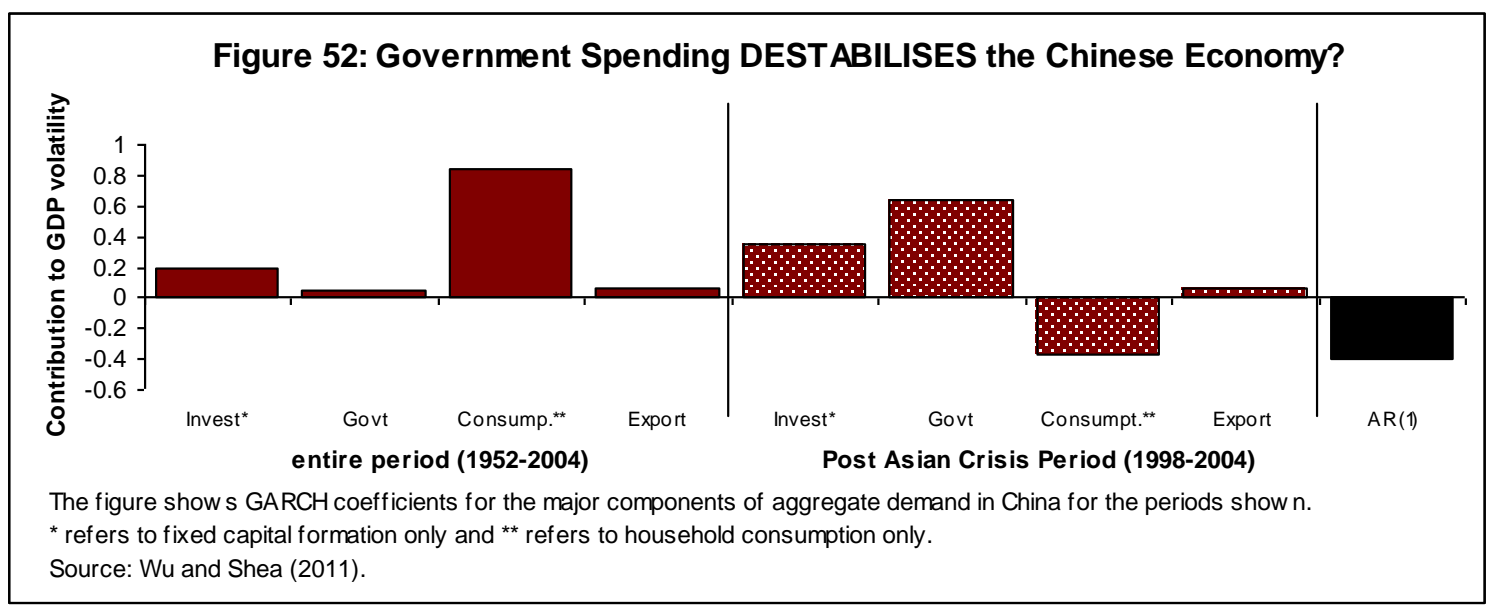

\section{$\underline{\text { Stock market channel }}$}

What effect will equity markets instability play in China's Bubble Economics? At the time of this writing, the Shanghai stock market had experienced a 300\% spike and subsequent dropleading many pundits to foresee the beginning of the crisis. Recent theoretical work suggests that we would observe such volatility right before a crash. Peng and co-authors (2009) test the extent to which the Chinese stock market causes changes in GDP, and vice-versa. They (as well as the other authors we review) show that causation runs one way. Changes in Chinese GDP affect the stock market. However, changes in the stock market do not affect Chinese real GDP. Figure 53 shows the estimated reaction of Chinese GDP to changes in equity valuations. The direct effects look remote. Yet, stock market valuations might influence GDP through the way they allow institutions like banks to tap resources. As stock prices rise, the value of banks' own equity rises (allowing them to expand lending), as does the value of equity-based collateral held on their books. Figure 54, for its part, shows the effect of changes in equity prices on GDP through their effects on bank balance sheets. To the extent that a booming (or busting) stock market affects the availability of credit, stock markets can affect GDP. 
Figure 53: None of the Economic Studies on China Find any Effect Going From the Stock Market to GDP

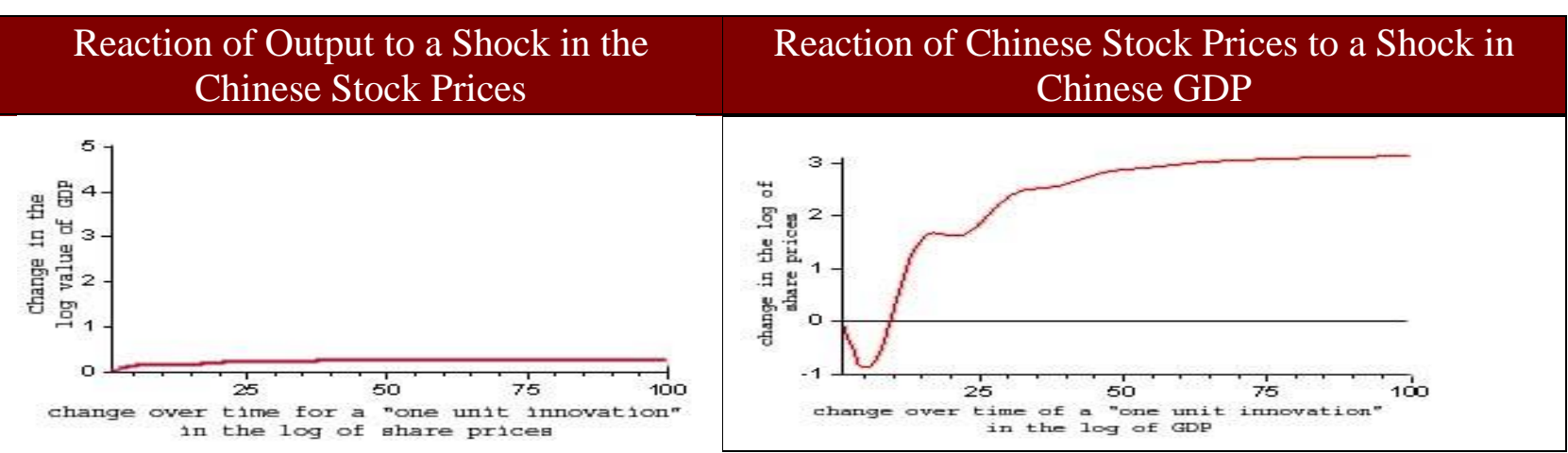

The figure shows the impact of a "one unit innovation" in share prices (left-hand side) and output (right-hand side). Time series analysis shows - for this study as in the other studies we review for this paper - that (Granger) causality runs from output to the stock market and not the other way around.

Source: Peng et al., 2009

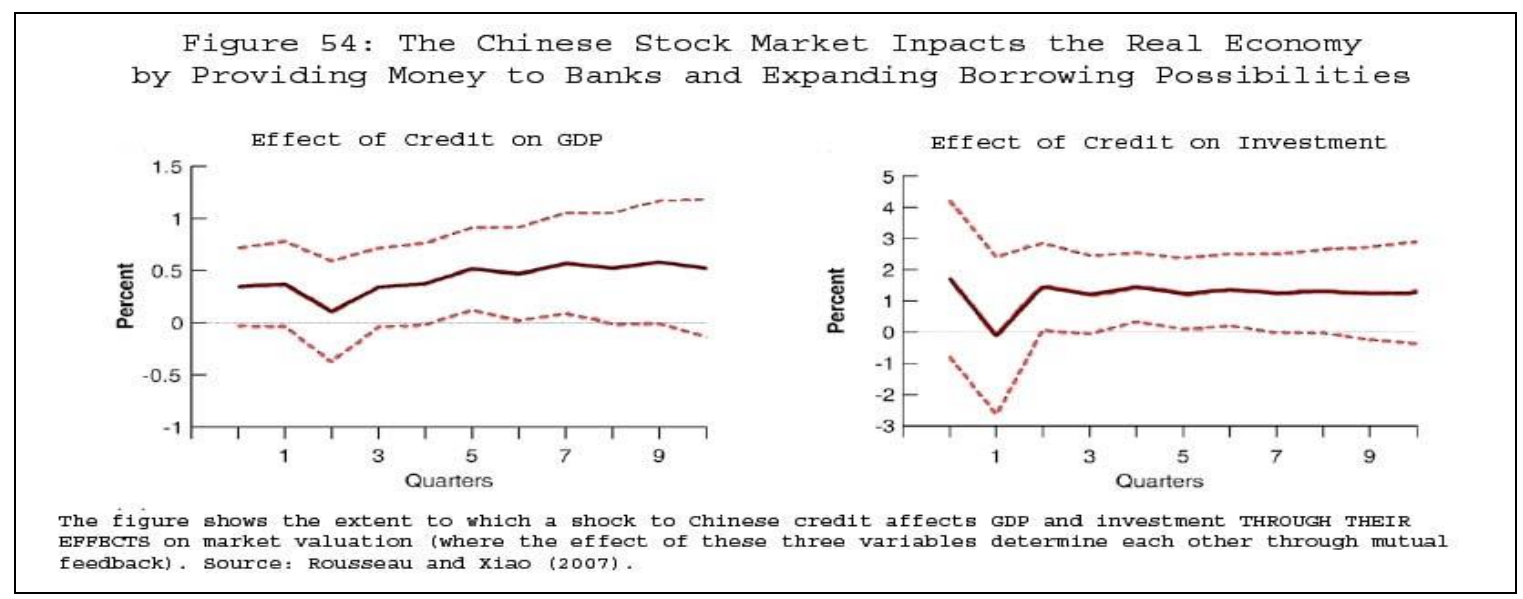

What about the relationship which interests us most: the way that stock market intermediates in the relationship between Chinese property prices and GDP growth? Figure 55 shows the way that property prices relate to the value of traded shares, after controlling for a range of factors which impact both these variables. As shown, the value of Chinese shares has historically risen when property prices fell. Yet, no one could believe that during a crisis, Chinese investors would call up their brokers. Indeed, as shown in Figure 56, if the experience of other large economies serves as a guide, equity markets probably won't react to any potential crisis. Indeed, as shown in Figure 57, standard deviations actually fell after the crisis, suggesting the post-crisis period represents a time of consolidation. 

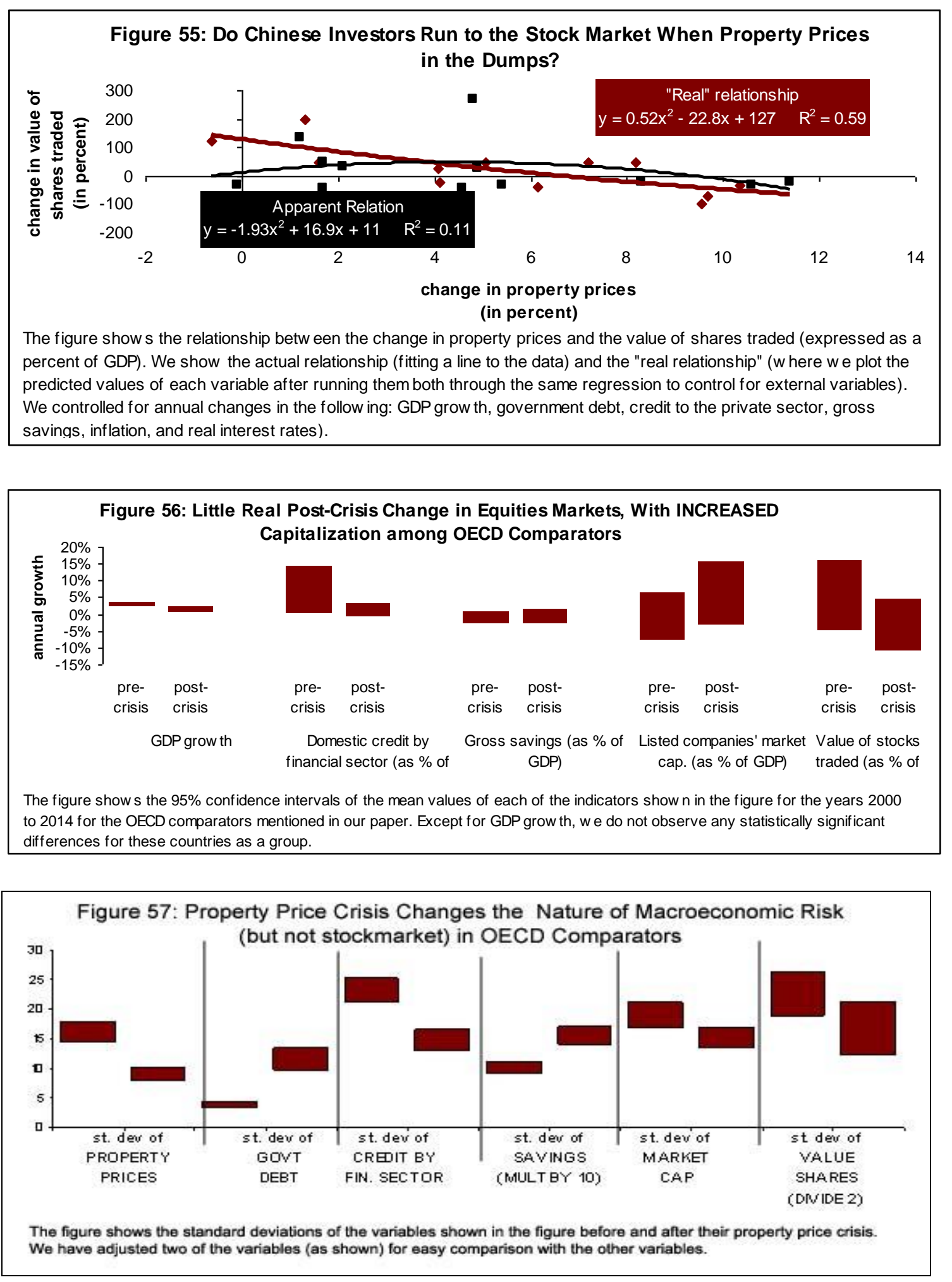

These data suggest two things about the way we should model Chinese equities markets. First, the model would need to explain and possibly even reproduce the patterns we see in the OECD 
comparator countries' data. GDP growth fell, but variables like market capitalization did not. Though, standard deviations did fall. Second, we know that stock market effects likely play out through the banking sector. Thus, our specification of credit markets could probably pick up the effects of equities markets without need to specify a separate structural relationship for stock markets.

\section{A Model of the Bubble Economy with Specific Reference to China}

\section{$\underline{\text { Previous work on modelling bubbles }}$}

Case and Shiller (2004) lies at one end of the spectrum - providing a relatively descriptive explanation for bubble formation in the U.S. before the financial crisis even occurred. Kiselev and Ryzhik lie at the other end of the spectrum - providing a "simple model for asset price formation" (quoting their paper's title), if you believe that stochastic differential equations represent a "simple" model! Glaeser and Nathanson (2014) provide an overview of the literature, with a focus on simple models whereby asset prices stray away from their fundamental values for rational reasons. Sherbina (2013) also provides a review of the bubble literature, showing how prices stray. Liu et al. (2014) come close to our own project, explaining the adjustment after the crisis. Order and Lai (2006) also come close to our project, by seeing bubbles as the effect of a "regime shift" (also before the U.S.'s own burst scenario). Case and Quigley (2006) foresaw the fallout of a burst scenario in the U.S. context, but explicitly avoided the complex task of attempting to quantify the likely post-crisis impacts. Bosworth (2015) finds that the U.S.'s own financial crisis changed economic structures sufficiently to lower productivity and thus long-term economic growth. Oulton and Sebastiá-Barriel (2013) discuss short-term and longer-term effects in the U.K. In our paper, we focus less on why prices diverge (taking these price diverges as exogenous), and model the effects when they do.

\section{The Mathematical and Statistical Problem}

Inertia and sudden momentum in property-related assets (physical property and the securities tied to it) characterizes Bubble Economics. As we highlighted in the first part of our paper, Bubble Economies experience sudden structural changes and jumps, which make techniques like computable stochastic general equilibrium models and other types of such models inappropriate (or at least incomplete). Figure 58 illustrates how existing models fail to capture the dynamics of Bubble Economies. We illustrate with data showing three sudden jumps in property pricesfrom the clearing of disequilibria in housing prices, falls brought about by changing in construction/investment, banking and other markets as structural parameters change, and from generalized decreased demand owing to a debt crisis (sovereign in the case of China but potentially household or corporate in other countries). Fitting relationships between changes in GDP and property prices fail to capture these jumps. Even stock-flow models of property markets like Ozbas et al. (2014), which use differential equations, remain far too continuous to accurately reflect reality. 


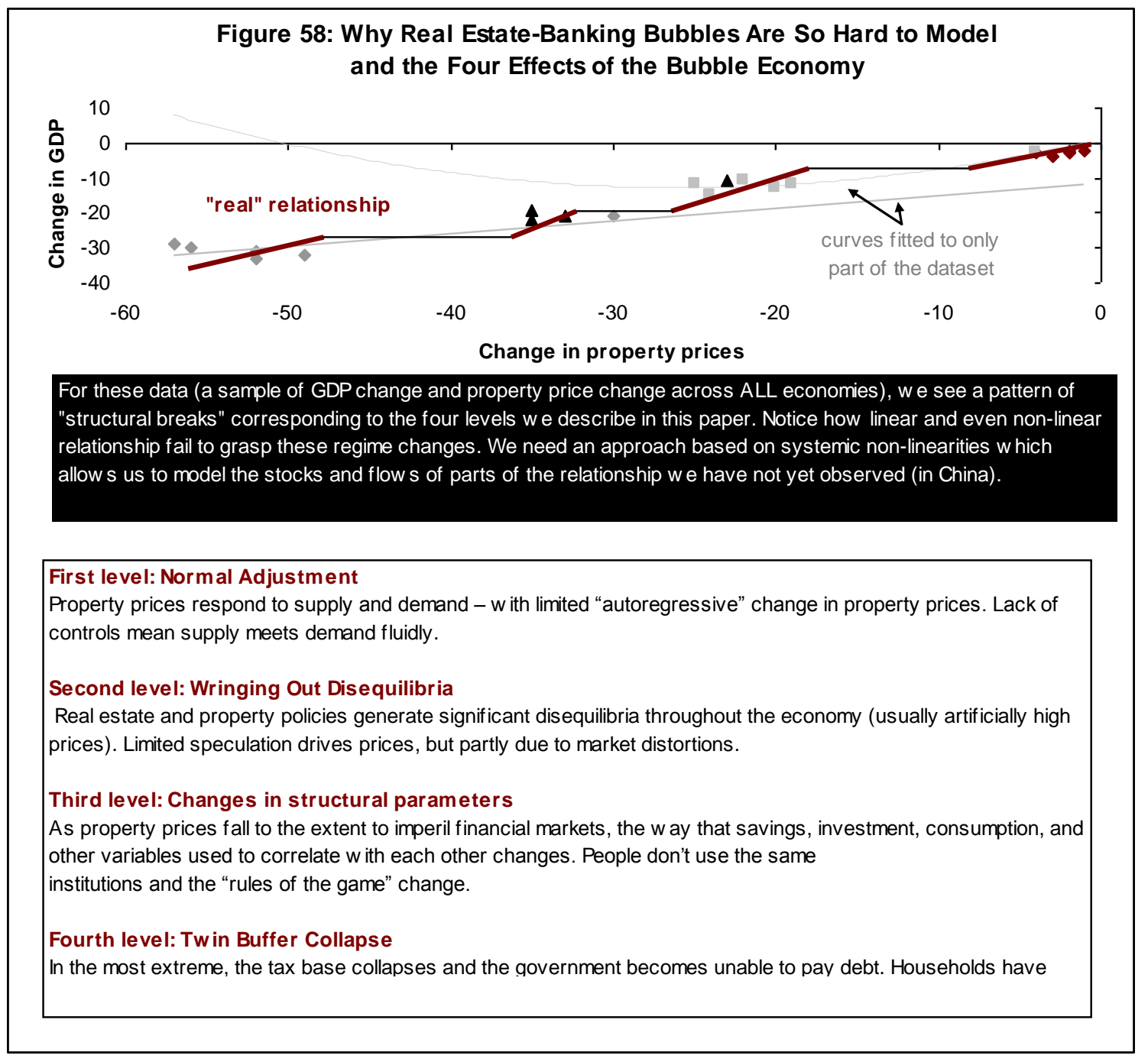

We see the problems of such an approach in our own regressions, as well as the many others we surveyed/reviewed for our study. Figure 59 shows the various explanatory variables we used to try and explain changes in GDP growth rates (with others shown in the Appendix). As shown, the explanatory power of these models remain exceedingly low-often explaining no more than $33 \%$ of the variation of GDP. As we explained, the inherent non-linearities in the data make modelling like this impossible. Even regression techniques used by most of the studies we have analyzed would completely fail to estimate the nature of the way property prices affect GDP. 
Figure 59: Regression Results for GDP Growth Rates

(Differences in natural logs)

OECD Comparators

Intercept*, Diff LN Price*, Diff LN Govt Debt, Diff LN Credit, Diff LN Savings*, Diff

LN Money

Intercept, Diff LN Price*, Diff LN Credit Banks, Diff LN Savings*, Diff LN Stocks*

0.33

Intercept*, Diff LN Price*, Diff LN Govt Debt, Diff LN Credit by Fin Sector, Diff LN

Savings*, Diff LN Market Cap, Diff LN Money, Diff LN Stocks,

Intercept*, Diff LN Price*, Crisis Dummy, Diff LN Govt Debt*, Diff LN Money,

Intercept*, Crisis Dummy, Diff LN Credit, Diff LN Savings*, Diff LN Market Cap, Diff

LN Price

Intercept*, Crisis Dummy, Diff LN Credit, Diff LN Savings* , Diff LN Market Cap, Diff

LN Money, Diff LN Price

Intercept, Crisis Dummy, Diff LN Credit by Fin Sector*, Diff LN Savings*, Diff LN

0.28

0.36

Money, Diff LN Stocks*, Diff LN Price*

\section{China}

Intercept, LN Credit, LN Savings, LN Money, LN Stocks

Intercept*, LN Credit*, LN Savings*, Diff Ln Price, LN Market Cap

Diff Ln Price, Change Government debt (percent GDP), CHANGE Domestic credit BY

financial sector (\% of GDP), CHANGE Gross savings (\% of GDP), CHANGE Money and quasi money (M2) as \% of GDP,

Intercept, * Standard Dev PRICE before/after*, Inflation, GDP deflator (annual \%)*, CHANGE Stocks traded, total value (\% of GDP)*, CHANGE Real interest rate (\%)* CHANGE Money and quasi money (M2) as \% of GDP, Standard Dev PRICE before/after*, CHANGE Stocks traded, total value (\% of GDP), CHANGE Market capitalization of listed companies (\% of GDP)

Models of any Bubble Economy need to take interactions between variables into account. Figure 60 shows the way that interactions between the variables in our model affect the models' results. ${ }^{50}$ The predictor variables in each equation perform relatively poorly in explaining GDP, property price, and money growth. However, as we show later in this section, combined they make for an excellent basis of explanation and prediction.

\section{Figure 60: The Huge Difference between Normal Regression and Simultaneous Equations for OECD Comparator Countries}

Equation 1: $g_{y}=1.6+11.3 g_{p}-1.9 g_{M}+4.8 g_{K}+20 g_{S}$
Equation 2: $g_{p}=0.02+0.33 g_{y}-0.21 g_{M}+0.31 g_{K}+0.12 g_{S}$
Equation 3: $g_{M}=0.02+0.44 g_{y}-0.16 g_{p}+1 g_{K}-0.04 g_{S}$

\footnotetext{
${ }^{50}$ We arrived at this growth rate by Cramer's Method. We found the determinant of the matrix on the right-hand side of Equation (58) as 6.7 which sits on the denominator of the solution. The numerator consists of the determinant of the matrix in which the column on the left hand side of the equation serves as the first column in the matrix on the right-hand side. The numerator equals $1.7+4 \mathrm{~g}_{\mathrm{K}}+21 \mathrm{~g}_{\mathrm{S}}$. We replace the middle and final column in the matrix by the vector on the left side of the equation in order to solve for the other two growth rates. The numerator for each of those expressions comes to $-8.7 \mathrm{~g}_{\mathrm{S}}-2.2 \mathrm{~g}_{\mathrm{K}}-0.6$ and $1+9 \mathrm{~g}_{\mathrm{S}}+5.6 \mathrm{~g}_{\mathrm{K}}$ respectively.
} 


$$
\left[\begin{array}{c}
1.6+20 g_{S}+4.8 g_{K} \\
0.02-0.12 g_{S}-0.31 g_{K} \\
0.02-0.04 g_{S}+1 g_{K}
\end{array}\right]=\left[\begin{array}{ccc}
1 & -11.3 & 1.9 \\
0.33 & 1 & 0.21 \\
-0.44 & 0.16 & 1
\end{array}\right]\left[\begin{array}{c}
g_{Y} \\
g_{p} \\
g_{M}
\end{array}\right] \quad\left[\begin{array}{c}
g_{Y}^{*} \\
g_{p}^{*} \\
g_{M}^{*}
\end{array}\right]=\left[\begin{array}{c}
0.25-0.6 g_{K}-3.1 g_{S} \\
-1.3 g_{S}-0.33 g_{K} \\
0.15+1.3 g_{S}+0.84 g_{K}
\end{array}\right]
$$

\begin{tabular}{|c|c|c|c|c|}
\hline & \multicolumn{2}{|c|}{ Savings } & \multicolumn{2}{|r|}{ Capital } \\
\hline & regression & $\begin{array}{l}\text { after simultaneous } \\
\text { equations }\end{array}$ & regression & $\begin{array}{l}\text { after simultaneous } \\
\text { equations }\end{array}$ \\
\hline Growth rate of output & 20 & -3.1 & 4.8 & -0.6 \\
\hline Growth rate of prices & 0.12 & -1.3 & 0.31 & -0.33 \\
\hline Growth rate of money & -0.04 & 1.3 & 1 & 0.84 \\
\hline
\end{tabular}

The figure shows the relationship between GDP growth rates, property price growth rates and the growth rates of credit and money (M2). For readers able to read the equations above, we show how the relationships above (called structural equations) yield very different final results because they depend on each other. The bottom part of the figure shows the difference between the way GDP growth (for example) correlates with savings growth in simple regression analysis and after solving the endogenous set of equations.

Using such structural models - or systems of equations - we can understand the bubbles better than before. However, as we see, these models cannot offer an explanation of sudden changes in variables like GDP or property prices. They do not take time into account and thus do not offer a truly stock-flow view of a Bubble Economy. If we take time and endogeneity into account, we can see just how much more accurate our models become. Figure 61 shows the results of three equations we put together and solved using a procedure known as systems of (first order) differential equations (actually they are difference equations). ${ }^{51}$ If we take the law of motion equation for GDP alone, it looks like a straight line. However, if we solve in a wider model, we see how GDP can accelerate or decelerate over time.

\footnotetext{
${ }^{51}$ The math behind these two concepts is relatively similar. We do not go in-depth into the math here, as readers familiar with these concepts will be bored and readers unfamiliar will be terrified.
} 


\section{Figure 61: Using Stock-Flow Models Allows Us to Model Sudden Sharp Declines in the Growth Rate of GDP}

$$
\begin{aligned}
& \frac{\ln Y_{t}-\ln Y_{t-1}}{t-(t-1)}=\ln \dot{y}=32.8+15.6 \ln y_{t}-38 \ln p_{t}+8.4 \ln K_{t} \\
& \frac{\ln p_{t}-\ln p_{t-1}}{t-(t-1)}=\ln \dot{p}=148.6+5.6 \ln Y_{t}+41.1 \ln p_{t}-0.55 \ln K_{t} \\
& \frac{\ln K_{t}-\ln K_{t-1}}{t-(t-1)}=\ln \dot{K}=-389.3+12.2 \ln Y_{t}-56 \ln p_{t}+114.9 \ln K_{t} \\
& {\left[\begin{array}{c}
\ln y^{*} \\
\ln p^{*} \\
\ln K^{*}
\end{array}\right]=\left[\begin{array}{c}
0.08 e^{115 t}-0.83 e^{30 t}-0.88 e^{27 t} \\
0.01 e^{115 t}+0.4 e^{30 t}-0.33 e^{27 t} \\
e^{115 t}+0.37 e^{30 t}-0.33 e^{27 t}
\end{array}\right]+\left[\begin{array}{c}
-8500 \\
6140 \\
4320
\end{array}\right]}
\end{aligned}
$$

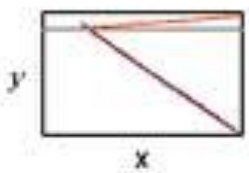

The figure shows the way that output, prices and credit move in the OECD comparator countries over time (and controlling for the crisis so it does not play an undue role in the analysis). Simply on its own, output grows over time. Yet, when viewed in the larger system (with housing prices and credit), we see a sudden collapse in these growth rates.

Even more astoundingly, we observe that fuller models - which consider the role of government debt - can exhibit very strange behavior. Figure 62 shows the equations we found using regression analysis and the results. ${ }^{52}$ As shown, we see the same "crash" that we saw in the previous example. However, in this example, we see the solution of these laws of motion require a variable outside our model. ${ }^{53}$ This extra variable, which the mechanics of mathematic attribute to a variable called "i" provide for a solution to our problem. Much of the math in our analysis does not work without some form of extra variable which helps us explain the onset of crises.

\footnotetext{
52 This gives three eigenvalues of $8.4+5.5 \mathrm{i}, 8.5-5.5 \mathrm{i}$ and -0.6 and corresponding eigenvectors of $0.8,0.33+0.004 \mathrm{i}, 0.3-0.39 \mathrm{i}),(0.8$, $0.33-0.04 \mathrm{i}, 0.3+0.4 \mathrm{i}),(-1,-0.02,-0.16)$.

${ }^{53}$ This solution consists of two parts - an adjustment path and a steady-state (shown in the two bracketed parts of the equation). We found the transition path by plugging in numbers from the previous footnote into the standard solution for a differential equation. We found the steady-state by taking the inverse of the matrix and multiplying it by the expression on the right-most side of equation (62).
} 


\section{Figure 62: We Need a Separate Unknown Variable to Explain Why GDP Varies in Response to Government Debt}

$$
\begin{aligned}
& Y_{t}-Y_{t-1}=\dot{y}=-160 y_{t}{ }^{0.226} p_{t}{ }^{28} D^{-8.6} K_{t}{ }^{7.1} S_{t}{ }^{11.7} \\
& \frac{\ln Y_{t}-\ln Y_{t-1}}{t-(t-1)}=\ln \dot{y}=-160+0.226 \ln y_{t}+28 \ln p_{t}-8.6 \ln D+7.1 \ln K_{t}+11.7 \ln S_{t} \\
& \frac{\ln p_{t}-\ln p_{t-1}}{t-(t-1)}=\ln \dot{p}=74.5+0.48 \ln Y_{t}+10.7 \ln p_{t}-4.4 \ln D-2 \ln K_{t}+0.49 \ln S_{t} \\
& \frac{\ln D_{t}-\ln D_{t-1}}{t-(t-1)}=\ln \dot{D}=39.6-1.2 \ln Y_{t}+12.2 \ln p_{t}-5.4 \ln D-7.4 \ln K_{t}-22 \ln S_{t} \\
& \begin{array}{l}
{\left[\begin{array}{l}
\ln y^{*} \\
\ln p^{*} \\
\ln D^{*}
\end{array}\right]=\left[\begin{array}{c}
0.8 e^{(8.5+5.5 i) t}+0.8 e^{(8.5-5.5 i) t}-e^{-0.6 t} \\
(0.4+0.04 i) e^{(8.5+5.5 i) t}+(0.33-0.04 i) e^{(8.5-5.5 i) t}-0.02 e^{-0.6 t} \\
(0.3-0.4 i) e^{(8.5+5.5 i) t}+(0.3+0.4 i) e^{(8.5-5.5 i) t}-0.16 e^{-0.6 t}
\end{array}\right]+\left[\begin{array}{c}
630-25 \ln K_{t}+12 \ln S_{t} \\
21+\ln K_{t}-2.3 \ln S_{t} \\
100-5 \ln K_{t}-8 \ln S_{t}
\end{array}\right]} \\
\ln y^{*}=0.8 e^{8.5 t}(\cos (5.5 t)+\cos (-5.5 t))+(0.8 i) e^{8.5 t}\left(\sin (5.5 t)+\sin (-5.5 t)-e^{-0.6 t}\right.
\end{array}
\end{aligned}
$$

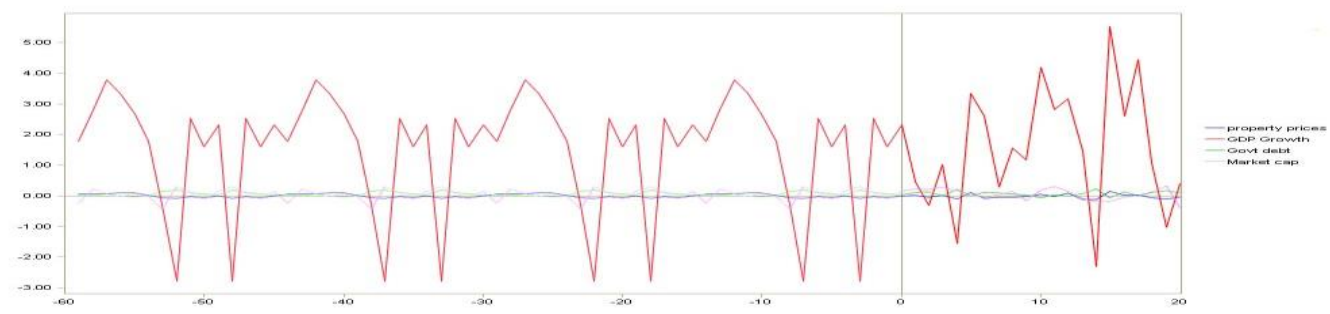

The figure shows the models we set up looking at the way the flows of output, property prices and government debt changes as their stocks change. We show the system of equations on the top, the matrix representation and the solution below. We show the way output growth "tips" in the upper part of the figure and the way such "tipping" leads to regular collapses in GDP growth in the autoregressive simulation below.

We observe a periodicity in the data which points to an unobservable factor in the data. We know such a factor exists for three reasons. First, we have already described in the literature review the way that "rational expectations" pricing can lead to price cycles over time. Second, as we have argued throughout this paper, economies witness "structural changes" which change the way parameters previously behaved. Third, we know that the five factors we previously talked about - banking, savings, government debt, the construction sector (to a lesser extent), and the stock market - interact to result in effects which seem to "build up" over time.

\section{$\underline{\text { Looking for a Bubble Risk Factor in Bubble Economies }}$}

How can we understand the way GDP reacts to a range of variables? One approach might be to model GDP as a function of the usual/known factors and then try to understand how "what we don't know" behaves. By understanding the way property prices and output interacts with (to put it simply) what-we-know and what-we-don't-know, we can better understand how property price changes affect the Bubble Economy. Figure 63 shows the way we have constructed two opposite variables - Bubble Risk Factor and Model Factors. 


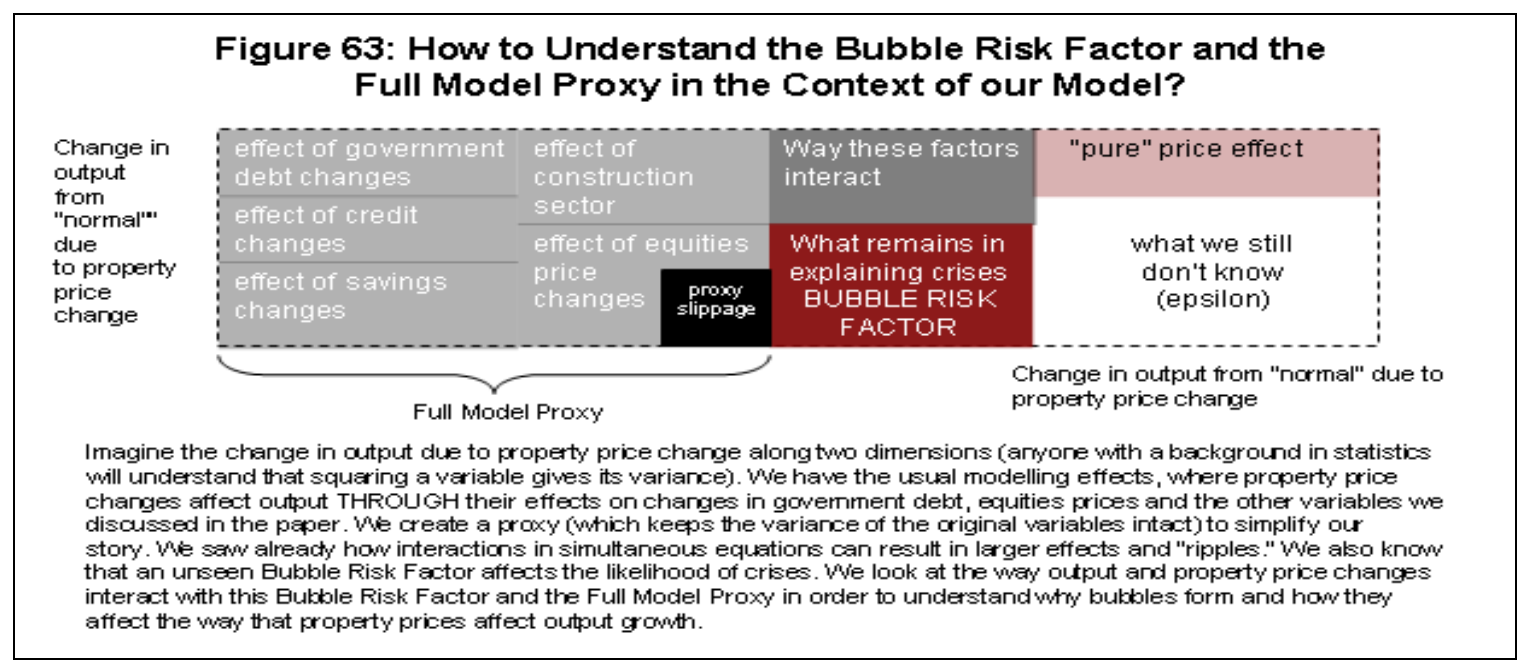

As we describe in the Appendix, we create the Bubble Risk Factor and the Full Model Proxy in order to simplify the way we tell our story of Bubble Economics. The Bubble Risk Factor consists of a tacit, implicit variable which explains the parts of crises which the variables in our full model cannot explain. After regressing crises on bank credit, savings rates, government debt, and equity prices, we scoop up the remaining variance and put it in a new variable. The Full Proxy allows us to depict the way our variables interact with changing property prices and GDP growth rates using only one variable. The Full Model Proxy "maps" or assigns all the variance in variables in our model - and the variance between these variables - into a summary or index variable. Having such a proxy helps simplify our story greatly, as we can show the reader only three equations (for output changes, property price changes, and full model proxy changes) instead of 8 or 9 variables if we depicted each variable separately.

What do we know about the stocks and flows of these two constructed variables in the last 15 years? Figure 64 shows the way the Bubble Risk Factor correlates with the growth of credit, savings, equity prices, real estate values (by implication), and government debt - through the Full Model Proxy we developed to illustrate the way these variables behave. In the U.S., a general expansion of these sectors correlates to an increase in our Bubble Risk Factor. As an economy that has already experienced a crisis shows, overheating in these sectors leads to building risks. In contrast, in China, we observe a decline in Bubble Risk Factor as the economy grows and matures. Up until now, a growing and developing economy has reduced the potential for crisis. The point remains-what happens when China's relationship suddenly shifts and looks more like the U.S. relationship? 


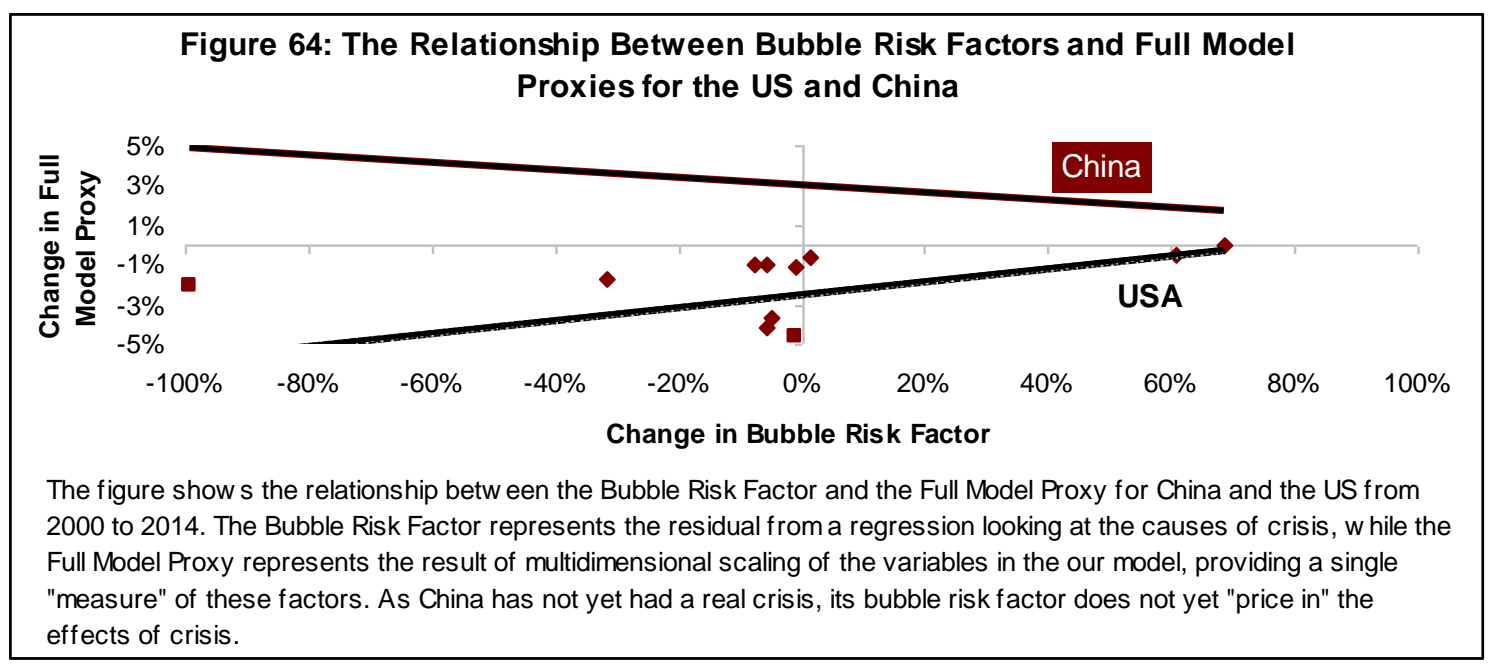

We actually observe the way that falling prices have reduced Bubble Risk Factors in the OECD comparator countries. Figure 65 shows the relationship(s) between the "build up" of our Bubble Risk Factor and changes in property prices. At first glance (before controlling for factors like the property price crash or the other factors contained in our full model), we see that increasing property prices lead to a build up of bubble tensions (unseen factors correlating with the onset of a crisis). Yet, once we control for these factors, we observe a negative relationship in the data. A "release" (through a sudden decrease in property prices) correlates with reduced Bubble Risk Factors. Even though we observe Chinese property prices growing quickly, their "equilibrium" level after accounting for crises corresponds to roughly a minus $10 \%$ to $15 \%$ change.

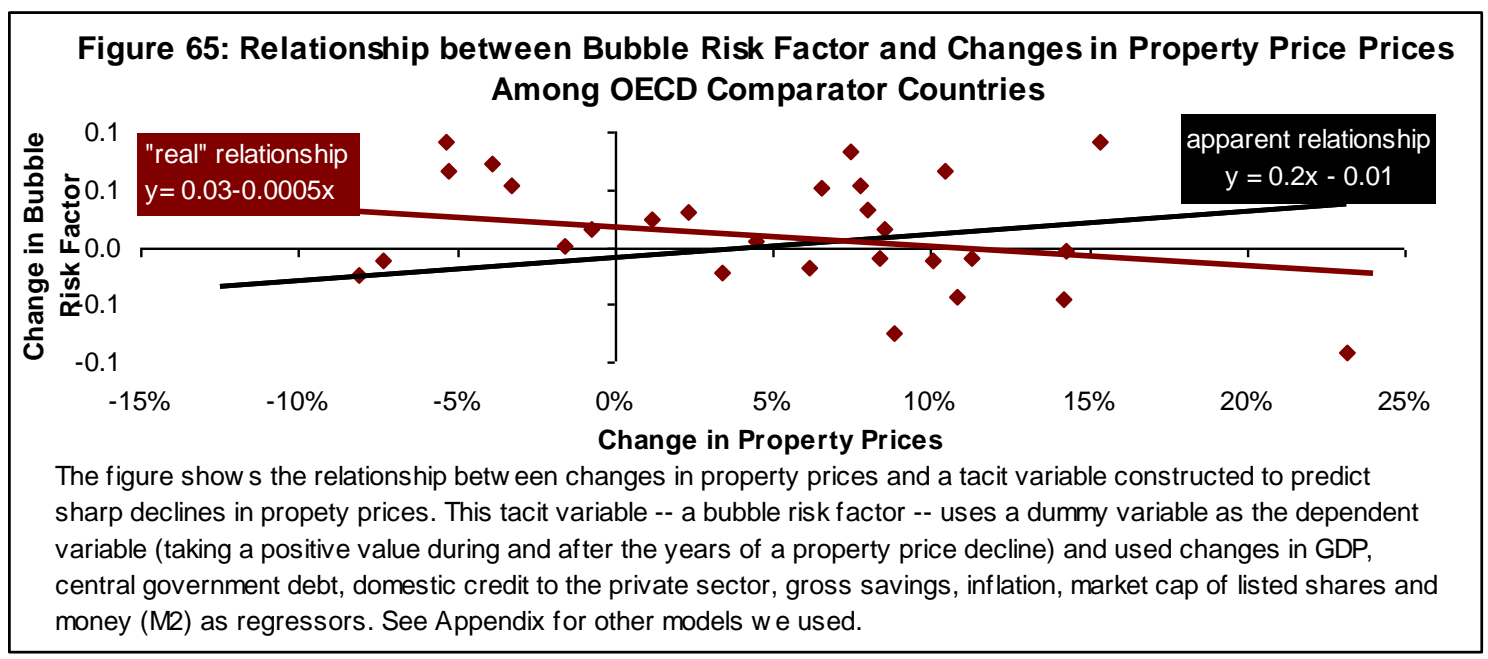

In the data, there is a risk that builds up due to momentum (or when markets bid up prices outside of supply and demand). We can deduce the size and scale of this factor as a residual from other factors in the model. Such a Bubble Risk Factor represents the part of economic activity not attributable to supply and demand. 
Figure 66: Could Bubble Economy Need Super-Heated Markets to Stave Off a Crisis?

\begin{tabular}{|lrr|}
\hline & OECD Comparators & China \\
Output growth & $-0.13+0.18 \mathrm{X}$ & $-2.2+0.5 \mathrm{X}$ \\
Property price growth & $0.11-0.3 \mathrm{X}$ & $-0.05+0.01 \mathrm{X}$ \\
Growth of Bubble Risk Factor & $24-41 \mathrm{X}$ & $1084-201 \mathrm{X}$ \\
\hline
\end{tabular}

The figure shows the solution to the three equation problem whereby the difference in log values of the Full Model Proxy (which equals a growth rate) equals a linear combination of the difference in log values between output, property prices and the Bubble Risk Factor for the OECD comparators as a group and for China from 2000 to 2014. The " $\mathrm{X}$ " in the figure refers to the growth of the factors in the full model (government debt, etc.)

We see that a model with the Bubble Risk Factor explains cleanly the data, whereas in any model without them requires an extra variable to solve. Interestingly, a solution in the OECD set of equations comes out when property prices fall by $2 \%$ but also when an unknown variable falls by $1.7 \%{ }^{54}$ Thus, if China becomes like its OECD comparators, it would need to see a $15 \%$ fall in property prices and a $7 \%$-ish fall in the bubble risk factor in order to experience a recession.

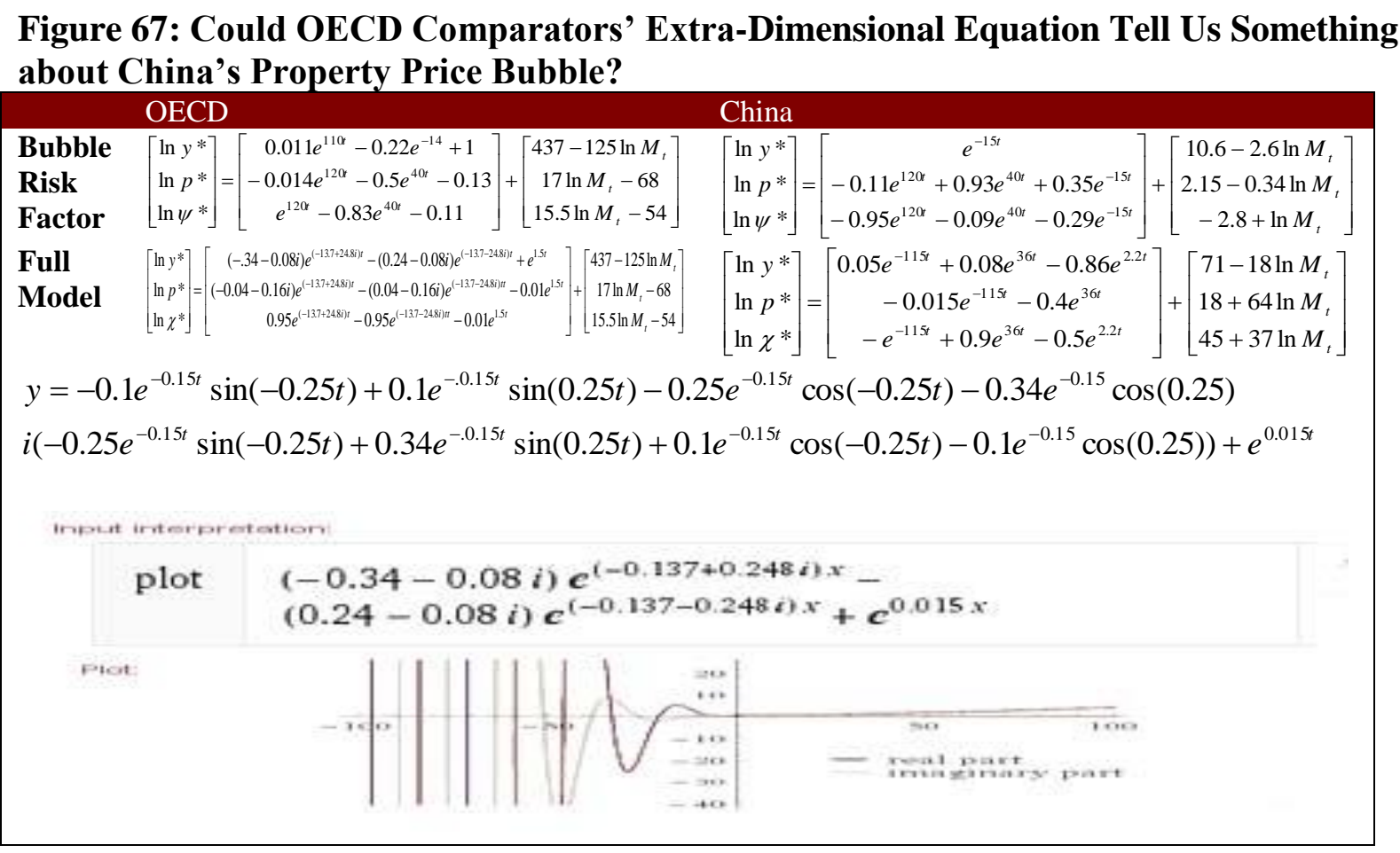

\footnotetext{
${ }^{54}$ We think an imaginary solution pops up in the full model but not in the bubble risk model because the bubble risk model includes the missing/unknown variable in the analysis. When we use the full model proxy (and leave out the bubble risk factor), the math can solve the problem by pulling in this extra variable. We assume that "complex" solutions-meaning solutions requiring a missing variable to solve- point to the existence of our bubble risk factor.
} 
Other evidence points to the existence of factors which regulate the extent of crisis. Figure 68 repeats the story we told previously about "cycles" in our data and factors which may build up over time which we can only observe at irregular, non-linear intervals. The Figure shows the elasticity of GDP growth with respect to property price change (again). However, this time, we report the "spectra" (or frequencies present in the data). ${ }^{55}$ Recall from the beginning of this section that we argued that the potential for little and big crises exist in all economies-we only need to find the extent to which factors leading up to large crises have "built up" in the economy. We provide this figure to illustrate the material in the next sub-section. The response of Chinese GDP to changes in property prices will depend on the levels and rates of change (stocks and flows) of other variables.

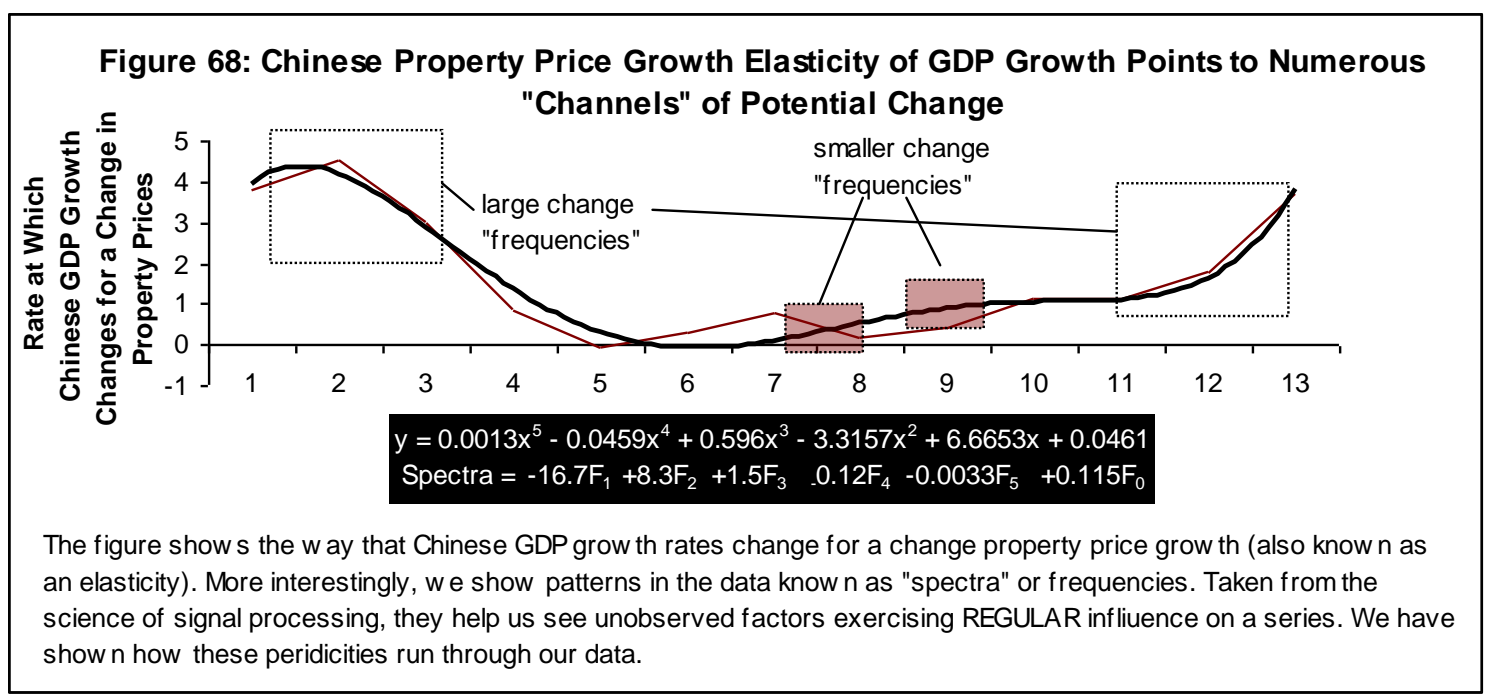

What effect will Bubble Economics play in a possible Chinese recession?

Recession in China looks more and more likely as property prices decline more sharply. We saw-both in our work and the work of other scholars - that roughly a 10\% drop in property prices leads to a $1 \%$ drop in GDP growth in "normal times" (using past data to predict the future). We also saw that, because income and future expectations of property prices can cause "serial correlation" in the data (where prices and GDP growth depends on its former self more than supply and demand), that a $10 \%$ drop in prices can reverberate into a $7 \%-8 \%$ decrease in GDP output at the extreme (when prices and GDP radically change course). We saw from the OECD comparator countries that structural change can shave another $2 \%-3 \%$ off of GDP growth in the post-crisis period and make GDP change more elastic to property price changes. We also saw, in the extreme, a banking/sovereign debt crisis can knock off $3 \%-7 \%$ in GDP growth, depending on the severity of the crisis.

\footnotetext{
${ }^{55}$ To find these frequencies, we fitting a polynomial line of best fit to the data and then took a Fourier transform of that polynomial. The resulting output points out "frequencies" in the data, or the extent to which little, frequent changes happen in comparison with big, less often changes.
} 
How far do property prices need to fall in order to wipe out GDP growth in our elaborate model of China-assuming that China reacts in a way similar to its OECD comparators and countries experiencing a banking/sovereign debt crisis? Figure 69 shows the total effect on GDP from property price changes and the contribution of each of the non-linearities we described in our paper. For low levels of price change, the dynamic, stochastic general equilibrium models and even simple linear regression do pretty well at predicting limited GDP growth losses. As property price declines come to their historical limits (of around 30\% during the Great Recession), we observe enough to knock off much GDP growth. Because of the "systemic" approach of our model, not all growth disappears. Indeed, without a banking/debt crisis, China would still maintain positive growth rates! At around $40 \%$ property price declines, we observe recession, even without banking/debt crises.

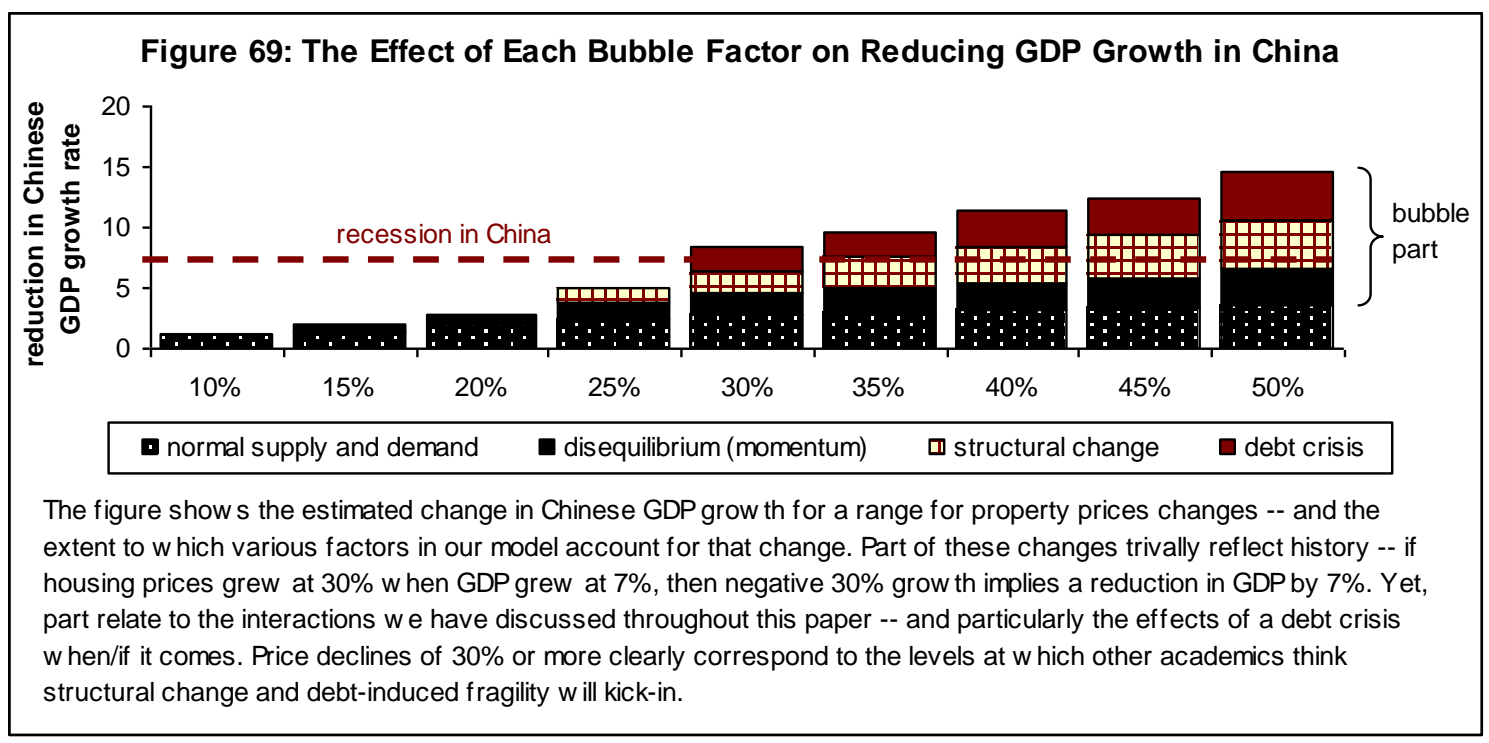

In line with our view of Bubble Economics, we see that much of this growth disappears due to factors other than historical supply and demand driving the relationship between prices and GDP growth in the past. At a 50\% property price decline, we observe almost three-quarters of GDP growth decline driven by factors outside of traditional economic, modelling theory. We previously showed how Bubble Risk Factors correlate with property prices - and by construction crises themselves. Understanding how these Bubble Risk Factors contribute the way property prices and GDP decline interact will remain a key challenge in the years ahead! ${ }^{56}$

Our model (systems of equations) certainly account(s) for the non-linearities in the way GDP contraction might respond to property price change in China. Figure 70 shows several simulations of the way GDP contraction in China might occur, as a 50\% property price decline plays out throughout the crisis. In the early periods, as property prices start declining, GDP growth remains healthy. As investors and others expect next years' property prices and output to reflect last years', we see the increasing role momentum plays in the Chinese economy. As

\footnotetext{
${ }^{56}$ We do not plot any comparisons with our Bubble Risk Factor variable, as we deliberately constructed the variable to pick up the unexplained parts of crises.
} 
property prices and GDP deceleration occurs, new structural parameters get swapped in - and economic decline continues. ${ }^{57}$ Finally, banking-debt crisis simply lops off $2 \%-3 \%$ of GDP growth, depending on the severity of the crisis underway. We keep the intrinsic variability in the original data (using GARCH methods) so we do not get single, deterministic lines. Notice, we have four "frequencies" of crisis in this data-from smaller oscillations to large-scale, full blown banking-debt crisis.

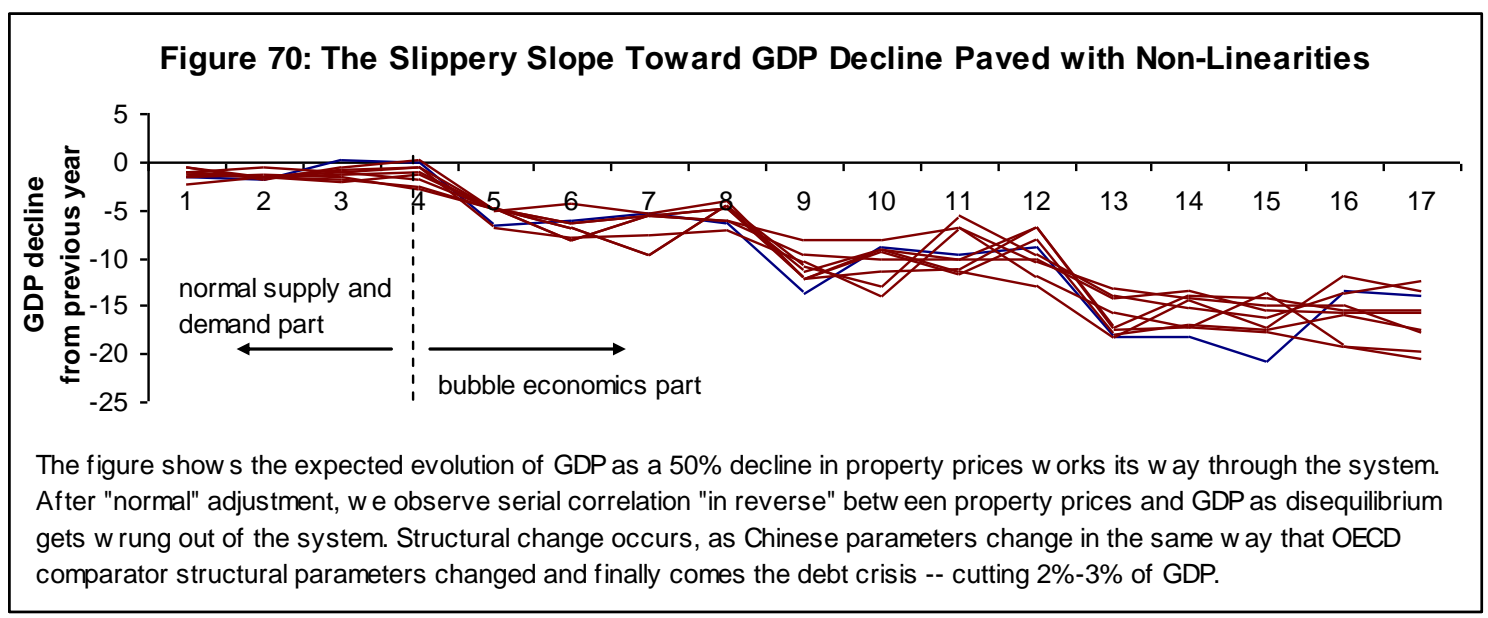

The problem with modelling a Bubble Economy lies in the fact that sudden collapses in output can occur as either "extreme events" or as the natural outcome of the non-linearities we have been discussing so far. Figure 71 for example, shows the results of several simulations looking at the way we see a rapid change in the way we showed above. For the red line, we simply shoved our variable measuring Chinese GDP growth elasticity with respect to property price change into a fat-tailed distribution (the one it actually comes from) and looked for cases of sudden spiking or collapse. In the other two cases, we used the non-linearities we found in the data to look for times which the elasticity changed suddenly of its own accord. Empirically speaking, we cannot detect when a structural non-linearity causes radical change — as opposed to a black swan risk coming true.

\footnotetext{
${ }^{57}$ These data "contain" the effect of GDP governments' expansionary fiscal and monetary policy to contain the crisis (as certainly the crises and changing structural parameters would have changed far more significantly without a government response). Since we cannot observe the counter-factual (no government intervention) AND we assume the Chinese authorities would react similarly, we can only assume that structural change in China would occur similarly to that in the OECD comparator countries we used.
} 


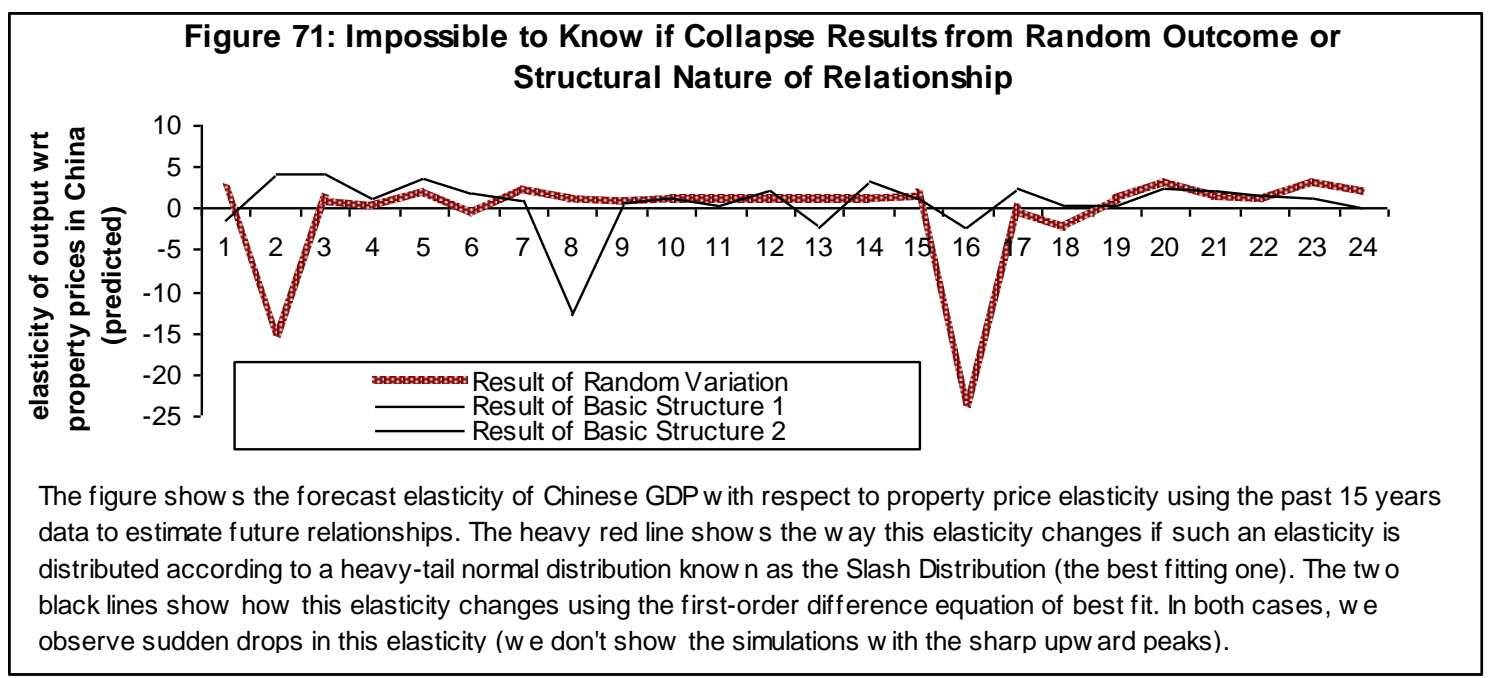

What happens to credit, savings, and the other variables in our model? After all, most economists spend all their time trying to figure out questions like this. We hope we convinced you that the values of these variables do not matter so much. Various configurations of the variables shown in models can lead to building up bubble (and thus crisis) pressures. As shown in Figure 72, solving "backwards" to calculate these variables represents little real problem. ${ }^{58}$ The figure combines Figure 64 and Figure 65 to show how changing property prices might filter through the Chinese economy. So we do not make an already 60 page paper longer, we leave these values unreported. The main challenge focuses on the way that the values in the Full Model contribute to the growth in Bubble Risk Factor which explains crises.

\footnotetext{
${ }^{58}$ Each value of the Full Model Proxy corresponds (in theory) to a vector-or set—of five values for bank credit, construction production, savings-to-GDP, equity values and government borrowing.
} 


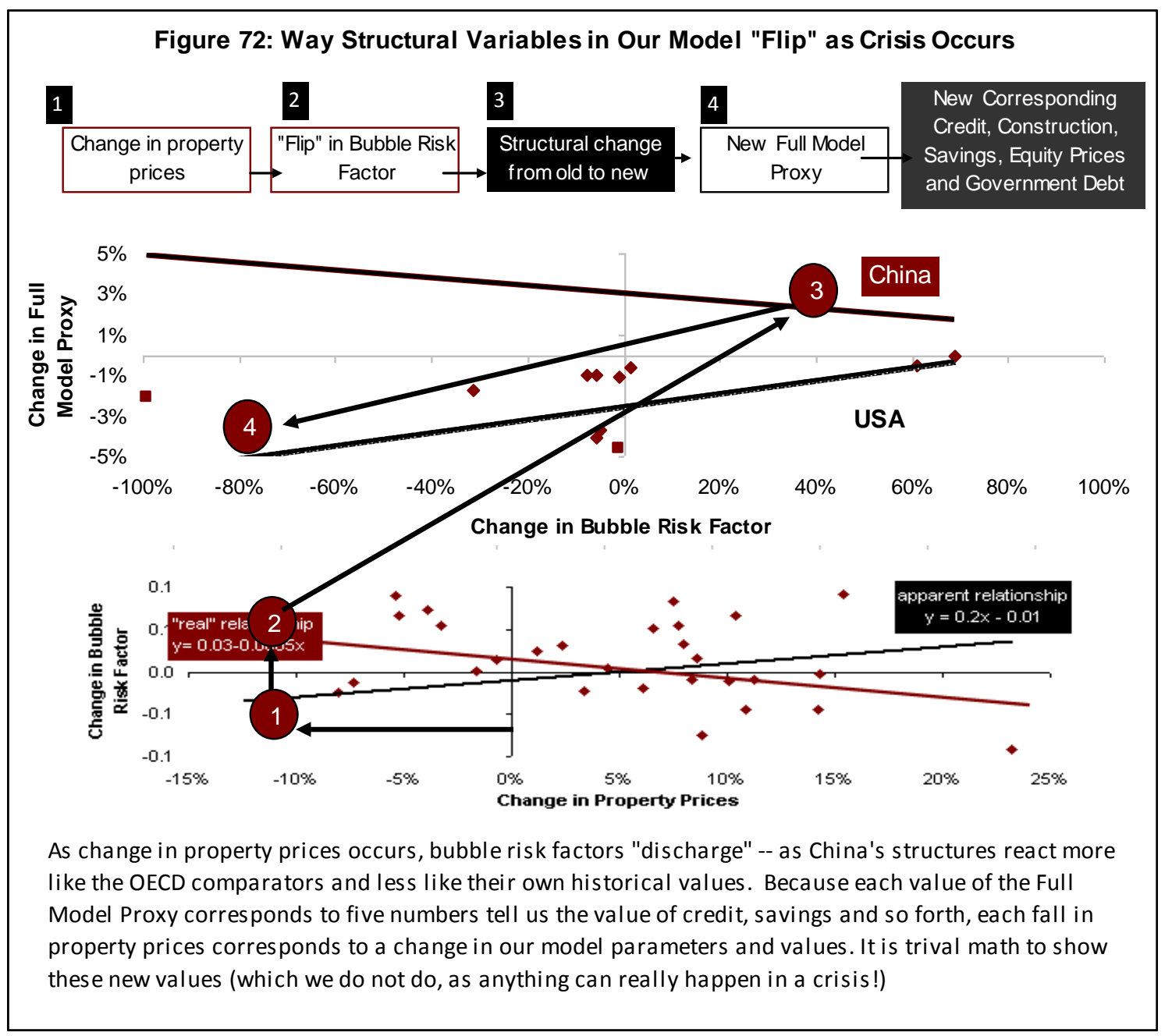

\section{Conclusions}

How far do Chinese property prices need to fall in order to send the Chinese economy into recession? What does such a potential fall teach us about the way Bubble Economies function? In this paper, we argue that a Bubble Risk Factor helps intermediate in how far property prices (or asset prices more generally) may fall and their affect on declining GDP growth rates. We show how non-linearities in the way GDP, property prices, and factors often cited (like credit expansion, construction sector growth, the rise and fall of household savings, equity price rises, and the accumulation of sovereign debt) interact. We develop a proxy for these five factors and develop a proxy for the "slippage" in the way they fail to explain GDP change. By modelling the way GDP growth, property price change, a proxy for our Model Factors, and a Bubble Risk Factor interact, we hope to shed light on the behavior of Bubble Economies. By speculating on the existence of such a Bubble Risk Factor-and providing the statistics/mathematics needed to understand it - we hope to understand how partially divorced Bubble Economics interacts with normal economics before, during, and after property bubble crises. 


\section{Bibliography}

Anderlini, Jamil. 2014. "Property bubble is 'major risk to China'." The Financial Times. August 25.

Angy, Andrew, Jennie Baiz, and Hao Zhou. 2016. "The Great Wall of Debt: The Cross Section of Chinese Local Government Credit Spreads." Georgetown McDonough School of Business Research Paper No. 2603022; Columbia Business School Research Paper No. 1557; PBCSF-NIFR Research Paper No. 15-02.

Arner, Douglas, David C. Donald, Say Hak Goo, Richard Weixing Hu, Chen Lin, Bryane Michael, Frank M. Song, Wilson H.S. Tong, Chenggang Xu, Dariusz Wojcik, and Simon X. Zhao. 2014. "Assessing Hong Kong as an International Financial Centre.” University of Hong Kong Faculty of Law Research Paper No. 2014/012.

Ahuja, Ashvin, Lillian Cheung, Gaofeng Han, Nathan Porter, and Wenlang Zhang. 2010. "Are House Prices Rising Too Fast in China?” Working Paper 10/274. International Monetary Fund.

Bonham, Carl and Calla Wiemer. 2012. "Chinese Saving Dynamics: The Impact of GDP Growth and the Dependent Share.” Working Paper 2010-11R. Honolulu, HI: University of Hawaii Economic Research Organisation.

Borensztein, Eduardo and Ugo Panizza. 2008. "The Costs of Sovereign Default.” Working Paper 08/238. International Monetary Fund.

Bosworth, Barry. 2015. "Impact of the Financial Crisis on Long-Term Growth.” Working Paper 2015-8. Boston, MA: Centre for Retirement Research of Boston College.

Bryson, Jay. 2014. "Implications of a House Price Collapse in China." Wells Fargo Securities Special Commentary. August 28.

Case, Karl and John Quigley. 2006. "How Housing Booms Unwind: Income Effects, Wealth Effects, and Sticky Prices." Paper prepared for the joint session of the American Economic Association and the American Real Estate and Urban Economics Association, Chicago (January 5).

Case, Karl and Robert Shiller. 2004. "Is There a Bubble in the Housing Market?" Cowles Foundation Paper No. 1089. New Haven, CT: Cowles Foundation for Research in Economics, Yale University.

Cerutti, Eugenio, Jihad Dagher, and Giovanni Dell'Ariccia. 2015. "Housing Finance and RealEstate Booms: A Cross-Country Perspective.” Staff Discussion Notes No. 15/12. International Monetary Fund.

Chamon, Marcos and Eswar Prasad. 2008. "Why Are Saving Rates of Urban Households in China Rising?” IZA Discussion Paper 3191. Bonn, Germany: The Institute for the Study of Labor.

Chen, Jie and Aiyong Zhu. 2008. "The Relationship between Housing Investment and Economic Growth in China: A Panel Analysis Using Quarterly Provincial Data.” Working Paper 2008:17. Uppsala, Sweden: Uppsala University Department of Economics. 
Chen, Kai-ji and Yi Wen. 2014. "The Great Housing Boom in China.” Working Paper 2014022B. Research Division of the Federal Reserve Bank of St. Louis.

China Statistics Office. Available at: http://data.stats.gov.cn/english/easyquery.htm?cn=A01

Chivakul, Mali and Raphael Lam. 2015. "Assessing China's Corporate Sector Vulnerabilities." Working Paper 15/72. International Monetary Fund.

Crowe, Christopher, Giovanni Dell'Ariccia, Deniz Igan, and Pau Rabanal. 2011. "How to Deal with Real Estate Booms: Lessons from Country Experiences.” Working Paper 11/91. International Monetary Fund.

Dell'Ariccia, Giovanni, Enrica Detragiache, and Raghuram Rajan. 2008. "The Real Effect of Banking Crises.” Journal of Financial Intermediation 17(1): 89-112.

Deng, Yong-heng, Joseph Gyourko, and Jing Wu. 2012. "RBA Land and Housing Price Measurement in China." Working Paper No. 18403. National Bureau of Economic Research.

Didier, Tatiana, Constantino Hevia, and Sergio Schmukler. 2012. "How resilient and countercyclical were emerging economies during the global financial crisis?" Journal of International Money and Finance 31(8): 2052-2077.

Garfinkel, Jon and Jay Sa-Aadu. 2011. "Houses, Banks, and Financial Markets: Why the Crisis this Time?" Working Paper 1191. International Monetary Fund. Available at: https://www.imf.org/external/pubs/ft/wp/2011/wp1191.pdf

Gaulard, Mylene. 2014. "The Real-Estate Bubble in China.” Problems of Development 45(178). Available at: http://www.probdes.iiec.unam.mx/en/revistas/v45n178/body/v45n178a3_1.php

Gaulard, Mylene. 2013. "Changes in the Chinese Property Market: An indicator of the difficulties faced by local authorities." China Perspectives. Available at: http://www.cefc.com.hk/download.php?file=659835c61e7197487b38175c8eb6e350\&id=1 $\underline{00044483}$

Gennaioli, Nicola, Aberto Martin, and Stefano Rossi. 2014. "Sovereign Default, Domestic Banks, and Financial Institutions." The Journal of Finance 69(2):819-866.

Glaeser, Edward and Charles Nathanson. 2014. "Housing Bubbles.” Working Paper No. 20426. National Bureau of Economic Research.

Gornemann, Nils. 2014. "Sovereign Default, Private Investment, and Economic Growth." Working Paper. University of Pennsylvania. Available at: https://editorialexpress.com/cgibin/conference/download.cgi?db_name=NASM2014\&paper_id=878

Heath, Alexandra, Frank Packer, and Callan Windsor. 2012. "Property Markets and Financial Stability." Proceedings of a Conference, Sydney (August 20-21).

Huang, Daisy, Charles Leung, and Bao-zhi Qu. 2015. "Do Bank Loans and Local Amenities Explain Chinese Urban House Prices?” Working Paper No. 230. Federal Reserve Bank of Dallas Globalization and Monetary Policy Institute.

Igan, Deniz and Prakash Loungani. 2012. “Global Housing Cycles.” Working Paper 12/217. International Monetary Fund. 
Jin, Yizhou. 2011. "Housing Wealth and Consumption in the Chinese Urban Economy: Evidence from Micro-Data.” Working Paper. University of California, Berkeley Department of Economics.

Kang, Hsin-Hong and Shu-Bing Liu. 2014. "The Impact of the 2008 Financial Crisis on Housing Prices in China and Taiwan: A Quantile Regression Analysis.” Economic Modelling 42(1): 356-362.

Kawaguchi, Yuichiro. 2009. “Japan's Real Estate Crisis. What Went Wrong? Why? What lesson can be learned?” Working Paper. Tokyo, Japan: Waseda University.

Kiselev, Alexander and Lenya Ryzhnik. 2010. “A Simple Model for Asset Price Bubble Formation and Collapse." Unpublished.

Lan, Ting. 2014. "House Price Bubbles in China." Research in Applied Economics 6(1).

Le, Vo, Kent Matthews, David Meenagh, Patrick Minford and Zhigui Xiao. 2013. "Banking and the Macroeconomy in China: A Banking Crisis Deferred?" Working Paper No. E2013/5. Cardiff, U.K.: Cardiff Business School.

Levintal, Oren. 2013. "The real effects of banking shocks: Evidence from OECD countries." Journal of International Money and Finance 32(1): 556-578.

Liang, Qi, and Hua Cao. 2011. "The Impact of Monetary Policy on Property Prices: Evidence from China.” Working Paper. Tianjin, China: Nankai University.

Liu, Crocker, Adam Nowak, and Stuart Rosenthal. 2014. "Bubbles, Post-Crash Dynamics, and the Housing Market." Working Paper. Ithaca, NY: The Center for Real Estate and Finance, Cornell University.

Liu, Hong-yu, Yun Park, and Siqi Zheng. 2002. "The Interaction between Housing Investment and Economic Growth in China." International Real Estate Review 5(1): 40-60.

Ma, Qing-Ping. 2010. "Housing market in China's growth recovery and house price determination." Paper presented at the 21st CEA(U.K.) and 2nd CEA(Europe) Annual Conference Global Economic Recovery: The Role of China and Other Emerging Economies, University of Oxford, U.K. (July 12-13).

Mehrotra, Aaron, Riikka Nuutilainen, and Jenni Paakkonen. 2011. "Changing economic structures and impacts of shocks - evidence from a DSGE for China." Discussion Paper 5/2011. Bank of Finland, Institute for Economies of Transition.

Mees, Helen and Raman Ahmed. 2012. "Why Do Chinese Households Save So Much?" Working Paper. London, U.K.: Centre for Economic Policy Research Policy Portal.

Nie, Jun and Guangye Cao.2014. "China's Slowing Housing Market and GDP Growth.” Federal Reserve Bank of Kansas City Macro Bulletin Aug 25.

Order, Robert and Rose Lai. 2006. "A Regime Shift Model of the Recent Housing Bubble in the United States.” Working Paper No. 1084. Ann Arbor, MI: Ross School of Business.

Oulton, Nicholas and Maria Sebastia-Barriel. 2013. "Long and Short-Term Effects of the Financial Crisis on Labour Productivity, Capital and Output.” CEP Discussion Paper No 1185. Centre for Economic Performance, London School of Economics and Political Science. 
Özbaş, Birnur, Onur Özgün, and Yaman Barlas. 2014. "Modeling and Simulation of the Endogenous Dynamics of Housing Market Cycles.” Journal of Artificial Societies and Social Simulation 17(1). Available at: http://jasss.soc.surrey.ac.uk/17/1/19.html.

Papell, David and Ruxandra Prodan. 2011. "The Statistical Behavior of GDP after Financial Crises and Severe Recessions." Paper presented at the Federal Reserve Bank of Boston Conference on 'Long-Term Effects of the Great Recession' (October 18 - 19).

Peng, Tao. 2012. "Business Cycles and Macroeconomic Policies in China: Evidence from an Estimated DSGE Model." Working Paper. Chengdu, China: Southwestern University of Finance and Economics. Available at: http://www.eea-esem.com/files/papers/eeaesem/2012/413/Business \%20Cycles\%20and\%20Macroeconomic\%20Policies\%20in\%20Ch ina\%20822.pdf

Peng, Jian-gang, Jie Cui, Fu-yong Qin, and Nicolaas Groenewold. 2009. "Stock Prices and the Macro Economy in China.” Discussion Paper 09/20. University of Western Australia.

Sandleris, Guido. 2012. "The Costs of Sovereign Defaults: Theory and Empirical Evidence." CIF Working Paper 02/2012. Centro de Investigacion en Finanzas, Universidad Torcuato di Tella.

Scherbina, Anna. 2013. "Asset Price Bubbles: A Selective Survey.” Working Paper 13/45. International Monetary Fund.

Seki, Shinichi. 2012. "Risk of a housing bubble collapse in China extremely remote." Pacific Business and Industries 12(44).

Shepard, Wade. 2015. Ghost Cities of China: The Story of Cities Without People in the World's Most Populous Country. London, U.K.: Zed Books.

Sinclair, Peter and Lixn Sun. 2014. “A DSGE Model for China's Monetary and Macroprudential Policies.” Munich Personal RePEc Archive. University Library of Munich, Germany.

Slettvag, Bjornar. 2014. "Consequences of an abrupt slowdown in China's property market." Bank of Norway Economic Commentaries 5/2014.

Stevenson, Simon. 2008. "Modelling Housing Market Fundamentals: Empirical Evidence of Extreme Market Conditions.” Real Estate Economics 36(1): 1-29.

Takahashi, Goro. 2015. "Two Main Conditions for Collapse of the Bubble Economy of ChinaLarge Number of Unsold Houses and Deregulation of Deposit Interest Rates." Journal of Financial Risk Management 4(1): 40-55.

Tan, Zheng-Xun and Ming Chen. 2013. "House Prices as Indicators of Monetary Policy: Evidence from China.” Working Paper 488. Stanford, CA: Stanford Centre for International Development.

Tan, Zheng and Zheng Qin. 2011. "An Empirical Study of the Correlation between Real Estate Prices and Bank Loans based on a VAR Model." Paper presented at the International Conference on Computer Science and Service System, Nanjing (June 27-29).

Wang, Jie-qiong and De-jun Xie. 2012. "The Empirical Analysis of Housing Prices in the Chinese Market." International Journal of Trade, Economics and Finance 3(5). 
Wang, Xin and Yi Wen. 2012. "Housing Prices and the High Chinese Saving Rate Puzzle." Working Paper 2012-038A. St. Louis Federal Reserve Bank. Available at: http://research.stlouisfed.org/wp/2012/2012-038.pdf

Wang, Tao. 2011. "Measuring Property Bubble in China.” UBS Investment Research Macro Keys. Available at: https://wikileaks.org/gifiles/attach/101/101347_MacroKeys220311.pdf

Wu, Jing, Yong-heng Deng, and Hong-yu Liu. 2012. "House Price Index Construction in the Nascent Housing Market: The Case of China.” Working Paper 2011-017. Singapore: Institute of Real Estate Studies.

Wu, Yan-rui. 2014. "Local government debt and economic growth in China." Discussion Paper No. 20/2014. Bank of Finland, Institute for Economies of Transition.

Wu, Harry and Esther Shea. 2011. "Explaining the China Puzzle: High Growth and Low Volatility in The Absence Of Healthy Financial Institutions." Paper prepared for EcoMod2011, Azores, Portugal (June 29 - July 1).

Xin Wang, Xin and Yi Wen. 2012. "Housing Prices and the High Chinese Saving Rate Puzzle." Working Paper 2012-038A. Federal Reserve Bank of St. Louis.

$\mathrm{Xu}$, Xiaoqing and Tao Chen. 2010. "The Effect of Monetary Policy on Real Estate Price Growth in China." Pacific-Basin Finance Journal, forthcoming.

Yan, Jiang, Feng Lei, Dan Mo, and Tan Xue-qin. 2010. "Housing Market Cycles in China: An Empirical Study Based on a Stock-Flow Model.” Paper prepared for the 2010 International Conference on Management Science and Engineering, Melbourne (November 24 -26).

Yuan, Fang-ying. 2011. "Macro Stress Testing with a Macroeconomic Credit Risk Model for China." Applied Informatics and Communication 227(1): 25-31.

Zhou Zhicheng and Prapatchon Jariyapan. 2013. “The Impact of Macroeconomic Policies to Real Estate Market in People's Republic of China." Empirical Econometrics and Quantitative Economics Letters 2(3): 75 - 92. 


\section{Appendix I: What is Bubble Economics?}

In order to provide to the non-technical reader a greater understanding of our argument, we summarize the main points in this Appendix.

\section{What is Bubble Economics?}

Bubble Economics is the study of the way economic relations allocate scarce goods and services in situations where prices no longer reflect the inherent supply and demand of the good/service itself. For example, housing prices may rise quickly because investors have access to low-cost credit and have reasonable expectations of higher future prices (and thus profits). How long do prices stay out of any intrinsic equilibrium? How can we model "bubbles" the same way we model abstract notions like risk? Or utility?

\section{Why have a special concept for Bubble Economies?}

We know that risks build up in economies, when credit and prices rise quickly. These economics have a "stock" of some ineffable something. Traditionally, we have tried to model this "something" as a tail risk or other rare event. What if economies actually build up some unseen "stock"- a notion which conforms to all of our common sense?

What led to you think about Bubble Economics?

We kept observing in our calculations the presence of "imaginary" solutions - a mathematician's way of saying that you need an extra variable in order to solve your equation. We observe large unexplained parts of any empirical model (known as the epsilon). If we create a variable - which we tentatively call the Bubble Risk Factor-we no longer have unexplained parts of the bubble story. Economies ready to experience a property/banking asset price crisis have bubble risks which have build up over time. The stock and flow of such risk depends on the typical variables we model in day-to-day work.

Aren't you just assigning what you don't know to a new variable?

Yes. It sounds simple and stupid, but economists haven't done this yet. Social scientists use tacit variables like "social capital" (or even human capital) in modelling! Yet, they have never ventured to hypothesize that Bubble Economics exists concurrently with normal economics. In economies like China, Bubble Economics explains a larger part of resource allocation and price information than in economies like Germany. Ultimately, like Milton Friedman says, if the concept helps us to predict crises, then we don't really care if it's "true." Use what works. 
Appendix II: Background Information on Statistics and Methods

Appendix III: Comparing With Structural Change in Chinese Dynamic Stochastic General Equilibrium

Appendix IV: Regression Summaries and Equations

These appendices available in summer 2016. 